\title{
ANÁLISE DAS MICROESTRUTURAS MAGNÉTICAS EM FILMES DE FeNi
}

DISSERTAÇÃO DE MESTRADO

EDGAR DAVID GUARIN CASTRO

Área de concentração:

FÍSICA DA MATÉRIA CONDENSADA

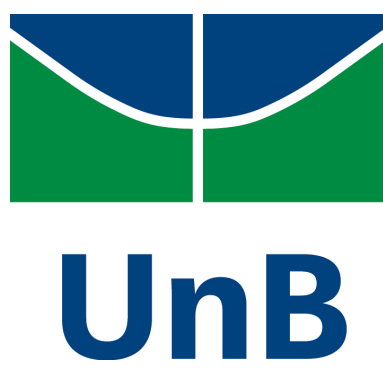

UNIVERSIDADE DE BRASÍLIA

INSTITUTO DE FÍSICA

BRASÍLIA,BRASIL

2017 


\section{ANÁLISE DAS MICROESTRUTURAS MAGNÉTICAS EM FILMES DE FeNi}

Edgar David Guarin Castro

Professor Orientador:

Dr. Paulo César de Morais

Dissertação apresentada ao Programa de Pós-Graduação em Física, do Instituto de Física da Universidade de Brasília, como parte dos requisitos necessários à obtenção do título de Mestre em Física.

UNIVERSIDADE DE BRASÍLIA INSTITUTO DE FÍSICA

BRASÍLIA, BRASIL

2017 


\section{"Análise das microestruturas magnéticas em filmes de FeNi."}

Por

Edgar David Guarin Castro.

Dissertaçào subnetida ao Instituto de Fisica da Ĺniversidade de Brasilia como parte dos requisitos para a obtenção do grau de Mestre em Física.

Aprovada por:

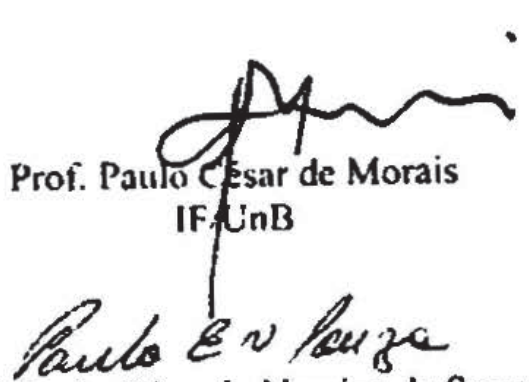

Prot: Paulo Eduardo Narcizo de Souza IF/inB

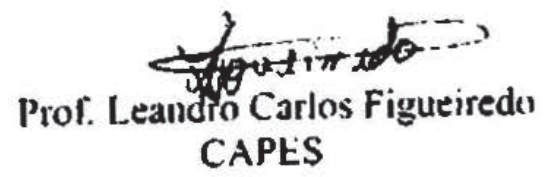

Prot. Dr. Fernando de Oliveira Albuquerque

Cuordenador de P’ós-Gruduução

Instituto de Fisica 
A Deus e minha família quem sempre tem motivado este sonho 


\section{Agradecimentos}

Como era esperado, a elaboração deste trabalho não foi isenta dos obstáculos e contratempos próprios da pesquisa. Muitos inconvenientes se apresentaram no caminho mas com a mão de Deus e com o afeto e apoio da minha família e do meu grande amor, Helena, consegui achar a inspiração e o sustento para me manter em pé e aproveitar esta oportunidade única da qual sou muito grato. Por isso agradeço primeiramente a Deus, a meus pais e a meus irmãos, que mesmo apesar da distância e do tempo, têm estado sempre presentes com alegria e sábios conselhos, enchendo-me de paz e tranquilidade.

Agradeço à Helena por ser a minha luz e companhia nesta viagem, por seu amor incondicional e por complementar minha alma. Com ela tudo se conjuga e se harmoniza de formas inexplicáveis para dar certo, mas sem ela tivesse sido impossível enfrentar os desafios do dia-a-dia.

Deus também colocou nessa estrada pessoas incríveis como os professores Leticia Coelho e Paulo Souza que nunca duvidaram por um segundo em dar sua mão amiga, me fazendo crescer como ser humano e como profissional. Sua colaboração, esforço e compromisso foram muito valiosos, além dos ensinamentos que nunca vou esquecer. Muito obrigado pela confiança e estima.

Agradeço ao professor Paulo César de Morais pela ajuda dispensada desde o início e aos meus companheiros e amigos Hailleen Varela, Eduardo Carvalho e Ernesto Ramos pela colaboração, pelos bons momentos, por abrir as portas das suas vidas e por partilhar seus conhecimentos comigo.

Agradeço à Coordenação de Aperfeiçoamento de Pessoal de Nível Superior (CAPES) e ao Instituto de Física da UnB pelo apoio econômico e pela formação acadêmica recebida, fundamental para o andamento desta pesquisa e do meu desenvolvimento profissional.

Finalmente gostaria agradecer a ajuda oferecida pelos diferentes professores e grupos de pesquisa na realização do trabalho experimental, que foi concluído graças à sua experiência e destreza nas diferentes técnicas experimentais:

Aos professores José Coaquira, John Mantilla, Leandro Figueiredo e Jorlándio Félix 
do Núcleo de Física Aplicada no Instituto de Física da Universidade de Brasília.

À equipe técnica da Central Analítica do Instituto de Química da Universidade de Brasília.

Ao senhor Joaquim Gomes do departamento de Física do Centro de Ciências Exatas e Tecnológicas da Universidade Federal de Viçosa.

À equipe técnica do Laboratório de Ciência de Superfícies (LCS), sob a direção de Christoph Deneke e Carlos Costa, no Laboratório Nacional de Nanotecnologia (LNNano) do Centro Nacional de Pesquisa em Energia e Materiais (CNPEM).

Agradeço grandemente a colaboração de todos vocês pois foi assim como este trabalho ganhou vida. 


\section{Resumo}

O presente trabalho expõe um estudo estrutural e magnético feito em filmes policristalinos de FeNi sobre substratos de Si. Medidas de energia dispersiva de raios X indicaram concentrações relativas de $64 \%$ para o ferro e $36 \%$ para o níquel, o que significa que os filmes possuem a concentração Invar, fenômeno caracterizado pela queda do coeficiente de dilatação da liga até valores muito baixos. Estudos experimentais mostram que este fenômeno deve estar fortemente vinculado com a estrutura magnética das ligas, mas os modelos teóricos ainda não conseguem explicar completamente a relação entre suas propriedades magnéticas e mecânicas, motivando continuados estudos sobre suas propriedades magnéticas.

Nesta pesquisa foi proposto estudar e analisar a configuração micromagnética para três filmes de FeNi na concentração Invar, para três diferentes espessuras (30, 70 e 140 $\mathrm{nm}$ ), por meio de técnicas experimentais como a magnetometria e a microscopia de força magnética (MFM), assim como por meio do uso de simulações computadorizadas, para oferecer mais bases experimentais que contribuam na compreensão dos fenômenos presentes nas ligas Invar.

Os resultados revelaram inomogeneidades magnéticas causadas pela policristalinidade dos filmes. As amostras também manifestaram um comportamento ferromagnético mole, com magnetizações de saturação e anisotropias efetivas crescentes com o aumento das espessuras. Os resultados também mostraram uma grande influência da anisotropia de forma que faz com que os filmes sejam facilmente magnetizados no plano.

Finalmente, com base nas medidas de magnetometria, a estrutura micromagnética dos filmes foi mapeada por medidas de MFM e posteriormente simulada com o software MUMAX3. Os mapas revelaram domínios com magnetizações locais paralelas à superfície dos filmes, enquanto que as paredes possuem uma estrutura tipo Bloch, principalmente no interior dos filmes mais grossos. Deste modo, percebe-se que a anisotropia do material define eixos fáceis de magnetização no plano dos filmes, por causa da anisotropia de forma, que obriga às paredes de domínio a se distribuírem nos filmes, formando padrões de ziguezague irregulares na superfície. 


\section{Abstract}

The present work reports structural and magnetic study of FeNi polycrystalline films on Si substrates. X-ray dispersive energy measurements indicated relative concentrations of $64 \%$ iron and $36 \%$ nickel, which means that the films present Invar concentration, a phenomenon characterized by the decrease of the thermal expansion coefficient of the alloy to very low values. Experimental studies show that this phenomenon is strongly related to the magnetic structure of the alloys, but current theoretical models still cannot fully explain the relation between magnetic and mechanical characteristics of Invar alloys, motivating continued studies on their magnetic properties.

In this research, the micromagnetic configuration for three FeNi films in Invar concentration and three different thicknesses (30, 70 and $140 \mathrm{~nm}$ ) is analyzed according to their thicknesses. Experimental techniques such as SQUID magnetometry and Magnetic Force Microscopy (MFM) were used, as well as computer simulations, to offer more experimental bases that contribute to the understanding of the phenomena present in FeNi36 Invar alloys.

Results revealed magnetic inhomogeneities caused by film polycrystallinity. The samples also showed a soft ferromagnetic behavior, with increasing saturation magnetizations and effective anisotropies with increasing thicknesses. Results also showed a great influence of shape anisotropy so that the films are easily magnetized in-plane.

Finally, magnetometry measurements were complemented by micromagnetic structure mapping by Magnetic Force Microscopy, the resulting magnetic images were later simulated with the software MUMAX3. The maps revealed domains with local magnetizations parallel to the surface of the films, while the walls have a Bloch-like structure, mainly inside the thicker films. In this way, the anisotropy of the material defines an easy axis of magnetization in the plane of the films, because of the shape anisotropy, which forces the domain walls to distribute in the films, forming irregular zigzag like patterns on the surface. 


\section{Sumário}

Agradecimentos ii

Resumo iv

$\begin{array}{lll}\text { Abstract } & \mathbf{v}\end{array}$

Introdução $\quad$ xi

1 Magnetismo em filmes 1

1.1 Formação de filmes ferromagnéticos . . . . . . . . . . . . . . 2

1.2 Modelo de banda para o ferromagnetismo . . . . . . . . . . . . . . . . 4

1.3 Contribuições energéticas em filmes ferromagnéticos . . . . . . . . . . 7

1.3.1 Energia de troca . . . . . . . . . . . . . . . . 8

1.3.2 Energia de desmagnetização . . . . . . . . . . . . . . 8

1.3.3 Energia de anisotropia magneto-cristalina . . . . . . . . . . 9

1.4 Domínios magnéticos em filmes . . . . . . . . . . . . . . . . . 10

1.4.1 Curvas de magnetização . . . . . . . . . . . . . . . . . 13

2 Materiais e caracterização $\quad 16$

2.1 Ligas Invar FeNi36 . . . . . . . . . . . . . . . . . . 16

2.2 Refletometria de raios X $(\mathrm{RRX}) \ldots \ldots \ldots \ldots$

2.3 Difração de raios $X(\mathrm{DRX}) \ldots \ldots \ldots \ldots \ldots$

2.4 Ressonância ferromagnética $($ FMR $) \ldots \ldots \ldots$. . . . . . . . . . . . 25

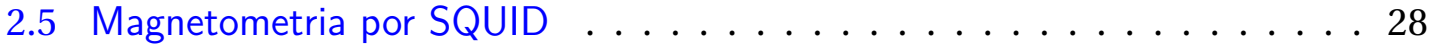

2.6 Microscopia de Força Atômica (AFM) . . . . . . . . . . . . . . 30

2.7 Microscopia de Força Magnética (MFM) . . . . . . . . . . . . . . . 32

2.8 Simulações micromagnéticas: O software MuMax3 . . . . . . . . . 35

3 Resultados e discussão $\quad 38$

3.1 Medidas de RRX e DRX . . . . . . . . . . . . . . . . . 39 
3.2 Medidas de FMR . . . . . . . . . . . . . . . . . . 41

3.3 Medidas de magnetometria por SQUID . . . . . . . . . . . . . . . 44

3.4 Medidas de AFM $/$ MFM . . . . . . . . . . . . . . . . 48

3.4.1 Imagens de AFM/MFM para o filme de $140 \mathrm{~nm}$ de espessura . . . . 51

3.4.2 Imagens de AFM/MFM para o filme de $70 \mathrm{~nm}$ de espessura . . . . . 54

3.4.3 Imagens de AFM/MFM para o filme de $30 \mathrm{~nm}$ de espessura . . . . . 55

3.5 Simulações das microestruturas magnéticas . . . . . . . . . . . . . 58

$\begin{array}{ll}\text { Conclusões } & 62\end{array}$

$\begin{array}{ll}\text { Referências Bibliográficas } & 65\end{array}$ 


\section{Lista de Figuras}

1.1 Esquema da estrutura de um filme convencional. . . . . . . . . . . . . 2

1.2 Processo de sputtering . . . . . . . . . . . . . . . . 3

1.3 Configuração do nível de energia $3 d$ no $\mathrm{Fe} \ldots \ldots \ldots \ldots \ldots$

1.4 Deslocamento das energias para os elétrons $3 d \ldots \ldots \ldots \ldots$

1.5 Representação dos domínios num filme ferromagnético . . . . . . . . . . . 11

1.6 Paredes de domínio em filmes finos . . . . . . . . . . . . . . . . . 12

1.7 Parede de Néel em presença de campo externo . . . . . . . . . . . . . 13

1.8 Curvas de magnetização . . . . . . . . . . . . . . . . . . . . . . 14

2.1 Coeficiente de dilatação e momento magnético para ligas FeNi em função da concentração de Ni . . . . . . . . . . . . . . . . . 17

2.2 Magnetização vs Temperatura para filmes de FeNi35 . . . . . . . . . . . . 18

2.3 Configurações de spin para diferentes volumes atômicos em ligas FeNi Invar 19

2.4 Esquema do processo de refletometria de RX em filmes finos . . . . . . . 20

2.5 Gráfico de refletometria de raios X para um filme fino . . . . . . . . . . . 21

2.6 FFT da curva de refletividade para obter a espessura do filme . . . . . . . 23

2.7 Esquema da geometria num experimento de DRX em ângulo rasante . . . 24

2.8 Diagrama da montagem experimental numa medida de FMR . . . . . . . 25

2.9 Exemplos de curvas FMR . . . . . . . . . . . . . . . 26

2.10 Princípio de funcionamento de um magnetômetro de SQUID . . . . . . . . 29

2.11 Esquema simplificado da operação do AFM . . . . . . . . . . . . . . . 30

2.12 Formação da imagem de MFM . . . . . . . . . . . . . . . . . . . . . . 34

3.1 Montagens no difratómetro Bruker D8 Discover . . . . . . . . . . . . . . . 39

3.2 Medidas de RRX para os filmes FeNi36 . . . . . . . . . . . . . . . . 40

3.3 Difratogramas para os filmes Invar de FeNi36 . . . . . . . . . . . . . . 41

3.4 Espectros de ressonância no plano para cada filme Invar . . . . . . . . . 42

3.5 Magnetômetro SQUID MPMS 3 e sinal do porta-amostra . . . . . . . . . . 44 
3.6 Curvas de magnetização para campo aplicados paralelos e perpendiculares à superfície dos filmes . . . . . . . . . . . . . . . . . . . 45

3.7 Microscópio Nanosurf Flex-Axiom AFM . . . . . . . . . . . . . . . . . . 48

3.8 Imagens 3D da topografia dos filmes de FeNi36 . . . . . . . . . . . . . . 50

3.9 Imagens de AFM e MFM para o filme de $140 \mathrm{~nm}$ de espessura . . . . . . . . 52

3.10 Imagens de AFM e MFM de tamanho reduzido para o filme de $140 \mathrm{~nm}$ de espessura . . . . . . . . . . . . . . . . . . . 5 52

3.11 Zoom das imagens de AFM e MFM para o filme de $140 \mathrm{~nm}$ de espessura 53

3.12 Influência do lift nas imagens de MFM . . . . . . . . . . . . . . . 53

3.13 Imagens de AFM e MFM para o filme de $70 \mathrm{~nm}$ de espessura . . . . . . . 54

3.14 Imagens de AFM e MFM para o filme de $30 \mathrm{~nm}$ de espessura . . . . . . . . 55

3.15 Comparativo entre as imagens de MFM dos filmes de FeNi36 . . . . . . . 56

3.16 Representação dos domínios nas imagens de MFM . . . . . . . . . . . . . . 57

3.17 Comparativo entre as imagens de MFM simuladas e medidas . . . . . . . . 59

3.18 Simulação dos domínios magnéticos na superfície do filme . . . . . . . . . 60

3.19 Simulação dos domínios magnéticos no interior do filme . . . . . . . . . . 61 


\section{Lista de Tabelas}

3.1 Concentrações relativas de Fe e Ni para os filmes estudados, estimadas por EDS. Erro percentual: $0.2 \%$. . . . . . . . . . . . . . . . 38

3.2 Campos de ressonância $H_{R}$, largura de banda $\Delta H$, tempo de relaxação $\tau$ e magnetização efetiva obtidos para cada filme Invar em medidas de FMR, segundo suas espessuras. . . . . . . . . . . . . . . . . . 44

3.3 Grandezas associadas às curvas de magnetização no plano para os três filmes estudados, segundo sua espessura. . . . . . . . . . . . . 46

3.4 Grandezas associadas às curvas de magnetização fora do plano para os três filmes estudados, segundo sua espessura. . . . . . . . . . . . . . 47

3.5 Parâmetros ajustados no software controlador do microscópio para as medidas de AFM/MFM. . . . . . . . . . . . . . . . . . . . . . . 49

3.6 Parâmetros de rugosidade calculados para uma área de $100 \mu \mathrm{m}^{2}$, de acordo com a espessura dos filmes. . . . . . . . . . . . . . 51

3.7 Parâmetros das amostras Invar usados para a elaboração das simulações. 58 


\section{Introdução}

O ferro (Fe) e o níquel (Ni) são elementos químicos interessantes para a ciência e a tecnologia pela grande abundância deles no planeta, mas também por causa das suas propriedades físicas, especialmente as magnéticas, fazendo deles elementos amplamente usados na indústria e fortemente estudados na Física de Materiais. Destes elementos é destacado seu comportamento ferromagnético abaixo da temperatura de Curie: $1043 \mathrm{~K}$ para o ferro e $627 \mathrm{~K}$ para o níquel [1]. Suas estruturas cristalinas mais comuns são corpo centrado (bcc) e face centrada (fcc) respectivamente, mas elas podem mudar já que estes elementos apresentam alotropia.

Não obstante, suas características tornam-se mais complexas quando formam ligas FeNi, dependendo das concentrações relativas. Por exemplo, é conhecido que o coeficiente de dilatação térmica das ligas $\mathrm{Fe}_{1-x} \mathrm{Ni}_{x}$ cai drasticamente, até ser quase nulo, quando a concentração $x$ de Ni fica no intervalo $0.30 \leqslant x \leqslant 0.40$.

Este fenômeno é chamado efeito Invar e foi verificado pela primeira vez em 1897, em ligas $\mathrm{Fe}_{0.65} \mathrm{Ni}_{0.35}$ (também chamadas de FeNi35), pelo físico suíço Charles Edouard Guillaume [2], trabalho que contribuiu a seu reconhecimento com o Premio Nobel em Física em 1920. Invar é o nome comercial dado pela empresa francesa Aperam Alloys Imphy, às ligas FeNi36, depois de industrializar sua produção a partir de 1907 [3] .

Hoje em dia tem se desenvolvido muitas aplicações industriais e tecnológicas para este tipo de ligas, como por exemplo sistemas de transporte de fluidos criogênicos, tubos de transferência, dispositivos óticos e de medição de alta precisão, quadros para telescópios e sondas espaciais, dispositivos de gravação perpendicular de mídia, etc. [3-5].

Muito tem-se estudado e proposto para os fenômenos físicos presentes nestas ligas [6-10], que podem ajudar na compreensão do ferromagnetismo dos metais de transição $3 d$, já que a teoria e os experimentos indicam que suas propriedades magnéticas tem a ver com o surgimento do fenômeno Invar, mas, como será mostrado posteriormente, os modelos teóricos não conseguem explicar completamente a relação entre estas propriedades, motivando assim continuados estudos acerca da sua configuração magnética. 
Atualmente existem inúmeras publicações que reportam os resultados experimentais de pesquisas sobre as características físicas destas ligas em super-redes e filmes finos, baseados no uso de diversas técnicas de medição como a magnetometria por SQUID com campos quase nulos, espectroscopia Mössbauer [11], microscopia eletrônica de transmissão [12-14], entre outras.

Mas a técnica mais concorrente é a difração de raios X (DRX) [10-14], já que ela permite caracterizar a estrutura cristalina e as fases dos filmes, em relação com a concentração de Ni [10, 12, 13, 15] em diferentes temperaturas, confirmando sua estrutura cúbica de face centrada (fcc) na concentração Invar. Assim, as medições com raios X evidenciam para o caso de filmes finos de FeNi35, constantes de rede de $3.589 \pm 0.005 \AA$ na temperatura ambiente, muito perto da constante da rede para o material no estado bulk [12]. Além disso, estas medições permitem inferir que em temperaturas entre $470 \mathrm{~K} \mathrm{e} 770 \mathrm{~K}$, as ligas apresentam uma estrutura de banda dupla pela superposição das camadas $d$ do Fe e do Ni [13].

A estrutura cristalina das ligas FeNi em diferentes concentrações também é analisada em muitos casos com ajuda do espalhamento inelástico de nêutrons [16, 17]. A dispersão de fônons parece manifestar que o efeito Invar por exemplo, tem relação com o acoplamento forte da rede cristalina e com a convergência das energias das bandas longitudinais e transversais nos limites da primeira zona de Brillouin [17]. Por outro lado, as curvas de magnetização são obtidas em muitas ocasiões com Magnetômetros de Amostras Vibrantes (Vibrating Sample Magnetometer-VSM), que revelam uma isotropia na magnetização a temperatura ambiente, indicando assim que muitas das estruturas bcc que ainda se encontram nas amostras, estão distribuídas aleatoriamente nas subcamadas de FeNi [10].

No entanto, são poucos os trabalhos onde são feitos estudos experimentais da configuração magnética destas ligas usando a técnica de Microscopia de Força Magnética (Magnetic Force Microscopy-MFM). Por exemplo, na pesquisa de Moghimi et. al. [18], são observados momentos magnéticos locais com MFM de alta resolução na análise da relação da geometria das nanopartículas de FeNi37 com suas propriedades magnéticas, apoiados com imagens de Microscopia Eletrônica de Varredura (Scanning Electron Microscopy-SEM).

Mas até agora não foi possível achar mais trabalhos que usem o MFM no estudo de filmes de ligas FeNi, particularmente na concentração Invar. Desse modo, neste trabalho foi proposto estudar o comportamento magnético de filmes de ligas FeNi a temperatura ambiente ( $T \sim 300 \mathrm{~K}$ ), cuja estrutura e concentrações relativas de Fe e Ni eram desconhecidas num começo, partindo da pergunta: 


\section{Como é a configuração micromagnética dos filmes de ligas FeNi?}

Neste sentido e para abordar esta questão, foi definido o seguinte objetivo geral:

Determinar as características mais importantes da configuração micromagnética de filmes de ligas FeNi.

Este objetivo esteve suportado pelos seguintes objetivos específicos:

1. Inquirir as bases experimentais no estudo de filmes de FeNi.

2. Caracterizar estruturalmente três filmes de FeNi com espessuras distintas.

3. Mapear o comportamento magnético dos filmes como um todo através de medidas de ressonância ferromagnética e magnetometria, em função das suas espessuras.

4. Obter imagens e medidas da configuração micromagnética a nanoescala dos filmes de FeNi por meio da MFM em temperatura ambiente ( $T \sim 300 \mathrm{~K})$.

5. Elaborar uma simulação computadorizada da estrutura micromagnética dos filmes de FeNi mediante os dados experimentais e o software MUMAX3.

6. Realizar uma caracterização micro e macro magnética dos filmes de FeNi.

Por conseguinte, no presente trabalho foi efetuada uma investigação documental pela qual foi reunida, organizada e analisada a informação disponível nas fontes bibliográficas, sobre os avanços experimentais e os fundamentos teóricos no estudo de filmes de FeNi.

Do mesmo modo foi realizada uma investigação quantitativa que permitiu explorar desde a análise experimental, a configuração micromagnética dos filmes de FeNi. Neste sentido e devido aos poucos trabalhos feitos neste campo usando a técnica MFM, a pesquisa teve um enfoque exploratório e descritivo, que ajudou na caracterização magnética destes filmes em nanoescala, de modo que a informação obtida possa ser usada como base para posteriores estudos, onde sejam correlacionadas estas características magnéticas com certos efeitos magnéticos.

O documento apresenta no primeiro capítulo aspectos gerais sobre o magnetismo em filmes ferromagnéticos, falando um pouco sobre sua formação, a teoria aceita atualmente que descreve seu comportamento magnético e as propriedades fundamentais que permitem estabelecer sua condição ferromagnética. Por isto, é necessário que o leitor possua conhecimentos básicos sobre magnetismo para abordar esta seção. 
No segundo capítulo, são expostas as características principais das ligas FeNi, especialmente na concentração Invar, e também são descritas as técnicas experimentais usadas para caracterizar os filmes aqui apresentados. O terceiro capitulo, mostra os resultados obtidos através de cada uma das técnicas usadas, com suas respectivas análises, dando ênfase nos dados gerados pelas medições de MFM e magnetometria, assim como pelas simulações computadorizadas. Finalmente, são estabelecidas as conclusões e as referências que suportaram o trabalho feito.

Assim, pretende-se oferecer bases experimentais na caracterização de filmes de FeNi, a partir do estudo realizado da sua nanoestrutura magnética. Se espera também contribuir na realização de estudos posteriores sobre o magnetismo em ligas FeNi, particularmente na UnB onde ainda não existem pesquisas neste campo, procurando assim beneficiar à comunidade acadêmica de pesquisadores da Universidade e do país, com os resultados encontrados nesta investigação. 


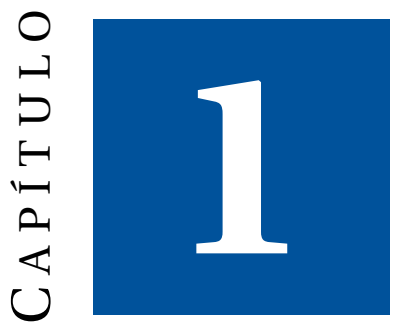

\section{Magnetismo em filmes}

O estudo de materiais nanoestruturados teve um grande sucesso nas ultimas décadas graças aos avanços científicos e tecnológicos nas técnicas de caracterização, manipulação e análise das propriedades físicas destes sistemas. O desenvolvimento da Mecânica Quântica e do Estado Sólido junto com as melhorias na precisão e processamento dos equipamentos de fabricação e medição, desencadearam o surgimento de diversos ramos do conhecimento focados na pesquisa e aproveitamento das características da matéria na nanoescala (1-100 nm), onde o comportamento dos objetos muda consideravelmente com respeito aos objetos macroscópicos. É por isso que muitas vezes não interessa somente o tipo de material que compõe o nano-objeto, senão também quão pequeno ele é.

Um destes campos de estudo é conhecido como Física dos Filmes Finos, especializado na pesquisa de materiais onde uma das suas três dimensões (a espessura) é nanométrica, diferentemente das outras duas dimensões (comprimento e largura) que podem ser mili ou centimétricas.

O interesse neste tipo de estruturas, particularmente nos filmes metálicos, se deve basicamente a duas razões: 1) A pouca espessura destes materiais faz com que a proporção de átomos em sua superfície aumente e que a sua interação com outras superfícies, como os substratos em que são depositados, seja crucial na alteração das propriedades mecânicas, elétricas, óticas ou magnéticas do sistema [19,20], e 2) tais propriedades podem ser usadas em dispositivos tecnológicos com um menor custo, recobrindo outros objetos com filmes do material de interesse, em vez de usar dito material em grandes 
quantidades.

Neste sentido, a grande variedade de propriedades magnéticas em filmes ferromagnéticos resulta num campo de pesquisa ativo e crescente na atualidade, tanto pelo debate surgido em torno à origem das possíveis configurações dos domínios magnéticos, quanto pelas aplicações tecnológicas que este tipo de filmes possui em relação ao armazenamento de informação, construção de sensores de alta precisão, microtransformadores, dispositivos para redução de ruído electromagnético, etc. [19,21-23]. A seguir, serão abordados os aspectos gerais dos filmes ferromagnéticos e suas características magnéticas, com o objetivo de fundamentar o estudo feito neste trabalho com filmes de FeNi.

\subsection{Formação de filmes ferromagnéticos}

Filmes ferromagnéticos são feitos pela deposição de elementos como o Fe, Ni, Co ou ligas entre eles, sobre diferentes tipos de substratos diamagnéticos como o Si ou $\mathrm{Cu}$, de modo que as propriedades magnéticas do substrato não afetem a configuração magnética do filme. Para evitar possíveis oxidações dos filmes, também é depositado sobre sua superfície, uma fina camada de revestimento (camada passivadora), feita de elementos como o Pd ou Al (Figura 1.1).

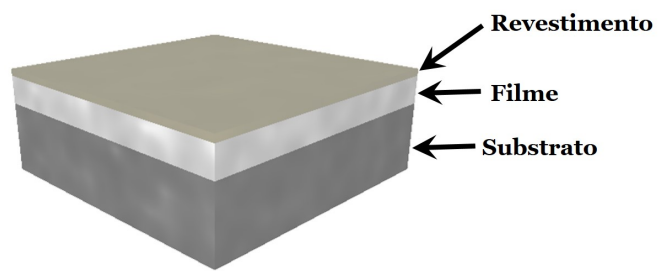

Figura 1.1 - Esquema da estrutura de um filme convencional.

A deposição do material ferromagnético pode ser feita por meio de diferentes métodos como evaporação, deposição eletrolítica, decomposição térmica, entre outras [19], mas uma das técnicas mais comuns é a pulverização ou sputtering (Figura 1.2). Nela, um gás inerte ionizado como o $\mathrm{Ar}^{+}$, é acelerado para um alvo conectado num cátodo e constituído pelo material em estado bulk que conformará o filme. Os íons do gás batem nos átomos ou moléculas do alvo, liberando-os para depois ser condensados no substrato conectado ao anodo, de modo que o campo elétrico gerado entre o alvo e o substrato facilite a aderência do material (sputtering DC) [24]. 


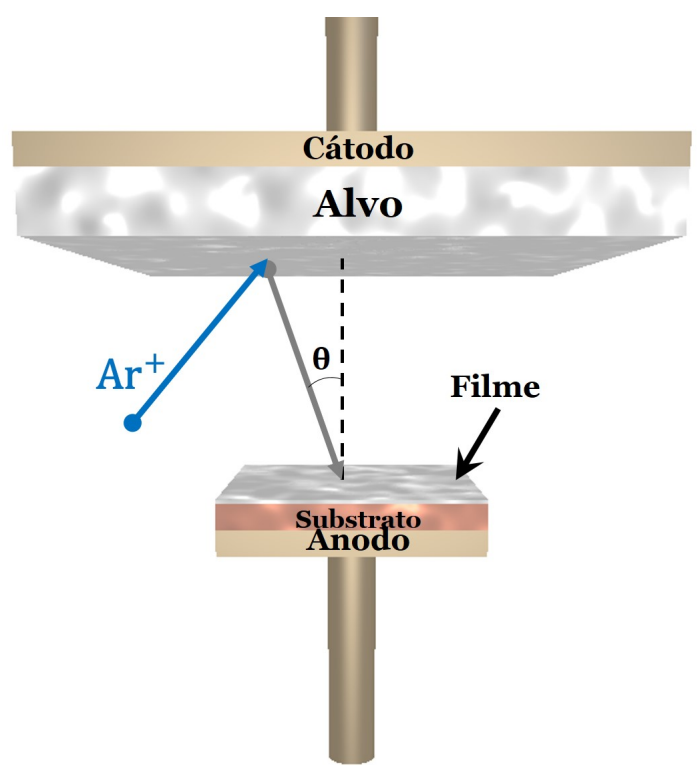

Figura 1.2 - No sputtering DC, o alvo de material ferromagnético é bombardeado com íons de um gás inerte, para retirar os átomos ou moléculas do alvo a serem depositadas no substrato.

Durante a deposição das partículas no substrato, têm lugar dois fenômenos principais:

Nucleação. Inicialmente são formados pequenos núcleos de material, os quais se distribuem na superfície do substrato, interagindo por meio de forças de dipolo elétrico. A acomodação das partículas vai depender da energia térmica entre elas e o substrato. Se a energia da partícula é muito alta, ela pode ser refletida pelo substrato ou pode migrar pela superfície num movimento browniano até se encontrar com outra partícula, conformando aglomerados de menor energia e que são adsorvidos mais facilmente pelo substrato [19,21].

Crescimento. Ao ser condensados os núcleos no substrato, são originadas ilhas aleatórias, que vão se juntando umas com as outras até ocuparem completamente a superfície do substrato, formando assim uma estrutura em rede plana. As ilhas de maior tamanho são as que determinam as propriedades físicas do filme ao final [19].

Nestas condições, o processo de formação do filme vai ser influenciado pelas impurezas pressentes na câmara de deposição ou no alvo, as quais mudam as energias de ligação dos núcleos com o substrato, gerando um aumento na aglomeração dos núcleos, impedindo a continuidade do filme [21]. A aglomeração pode ser acrescentada também por energias cinéticas ou ângulos de incidência altos, entre outros fatores. 
Não obstante, os enlaces metálicos presentes em filmes ferromagnéticos fazem com que a nucleação e crescimento sejam muito organizados e estáveis, dando passo à formação de redes cristalinas no material, e por conseguinte, a filmes muito planos, que são afetados nas primeiras camadas atômicas pelas características do substrato. Este fenômeno é conhecido como pseudomorfismo e acontece quando a constante de rede do material é comparável com a constante do substrato, mas pode ser reduzido com o aumento na espessura do filme [21]. Neste sentido, filmes de Fe cristalizam geralmente em estruturas cúbicas de corpo centrado (body-centered cubic-bcc), filmes de Ni tendem a formar estruturas cúbicas de face centrada (face-centered cubic-fcc) e filmes de Co possuem uma estrutura hexagonal de empacotamento compacto (hexagonal close packing-hcp).

Portanto, os filmes ferromagnéticos tendem a ser monocristalinos, no caso de estar conformados por somente um elemento químico, ou policristalinos quando são feitos de ligas metálicas. Neste último caso, o tamanho dos cristalitos $(\sim 100 \AA)$, é diretamente proporcional à mobilidade superficial, à temperatura do substrato, à rugosidade da superfície, etc. [21], além disso resulta mais difícil obter planos cristalográficos preferenciais, já que a condensação das moléculas é mais aleatória.

\subsection{Modelo de banda para o ferromagnetismo}

Os átomos dos elementos que integram os filmes ferromagnéticos como o $\mathrm{Fe}$, $\mathrm{Co} \mathrm{ou}$ $\mathrm{Ni}$, têm seus últimos orbitais parcialmente ocupados pelos seus elétrons. Por exemplo, o átomo isolado de Fe possui 26 elétrons distribuídos nos seus orbitais do seguinte modo, segundo o principio de Aufbau, o princípio de exclusão de Pauli e a regra de Hund:

$$
1 s^{2} 2 s^{2} 2 p^{6} 3 s^{2} 3 p^{6} 4 s^{2} 3 d^{6}
$$

aqui o par coeficiente-letra representa os números quânticos $n$ e $l$ respectivamente, sendo que $s$ corresponde a $l=0, p$ a $l=1, d$ a $l=2$, etc. O número quântico $n$ também define as camadas ou bandas energéticas, denominadas com as letras K para $n=1, \mathrm{~L}$ para $n=2$, M para $n=3$, etc. Assim, cada par coeficiente-letra constitui um nível de energia que pode estar degenerado, já que o número de orbitais dentro de cada nível vem dado por $2 l+1$. Os exponentes representam o número de elétrons contidos em cada nível de energia.

Assim o nível $1 s$, correspondente à camada $\mathrm{K}$, possui somente um orbital que pode ser preenchido com dois elétrons de spins antiparalelos como regido pelo princípio de 
exclusão de Pauli. Por outro lado, os níveis $3 s, 3 p, 3 d$, que conformam a camada $\mathrm{M}$, tem 1, 3 e 5 orbitais respectivamente, pelo que podem incluir 2, 6 e 10 elétrons cada (2 elétrons em cada orbital).

No entanto, o átomo de Fe conta apenas com 6 elétrons para o nível $3 d$, dos quais, dois preenchem o primeiro orbital, pela regra de Hund, e os outros quatro são distribuídos nos orbitais restantes, sendo que estes 4 elétrons ocupam um orbital cada, ficando desemparelhados (Figura 1.3). Um efeito semelhante acontece com o Co e o Ni, que ficam com 3 e 2 elétrons desemparelhados respectivamente no orbital $3 d$. Os elétrons desemparelhados nos orbitais $3 d$ encontram-se com seus spins paralelos [25], gerando assim um momento magnético total no átomo.

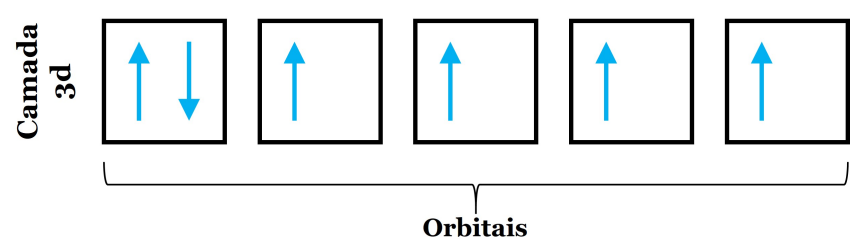

Figura 1.3 - Configuração do nível de energia $3 d$ num átomo de Fe. Os quadrados representam os orbitais neste nível e as setas os spins dos elétrons em cada orbital.

Porém, quando estes elementos formam redes cristalinas, o modo em que são preenchidos os orbitais eletrônicos muda, já que os elétrons desemparelhados podem interagir com os elétrons da mesma camada, com os elétrons da camada de valência composta pelo nível $4 s$ [26] ou com os elétrons dos átomos vizinhos, sendo que essas interações dependem da energia de troca entre as funções de onda de spin dos elétrons, da energia de campo cristalina e da energia de Coulomb entre os átomos [27]. A competição entre este tipo de energias, dependente também do tipo de simetria do ambiente local de cada átomo, determina a ordem de preenchimento dos orbitais eletrônicos e portanto, o momento magnético efetivo dos átomos [27].

Contudo, os elétrons de átomos vizinhos conseguem interagir através da interação de troca indireta ou troca itinerante $E_{T}$, mediada pelos elétrons de condução [27]. essa interação gera um campo molecular de troca que provoca um deslocamento do nível de energia $3 d$ com respeito à densidade dos estados (DE), que é a quantidade de estados de elétrons presentes em um certo intervalo de energia. O campo supracitado faz com que os níveis de energia para elétrons com spin up diminuam e para elétrons com spin down aumentem, incluindo o nível de Fermi, $E_{F}$ (Figura 1.4, a.).

Não obstante, o nível de Fermi não pode ser distinto para os dois canais de spins, pelo que alguns elétrons com spin down são transferidos para o canal de spin up, até 


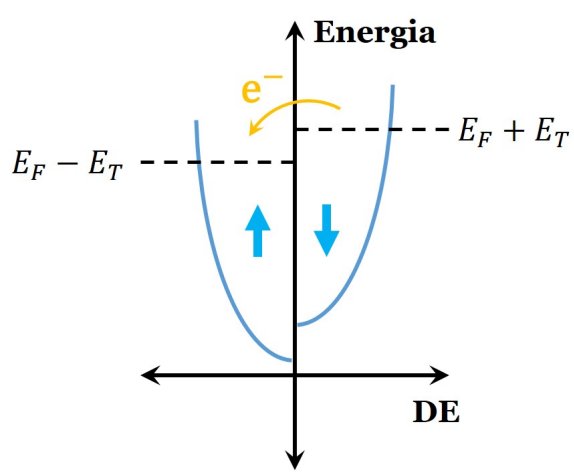

a.

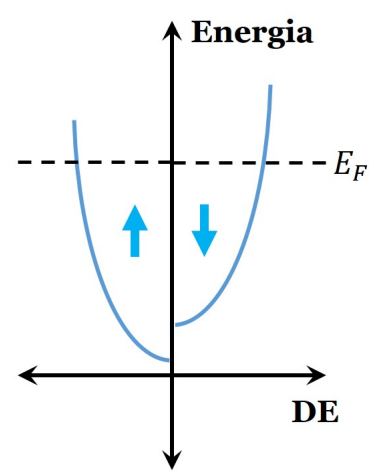

b.

Figura 1.4 - Deslocamento das energias dos elétrons no nível $3 d$ a. A energia de troca $\left(E_{T}\right)$ gera um deslocamento nos níveis de energia dos canais de spin, b. A migração de elétrons deixa o nível de Fermi igual para os dois canais [25].

que a energia de Fermi seja nivelada ${ }^{1}$ (Figura 1.4, b.). A forma da curva da DE depende do tipo de material, sendo na figura simplificada para ilustrar melhor o processo. A diferença de elétrons entre os canais de spin ocasiona uma polarização dos spins e portanto uma variação na energia total do sistema $\Delta E$, dada por [27]:

$$
\Delta E=\frac{1}{2} D\left(E_{F}\right)(\delta E)^{2}\left(1-U D\left(E_{F}\right)\right)
$$

sendo $D\left(E_{F}\right)$ a densidade de estados no nível de Fermi, $\delta E$ a variação de energia por causa da interação de troca e $U$ é uma medida da energia de Coulomb, responsável da interação de troca [27]. O ferromagnetismo surge se $\Delta E<0$, o que acontece quando:

$$
U D\left(E_{F}\right) \geq 1
$$

condição conhecida como o critério de Stoner para o ferromagnetismo [27]. O anterior implica que se a densidade de energia no nível de Fermi é alta e aliás a interação de Coulomb e de troca são fortes, então surge o ferromagnetismo espontâneo, assim como o momento magnético total do material.

Desta forma, o Ni, o Co e o Fe tem momentos magnéticos resultantes equivalentes a $0.6 \mu_{B}, 1.7 \mu_{B}$ e $2.2 \mu_{B}$, sendo $\mu_{B}$ o magneton de Bohr [1,25,29]. Estes momentos magnéticos produzem o surgimento da magnetização espontânea dos materiais ferromagnéticos, e por conseguinte, o campo magnético intrínseco do material, que permite

\footnotetext{
${ }^{1}$ Esta teoria é chamada de Teoria de Banda e foi formulada pela primeira vez pelos físicos britânicos Edmund Stoner e Nevill Mott. depois foi formulado independentemente pelo físico americano John Slater $[25,28]$
} 
uma forte interação com campos magnéticos externos.

Na ausência de campos externos, a distribuição destes momentos magnéticos, assim como a configuração da magnetização e do campo intrínseco da amostra, é complexa dado que pode ser modificada mudando, entre outras coisas, a espessura do filme, as dimensões laterais da estrutura [30], as concentrações relativas dos elementos que constituem o filme ou variando a temperatura, já que os incrementos de temperatura reduzem a magnetização do material até atingir a temperatura de Curie, acima da qual o material ferromagnético se forma paramagnético [28,31].

Além disso, dita configuração depende da interação do filme com seu entorno imediato, o tipo de revestimento e o substrato usados na fabricação. Tais substâncias devem ser bem escolhidas para evitar efeitos não desejados no filme. Tudo isto obriga a levar em consideração diferentes aportes energéticos que afetam a magnetização do material, como será apresentado a seguir.

\subsection{Contribuições energéticas em filmes ferromagné- ticos}

Para dar conta das interações magnéticas das estruturas nanométricas como no caso dos filmes, costuma-se usar a energía livre de Gibbs, dada no sistema CGS por:

$$
\phi=\int_{V}\left(U-T \cdot S-\sigma \cdot \varepsilon-\vec{M} \cdot \vec{H}_{e x t}\right) d V
$$

nela $U$ é a energia interna do sistema, $T$ a temperatura, $S$ a entropia, $\sigma$ e $\varepsilon$ são os tensores de deformação e tensão respectivamente, $\vec{M}$ a magnetização do material e $\vec{H}_{\text {ext }}$ o campo magnético externo [20]. A integração é feita no volume da amostra.

O termo de temperatura tem a ver com a energia de agitação térmica do sistema, que é somente importante para nanopartículas ou em situações onde a temperatura fica perto da temperatura de Curie [32]. O seguinte termo representa o aporte energético induzido por deformações mecânicas no material, provocadas intencionalmente na hora da deposição ou pelo contato com o substrato.

O último termo, chamado de Energia de Zeeman, corresponde à interação da magnetização da estrutura com campos magnéticos externos. Este não depende da configuração particular dos momentos magnéticos na amostra, mas é influenciado pela magnetização média do material [32], que é alinhada na direção do campo magnético externo. 
Entretanto, o termo de energia interna contém outro tipo de interações relacionadas com a morfologia, as propriedades físicas do objeto nanoestruturado, as impurezas ou defeitos na rede cristalina, entre outros, mas aqui serão considerados somente os termos mais relevantes para o caso dos filmes estudados neste trabalho, como veremos a seguir.

\subsubsection{Energia de troca}

A interação de troca é um tipo de acoplamento entre spins vizinhos, sendo de curto alcance [31]. Como já foi apresentado, é uma das principais fontes do ferromagnetismo, ao ser a responsável pelo acoplamento entre os spins desemparelhados das camadas $3 d$ dos metais de transição. Sua origem quântica vem da superposição das funções de onda dos elétrons das camadas externas do átomo, favorecendo a troca de informação entre os estados de spin [31].

A energia de troca $\left(E_{T}\right)$ para elétrons localizados, segundo o modelo de Heisenberg, tem a seguinte forma [27]:

$$
E_{T}=-2 \sum_{i, j=1}^{N} J_{i j} S_{i} \cdot S_{j}
$$

é a soma de todas as interações spin-spin $\left(S_{i} \cdot S_{j}\right)$ entre os $N$ elétrons do sistema, onde $J_{i j}$ representa a integral de troca. O produto escalar indica que a energia de troca é inversamente proporcional ao ângulo entre os spins dos elétrons. Quando $J_{i j}>0$, o acoplamento é de tipo ferromagnético com spins paralelos, como acontece com elétrons do mesmo átomo, porém se $J_{i j}<0$ então o acoplamento é antiferromagnético com spins antiparalelos, como sucede com elétrons de átomos distintos [31].

\subsubsection{Energia de desmagnetização}

Devido à presença dos momentos magnéticos nos átomos dos filmes ferromagnéticos, surgem acoplamentos dipolares de longo alcance responsáveis pela criação do campo magnético intrínseco ou de desmagnetização do material, $\vec{H}_{d}$. Isto é, o filme produz seu próprio campo magnético, que irá influenciar a formação das estruturas magnéticas particulares do material. A energia de desmagnetização associada com este campo, em unidades do sistema CGS, é [32]:

$$
E_{d}=-\frac{1}{2} \int_{V} \vec{M} \cdot \vec{H}_{d} d V
$$


onde o fator 1/2 é usado para evitar a recontagem da interação entre o mesmo par de dipolos [20]. Esta contribuição energética também é chamada de energia de anisotropia de forma, já que depende de três características: o volume da amostra, a sua forma e direção da magnetização dentro do material [33], sendo mínima no caso em que $\vec{H}_{d}$ é paralelo a $\vec{M}$ [34].

A energia de desmagnetização permite que todos os momentos magnéticos da amostra interajam uns com os outros, o que faz com que o campo magnético intrínseco do material não resulte uniforme e portanto a configuração magnética torna-se complexa na sua descrição, sendo necessária a utilização de métodos numéricos e de rotinas computacionais lentas para estimar esta energia.

\subsubsection{Energia de anisotropia magneto-cristalina}

Os spins responsáveis pela magnetização intrínseca dos filmes ferromagnéticos, encontram se acoplados debilmente às órbitas dos elétrons em torno do núcleo, entretanto estas órbitas possuem um forte acoplamento com a rede cristalina do material [28], o que faz com que os momentos magnéticos sejam alinhados nas direções dos eixos cristalográficos principais, os quais viram eixos de fácil magnetização. Geralmente direções perpendiculares aos eixos fáceis dificultam a magnetização.

$\mathrm{O}$ anterior produz uma anisotropia que depende do tipo de estrutura cristalina do filme, isto faz com que os spins sejam alinhados ao longo dos eixos fáceis, para atingir o nível mínimo de energia [20,31]. A energia associada é denominada energia de anisotropia magneto-cristalina, $E_{K}$, que depende do volume da amostra e de uma constante $K$, oriunda de uma função angular que representa a simetria da rede cristalina, $f(\theta \varphi)$, de modo que:

$$
E_{K}=\int_{V} K f(\theta \varphi) d V
$$

Por exemplo, para filmes com estrutura cristalina cúbica, a energia de anisotropia sobre os eixos fáceis vem dada por:

$$
E_{K}=\int_{V}\left[K_{0}+K_{1}\left(\alpha_{1}^{2} \alpha_{2}^{2}+\alpha_{2}^{2} \alpha_{3}^{2}+\alpha_{3}^{2} \alpha_{1}^{2}\right)+K_{2} \alpha_{1}^{2} \alpha_{2}^{2} \alpha_{3}^{2}+\cdots\right] d V
$$

onde $K_{0}, K_{1}, K_{2}$, etc., são constantes de anisotropia do material dadas em erg $/ \mathrm{cm}^{3}$ e calculadas com dados experimentais como será mostrado posteriormente. Sua magnitude indica a dificuldade de magnetizar o material numa certa direção. Por outro lado, $\alpha_{1}$, $\alpha_{2}$ e $\alpha_{3}$ representam os cossenos diretores dos ângulos entre a magnetização e os eixos cristalográficos $[32,35]$. Geralmente, termos de maior ordem podem ser desprezados, 
pois suas contribuições são muito baixas.

Se o filme tem uma estrutura cristalina do tipo hexagonal ou tetragonal, ou se na hora da deposição foi induzido um eixo fácil aplicando campos magnéticos ou tensões mecânicas numa certa direção, então a estrutura adquire uma anisotropia uniaxial da forma [20]:

$$
E_{K}=\int_{V}\left(K_{u 1} \sin ^{2} \theta+K_{u 2} \sin ^{4} \theta+\cdots\right) d V
$$

sendo $\theta$ o ângulo entre a magnetização e o eixo fácil. Mas se este ângulo é pequeno, a energia de anisotropia uniaxial pode ser aproximada a:

$$
E_{K}=\int_{V}\left(K_{u 1} \sin ^{2} \theta\right) d V \approx \int_{V}\left(K_{u 1} \theta^{2}\right) d V
$$

Nesta situação, a energia de anisotropia produz um torque que gira a magnetização espontânea para o eixo fácil, como se fosse aplicado um campo magnético externo chamado de campo de anisotropia $H_{K}$. Assim a energia de anisotropia é equivalente a [35]:

$$
E_{K}=-\int_{V} M_{S} H_{K} \cos \theta d V \approx-M_{S} H_{K}\left(1-\frac{1}{2} \theta^{2}\right)
$$

onde $M_{S}$ é a magnetização de saturação do filme, ou a magnetização máxima atingida pelo material na presença de campo externos. Portanto, comparando os termos que contêm $\theta^{2}$ nas equações (1.9) e (1.10), resulta que a constante de anisotropia uniaxial é [35]:

$$
K_{u 1}=\frac{1}{2} M_{S} H_{K}
$$

No caso dos filmes, geralmente também costuma-se usar uma anisotropia efetiva $K_{e f}$, já que neste tipo de estruturas existe uma contribuição volumétrica $K_{V}$, e outra superficial $K_{S}$, para a energia de anisotropia, tal que [36]:

$$
K_{e f}=K_{V}+\frac{2}{t} K_{S}
$$

sendo $t$ a espessura do filme. Logo se $K_{e f}>0$ então a anisotropia é perpendicular à superfície do filme, mas se $K_{e f}<0$ então a anisotropia é paralela à superfície do filme [36].

\subsection{Domínios magnéticos em filmes}

Todas as contribuições energéticas dentro dos filmes ferromagnéticos, se combinam de diferentes formas segundo as características do material, induzindo a distribuição 
dos momentos magnéticos aleatoriamente ao longo da amostra. Não obstante, por meio de diferentes técnicas experimentais, é possível observar que apesar dessa aleatoriedade, existem regiões no volume da estrutura que partilham certas direções de magnetização, devido a que a grande maioria dos momentos magnéticos nestas regiões encontram-se paralelos entre si, por causa da anisotropia de troca.

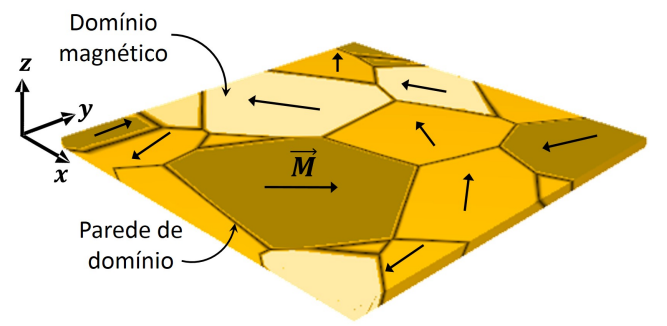

a.

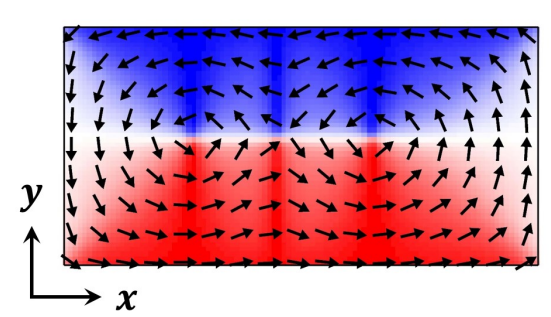

b.

Figura 1.5 - a. Representação dos domínios num filme ferromagnético com uma configuração micromagnética irregular, b. simulação dos domínios magnéticos na superfície de uma nanoestrutura de Ni de $1 \times 0.5 \mu \mathrm{m}^{2}$ e $20 \mathrm{~nm}$ de espessura. As cores mostram o contraste dos momentos na direção $x$ [37].

Tais zonas de magnetização comum, são nomeadas domínios magnéticos (Figura 1.5), sendo que cada domínio possui uma direção de magnetização distinta à de seus vizinhos. Neste caso, como os momentos magnéticos estão alinhados, se diz que cada domínio está saturado [25], organizando-se de modo que a energia total do sistema seja mínima.

A anisotropia magneto-cristalina controla a formação dos domínios magnéticos. Quanto maior é a anisotropia, mais irregulares e menores são as zonas ocupadas por eles (Figura 1.5, a.). Não obstante a anisotropia de forma, resultado da energia de desmagnetização, obriga à formação de uma maior quantidade de domínios [33]. Além disso, o formato e tamanho da amostra também condiciona suas características [32], dado que a finitude da estrutura origina configurações mais regulares (Figura 1.5, b.).

Cada domínio encontra-se por sua vez limitado por paredes de domínio, as quais contém uma certa quantidade de átomos que permitem a mudança da magnetização entre domínios vizinhos. Este processo pode ser mais gradual ou mais abrupto, dependendo da competição entre a energia de troca e a energia magneto-cristalina. Se a magnetização de um domínio é perpendicular à de seu vizinho, então a fronteira entre eles é uma parede de $90^{\circ}$, mas se as magnetizações são antiparalelas, então tem-se uma parede de $180^{\circ}$.

Dependendo do modo em que é feita a transição, as paredes podem ser classificadas de dois modos: 
Paredes tipo Bloch. Nelas os momentos magnéticos começam a sair continuamente da superfície do filme, onde se encontram os domínios, ficando perpendicular no meio da parede e retornando para o plano com uma direção distinta à original (Figura 1.6, a.). Como este processo requer um gasto energético alto, é favorecido em filmes de maior espessura. A energia de desmagnetização por unidade de área da parede no sistema CGS, vem dada por [28]:

$$
\gamma_{B}=\frac{4 \pi}{2} \frac{a^{2} M_{s}^{2}}{t+a}
$$

onde $a$ é a largura da parede e $t$ a espessura do filme. Note-se que a energia da parede Bloch diminui com o aumento na espessura do filme.

Paredes tipo Néel. Se o filme é muito fino, o processo de transição de um domínio para o outro acontece no plano da superfície, de modo que os momentos magnéticos dentro das paredes giram progressivamente paralelos à superfície da amostra, originando as paredes Néel (Figura 1.6, b.). Neste caso o gasto energético é menor, sendo sua energia de desmagnetização por unidade de área dada por [28]:

$$
\gamma_{N}=\frac{4 \pi}{2} \frac{t a M_{s}^{2}}{t+a}
$$

Comparando esta energia com a energia das paredes Bloch, obtém-se que:

$$
\frac{\gamma_{B}}{\gamma_{N}}=\frac{a}{t}
$$

isto é, a energia das paredes tipo Néel é menor que a energia das paredes tipo Bloch, sempre e quando a espessura do filme seja menor que a largura da parede $(t<a)[28]$.

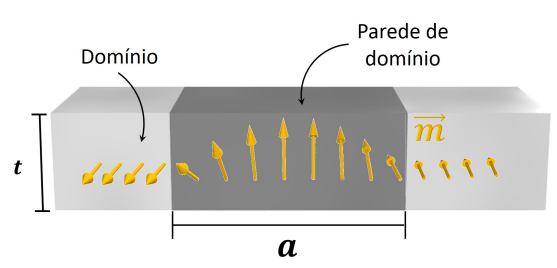

a.

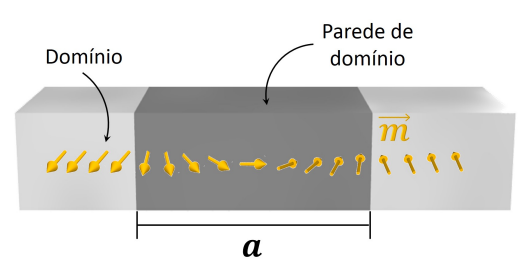

b.

Figura 1.6 - a. Esquema de uma parede de domínio tipo Bloch, b. de uma parede de domínio tipo Néel.

O surgimento destas ou de outras possíveis configurações produto da combinação 
deste tipo de paredes, vai determinar as características magnéticas do filme na presença de campos magnéticos externos, pois as direções dos momentos magnéticos definem as direções do campo intrínseco do material.

Filmes com eixos fáceis de magnetização no plano, tenderão a ter paredes de domínio tipo Néel, assim como magnetização espontânea paralela à superfície da amostra, enquanto que filmes com eixos fáceis perpendiculares, geralmente terão paredes de domínio tipo Bloch e magnetização perpendicular à superfície do filme. Estas propriedades são estabelecidas por meio do uso das curvas de magnetização.

\subsubsection{Curvas de magnetização}

Mudanças nas direções de magnetização nos domínios e nas suas paredes, podem ser provocadas por campos magnéticos externos aplicados sobre os filmes. Essas mudanças dependem da intensidade e direção do campo com respeito aos eixos fáceis da amostra. Por exemplo, se o filme possui eixos fáceis no plano com paredes de domínio tipo Néel (Figura 1.7, b.), um campo $\vec{H}$ de baixa intensidade paralelo à superfície do filme, será suficiente para alinhar todos os momentos magnéticos na sua direção, destruindo desta forma as paredes de domínio.

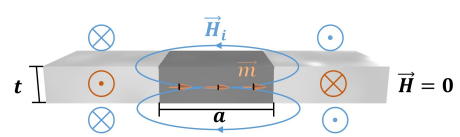

a.

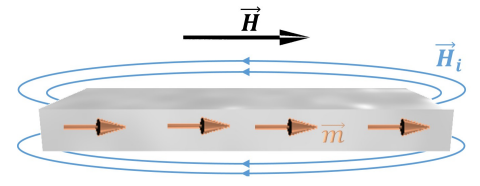

b.

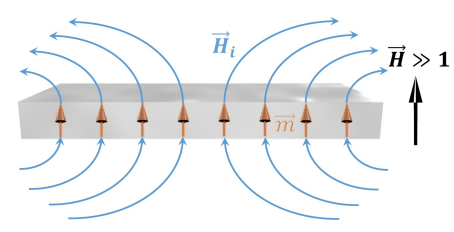

c.

Figura 1.7 - Momentos magnéticos numa parede tipo Néel: a. em ausência de campo externo, b. com campo no plano, c. com campo perpendicular à superfície do filme. $\vec{H}_{i}$ representa o campo intrínseco da amostra.

Mas se o campo for aplicado sobre o mesmo filme na direção perpendicular à sua superfície, o gasto energético investido para alinhar os momentos com o campo será maior, e portanto a intensidade do campo externo também deve aumentar (Figura 1.7, c.).

Estes fenômenos geram um comportamento histerético que pode ser visualizado com ajuda das curvas de magnetização (Figura 1.8). O filme desmagnetizado (Figura 1.8, ponto 1) é submetido a um campo magnético com intensidade crescente, até atingir a magnetização de saturação, $M_{s}$, onde os momentos magnéticos ficam paralelos ao campo externo (Figura 1.8, ponto 2). Este primeiro trecho é nomeado curva virgem. 


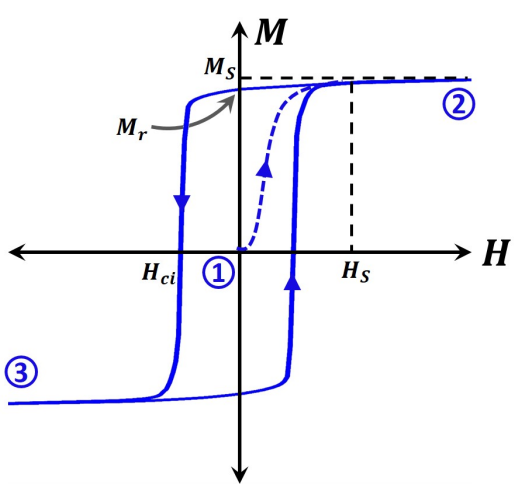

a.

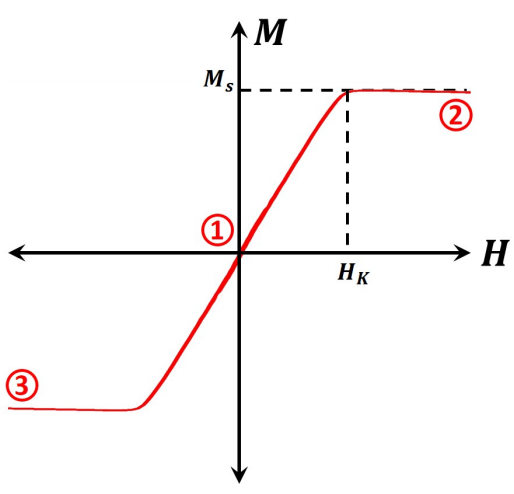

b.

Figura 1.8 - Curvas de magnetização nos eixos fácil (a.) e difícil (b.), em função do campo magnético aplicado.

Se o campo é aplicado paralelo aos eixos fáceis, a saturação é obtida com intensidades relativamente baixas do campo de saturação, $H_{s}$ (Figura 1.8, a.), mas se o campo é aplicado paralelo aos eixos difíceis, a saturação é alcançada em campos relativamente altos, nomeados de campos de anisotropia, $H_{K}$ (Figura 1.8, b.). Acima destes valores de campo a magnetização é constante.

O campo $H_{K}$ é determinado experimentalmente e seu valor permite estimar a constante de anisotropia $K_{u 1}$ por meio da equação (1.11), assim como a anisotropia efetiva expressa como [38]:

$$
K_{e f}=\frac{1}{2} M_{s} H_{K}-\frac{1}{2} M_{s}^{2}
$$

Após da saturação, a intensidade do campo é reduzida até que seja nula. Para campos paralelos ao eixo fácil, a amostra mantém uma magnetização com $H=0$, chamada de magnetização de remanência, $M_{r}$, onde a maioria dos momentos se alinham com o eixo fácil mais próximo. Quanto mais próximo esteja $M_{r}$ de $M_{s}$, menor será o ângulo de rotação, $\theta$, entre a direção do campo e o eixo fácil do filme, através do qual é possível definir o coeficiente de alinhamento do material, $c_{o}$ como [39]:

$$
c_{o}=\frac{M_{r}}{M_{s}}=\cos \theta
$$

onde $c_{o} \leq 1$, é um indicativo da porcentagem de momentos magnéticos em remanência. Para campos perpendiculares não existe remanência e a amostra fica desmagnetizada ao retirar o campo externo.

Assim, o filme pode ser desmagnetizado unicamente se for aplicado um campo na direção contrária. Dito campo é nomeado campo coercitivo intrínseco, $H_{c i}$ [25] e 
permite diferenciar os filmes ferromagnéticos duros $\left(H_{c i} \geq 100\right.$ Oe) dos ferromagnéticos moles $\left(H_{c i} \leq 30 \mathrm{Oe}\right)$. Para valores mais altos que este campo, a amostra começa a magnetizar de novo na direção contrária, até atingir o ponto de saturação negativa (Figura 1.8, ponto 3). Repetindo o processo acrescentando o campo para valores positivos, o laço de histerese é fechado.

O surgimento da histerese tem a ver com dois processos principais, inicialmente, se assume que o campo externo exerce uma pressão sobre as paredes de domínio, empurrando-as para as bordas do filme, favorecendo assim o aumento do tamanho dos domínios com magnetização paralela ao campo. Posteriormente, se alguns dos domínios não se alinharem ao campo, os momentos deixam os eixos fáceis e passam a se alinhar como o campo $H$. Em qualquer caso, a configuração dos momentos magnéticos no filme não voltam às condições iniciais. 


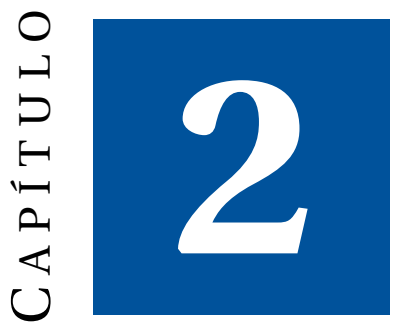

\section{Materiais e caracterização}

No presente trabalho foi estudada a microestrutura magnética de três filmes de FeNi na concentração Invar, com diferentes espessuras. Inicialmente os filmes foram caracterizados em termos da sua espessura e sua estrutura cristalina, através de medidas de refletometria e difração de raios X, para após analisar com mais detalhe seu comportamento magnético, a través das técnicas de magnetometria e Microscopia de Força Atômica e Magnética.

Deste modo, são apresentadas a seguir as características física mais importantes deste tipo de ligas, assim como as técnicas usadas para a caracterização dos filmes, o que permitirá compreender melhor os resultados obtidos, a serem mostrados no próximo capítulo.

\subsection{Ligas Invar FeNi36}

Ligas Invar do tipo FeNi36, apresentam coeficientes de dilatação muito baixos, posto que são da ordem de $1.2 \times 10^{-6}{ }^{\circ} \mathrm{C}^{-1}$ (Figura 2.1, a.) na faixa de temperaturas desde $273 \mathrm{~K}$ até $373 \mathrm{~K}$, sendo a temperatura de Curie de $500 \mathrm{~K}$ para estas ligas [40-42].

Os dados experimentais também mostram que as ligas FeNi36 possuem um momento magnético de $1.6 \mu_{B}$ por átomo aproximadamente, para o caso das super-redes (linha contínua, Figura 2.1, b.), indicando a relação entre este fenômeno e as suas propriedades magnéticas $[10,40]$.

Além disso, nas ligas Invar FeNi35 a estrutura cristalina estabiliza-se numa rede cúbica de face centrada (fcc), muito próxima da transição de fase entre a estrutura bcc 


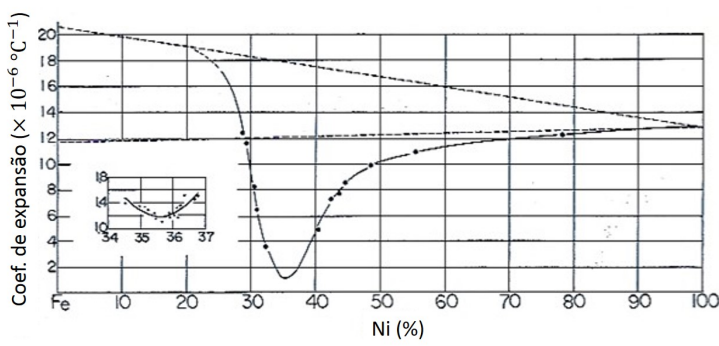

a.

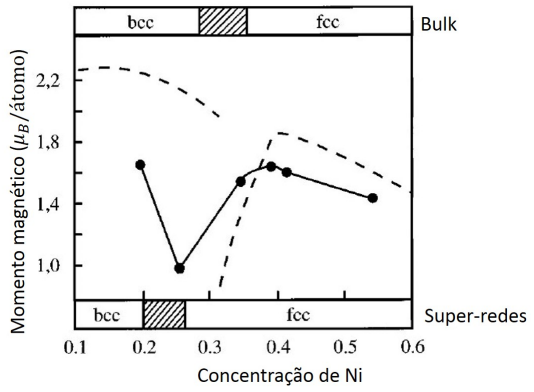

b.

Figura 2.1 - a. Coeficiente de dilatação térmica [43] e b. momento magnético por átomo para ligas FeNi em estado bulk (linhas pontilhadas) e em super-redes (linhas contínuas) [10], em função da concentração de Ni. As zonas sombreadas em b. indicam regiões de coexistência das estruturas bcc e fcc.

e a fcc (Faixas sombreadas, Figura 2.1, b.). Mas as fases cristalográfica e magnética, dependem da temperatura, já que existe uma fase tipo bcc de alto spin ferromagnética (fase $\alpha$ ) abaixo dos $1000 \mathrm{~K}$, uma fase tipo fcc de alto spin ferromagnética (fase $\gamma$ ) abaixo dos $500 \mathrm{~K}$ e uma fase tipo fcc de baixo spin antiferromagnética (fase $\gamma^{\prime}$ ) abaixo dos $20 \mathrm{~K}[11,41,44]$.

A magnetização destas ligas também apresenta altos valores de saturação em $T \sim 0 \mathrm{~K}$, já que nessa região o estado magnético fica quase homogêneo [11,12]. Mas quando a temperatura aumenta, a magnetização espontânea $M(T)$ das ligas Invar não se comportam como estabelece a lei de Bloch:

$$
M(T)=M(0)\left(1-C T^{3 / 2}\right)
$$

ou seja, diminuindo proporcionalmente a $T^{3 / 2}$, com $C$ como a constante de Bloch relacionada com a energia de troca $[14,16,45]$. Por exemplo, no caso de filmes de FeNi35, com $200 \mathrm{~nm}$ de espessura sobre substrato de quartzo [12], os resultados da magnetização em função da temperatura, expõem uma saturação $M_{s}(0)$ e uma temperatura de Curie muito maior que no caso do material no estado bulk, ao ser preparados por evaporação sem nenhum outro tipo de tratamento (pontos brancos, Figura 2.2). Mas quando os filmes são aquecidos a $900 \mathrm{~K}$, voltam a ter as propriedades magnéticas das ligas no estado bulk (pontos pretos, Figura 2.2), seguindo uma curva que não se ajusta com a lei de Bloch.

Outro tipo de estudos têm permitido estabelecer também, que as ligas Invar possuem uma magnetostricção de volume espontânea ${ }^{1}\left(\omega_{s}\right)$ muito alta $[40,46]$. Katsuki e

\footnotetext{
${ }^{1}$ Magnetostricção de volume espontânea é definida como a diferença entre a tensão coesiva gerada
} 


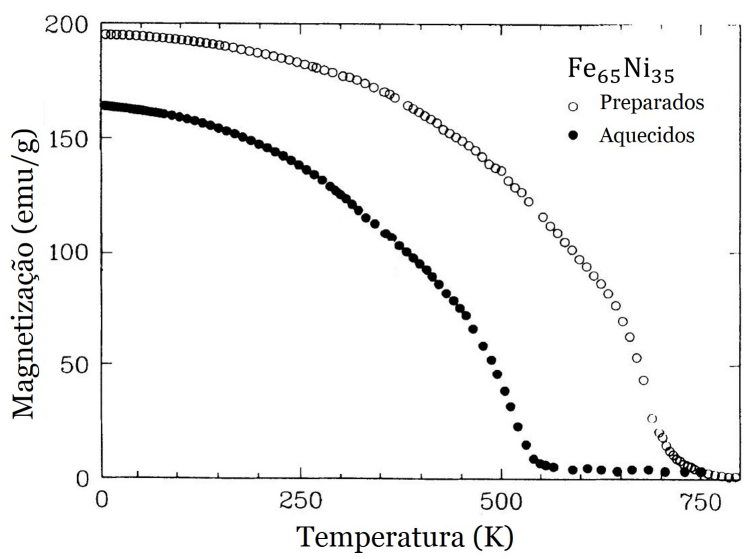

Figura 2.2 - Magnetização vs Temperatura para filmes de FeNi35. Os filmes preparados sem recozimento (pontos brancos) têm um comportamento distinto aos filmes recozidos (pontos pretos), os quais possuem um comportamento muito semelhante às ligas bulk [12].

Terao [46], mostram que $\omega_{s}$ depende da largura da banda eletrônica $W$ e da interação de troca efetiva $J$ numa temperatura de $0 \mathrm{~K}$, da seguinte forma:

$$
\omega_{s}=\kappa\left(E_{f}-E_{p}\right)\left(-\frac{W^{\prime}}{W}\right)+2 \mu^{2} J^{\prime}
$$

onde $\kappa$ é a compressibilidade, $E_{f}$ e $E_{p}$ são as energias nas camadas eletrônicas de átomos no estado ferromagnético e paramagnético respectivamente, $W^{\prime}=\partial W / \partial v$, $J^{\prime}=\partial J / \partial v, v$ é o volume atômico do metal e $\mu$ é o momento magnético por átomo. Partindo desta relação, é possível mostrar que $\omega_{s}$ apresenta valores altos e positivos para as ligas FeNi, ou seja, as tensões coesivas no material causadas pelas camadas eletrônicas, são muito maiores no estado ferromagnético que no estado paramagnético, o que é um aspecto importante, já que essas tensões evitam que a repulsão entre núcleos e os efeitos da agitação térmica aumentem o volume do material.

Atualmente, um dos modelos mais aceito para explicar a origem do efeito Invar, é o modelo $2 \gamma$ ( $2 \gamma$-state model), proposto por Weiss em 1963 [47]. Este modelo sugere a existência de dois estados estáveis de $\gamma$-Fe com estrutura fcc: um estado ferromagnético com alta densidade de spins (High Spin-HS) e grande volume, e outro estado antiferromagnético, com baixa densidade de spins (Low Spin-LS) e também com menor volume. Ao aquecer a liga, as vibrações térmicas fazem diminuir o percentual do estado LS compensando assim as vibrações anarmônicas responsáveis pela expansão térmica

pelas camadas eletrônicas no estado ferromagnético e a mesma tensão no estado paramagnético. Essas tensões contrapesam o efeito da repulsão devida às tensões entre núcleos iônicos. É uma propriedade fundamental dos compostos magnéticos e das ligas. 
e mantendo o volume constante.

Diversos trabalhos teóricos $[9,48,49]$ têm concordado com a teoria de Weiss. Pesquisas feitas a partir de simulações em supercélulas [48], indicam que o efeito Invar deve ter sua origem nas estruturas magnéticas não colineares das ligas FeNi35, já que para volumes atômicos altos os momentos magnéticos do Fe e do Ni (setas vermelhas e azuis respectivamente, Figura 2.3) tendem a se alinhar colinearmente, formando um estado de alto volume e alto spin (HS) [48].
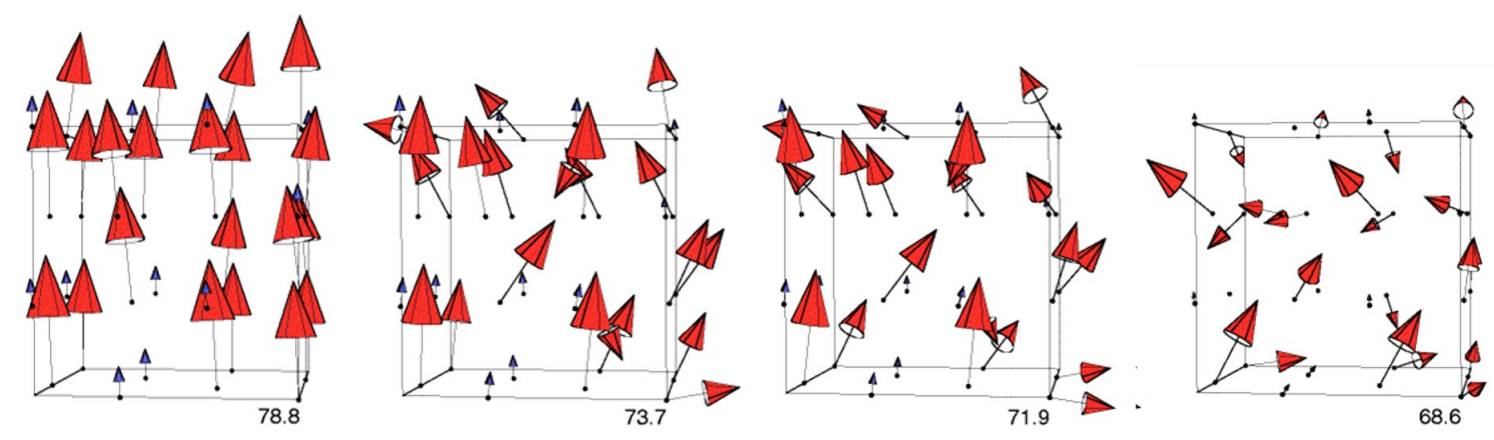

Figura 2.3 - Configurações de spin para diferentes volumes atômicos (canto inferior das células) em ligas FeNi Invar. Setas vermelhas representam os momentos magnéticos do Fe e azuis do Ni [48].

Mas ao diminuir o volume da célula, o sistema tende a um estado de não colinearidade de baixo spin (LS), se estabilizando num volume intermeio de 74 u.a. (1 u.a. $=a_{0}^{3}$ sendo $a_{0}$ o raio de Bohr) entre os estados HS e LS, onde o módulo de compressibilidade é mínimo o que permite ao sistema relaxar sua estrutura magnética [48].

Não obstante, ainda há incompatibilidades com os resultados experimentais, já que por exemplo, pela teoria de Weiss a transição entre os estados HS e LS em função da concentração de Ni deveria ser de primeira ordem, mas as medidas não comprovam essa hipótese. Assim, os modelos ainda não permitem esclarecer completamente todas as evidências experimentais sobre o fenômeno, portanto, a caracterização física destes materiais torna-se importante, dado que ela pode proporcionar mais informação das ligas FeNi36 em nanoescala.

\subsection{Refletometria de raios $X(R R X)$}

Medidas de refletividade especular de raios X (RRX) são geralmente usadas para determinar a espessura de filmes, sendo que ela é uma das características mais importantes destas estruturas, pois suas propriedades podem mudar ao variar a espessura. A 
técnica de RRX não é destrutiva e permite obter espessuras com alta precisão, assim como densidades e rugosidades superficiais das amostras estudadas.

Nesta técnica, um feixe monocromático de raios X com um comprimento de onda $\lambda$, incide sobre o filme num ângulo rasante $\theta$, geralmente dentre $0.3^{\circ} \mathrm{e} 8^{\circ}$ com respeito à superfície do filme. O feixe é refletido pela amostra e sua intensidade é monitorada por um detector que gira verticalmente num ângulo $2 \theta$ com respeito ao feixe incidente (Figura 2.4, a.).

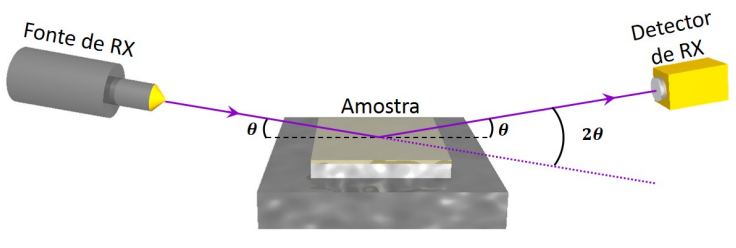

a.

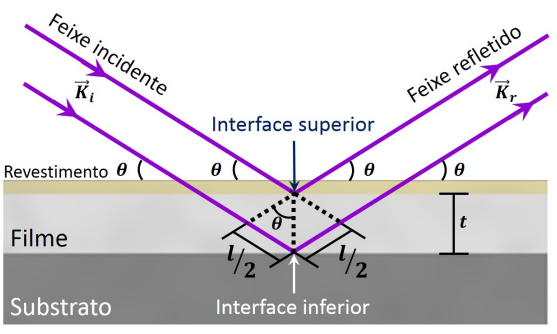

b.

Figura 2.4 - a. Esquema do processo de refletometria de RX em filmes finos, o feixe incide num ângulo rasante $\theta$ sobre a superfície e é refletido para o detector, $\mathrm{b}$. a reflexão é produzida pelas interfaces do filme, gerando um padrão de interferência que permite determinar a espessura $t$ entre as interfaces.

A reflexão de raios X é gerada pelas densidades eletrônicas presentes no filme (interface superior) e no substrato (interface inferior) do material, de modo que é produzida uma diferença de caminhos óticos ( $l$ ) entre os feixes superior e inferior (Figura 2.4, b.), cuja intensidade após da reflexão, diminui rapidamente com o aumento do ângulo de incidência [50,51]. Dita intensidade é analisada em função do vetor de onda de transferência $\vec{k}$ [52], definido como a diferença entre o vetor de onda refletido $\left(\vec{k}_{r}\right)$ e o vetor de onda incidente $\left(\vec{k}_{i}\right): \vec{k}=\vec{k}_{r}-\vec{k}_{i}$.

Quando a magnitude de $\vec{k}$ é pequena, sendo sua componente paralela à superfície do filme diferente de zero, a escala de medida da espessura $t$ do filme aumenta, sendo possível determinar espessuras desde 1 até $200 \mathrm{~nm}$, segundo a intensidade e comprimento de onda do feixe incidente, a resolução angular do equipamento, entre outros fatores [50,51]. Portanto, os feixes superior e inferior podem interferir destrutiva $(\vec{k} \rightarrow$ mín. $)$ ou construtivamente $(\vec{k} \rightarrow$ máx. $)$, induzindo um padrão de interferência detectável, onde a intensidade observada depende do ângulo de incidência (Figura 2.5).

Nas curvas de RRX, a posição angular do primeiro máximo determina o ângulo crítico $\theta_{c}$, abaixo do qual ocorre a reflexão externa total do feixe de raios X. Nesta região, onde $\theta \leqslant \theta_{c}$, e assumindo que a absorção do filme é nula, pode-se calcular 


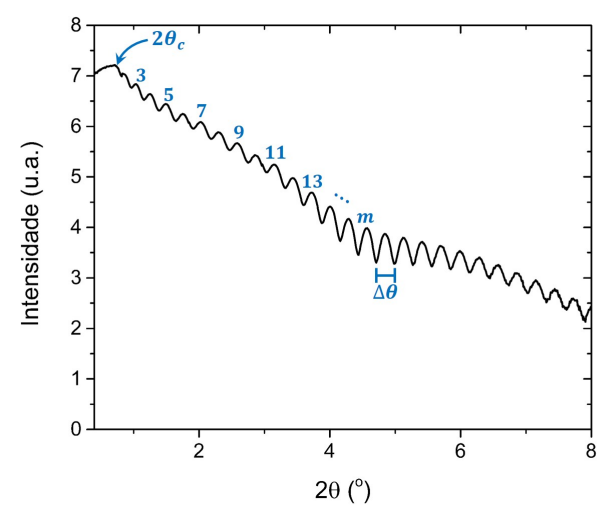

Figura 2.5 - Gráfico de refletometria de raios X para um filme fino, em função do ângulo do detector $2 \theta$. Os números indicam a ordem $m$ das faixas de interferência e $\theta_{c}$ é o ângulo crítico.

aproximadamente a densidade de elétrons $n_{e}$ do filme, com a seguinte expressão [50]:

$$
n_{e}=\frac{\theta_{c}^{2} \pi}{r_{e} \lambda^{2}}
$$

com $r_{e}=2.82 \times 10^{-15} \mathrm{~m}$ como o raio clássico do elétron e $\lambda$ o comprimento de onda do feixe de raios $\mathrm{X}$. Os outros mínimos e máximos representam as faixas de interferência destrutiva e construtiva respectivamente, também nomeadas como faixas de Kiessig [53]. O número de máximos ou mínimos indica a ordem $m$ das faixas, tal que segundo a lei de Bragg, os máximos são obtidos quando cumpre-se que:

$$
2 t \sin (\theta)=m \lambda
$$

Por outro lado, os mínimos surgem quando:

$$
2 t \sin (\theta)=\left(m+\frac{1}{2}\right) \lambda
$$

Para o caso de dois mínimos consecutivos por exemplo, $m_{1}$ e $m_{2}$, com ângulos $\theta_{1}$ e $\theta_{2}$ respectivamente, tem-se que $m_{2}=m_{1}+1$ e a diferença angular entre eles, permite obter a espessura do filme $t$, já que:

$$
\begin{aligned}
2 t \sin \theta_{2}-2 t \sin \theta_{1} & =\left(m_{2}+\frac{1}{2}\right) \lambda-\left(m_{1}+\frac{1}{2}\right) \lambda \\
\lambda & =2 t\left(\sin \theta_{2}-\sin \theta_{1}\right) \\
t & =\frac{\lambda}{2\left(\sin \theta_{2}-\sin \theta_{1}\right)}
\end{aligned}
$$


Devemos recordar que o ângulo de giro do detector $2 \theta$ é usado nas medidas, logo esse valor deve ser dividido por 2 para obter $\theta$. Como a espessura é inversamente proporcional à diferença angular, o período de oscilação vai diminuir com o aumento na espessura do filme. Além disso, é possível calcular a precisão da estimativa da espessura tendo em conta que [50]:

$$
\delta t=t \frac{\delta \Delta \theta}{\Delta \theta}
$$

A expressão (2.6) é aproximada e portanto, incompleta, pois não considera todas as ordens $m$ das faixas, por isso podem ser usados outro tipo de métodos como a transformada rápida de Fourier (Fast Fourier Transform-FFT), em função dos vetores da rede recíproca $\vec{q}$ cujas magnitudes podem ser determinadas pela relação:

$$
\vec{q} \approx \frac{4 \pi \theta}{\lambda}
$$

Este método tem a vantagem de usar uma análise das frequências causadas pelas oscilações das faixas de interferência, evitando o uso de modelos teóricos que muitas vezes não se ajustam às características do material estudado.

A FFT usa o formalismo de Parratt [54], segundo o qual o coeficiente de reflexão $R_{n-1, n}$ na interface superior, entre as camadas $n-1$ e $n$, vem dado por:

$$
R_{n-1, n}=a_{n-1}^{4}\left(\frac{R_{n, n+1}+F_{n-1, n}}{R_{n, n+1} F_{n-1, n}+1}\right)
$$

sendo $a_{n-1}$ o fator de amplitude para a camada $n-1, R_{n, n+1}$ o coeficiente de reflexão para a interface inferior e $F_{n-1, n}$ o coeficiente de Fresnel para a interface superior. No caso simples de um filme singular depositado sobre um substrato de espessura infinita, e tomando 1, 2 e 3 como os índices para o vácuo, o filme e o substrato respectivamente, a refletividade do raios X em função do vetor de onda $R(k)$, pode ser escrita como [55]:

$$
R(k)=\frac{F_{1,2}^{2}+F_{2,3}^{2}+2 F_{1,2} F_{2,3} \cos \left(\sqrt{k^{2}-k_{c}^{2}} d_{2}\right)}{\left(1-F_{1,2}^{2}\right)\left(1-F_{2,3}^{2}\right)}
$$

onde $k_{c}$ é o vetor de onda crítico e $d_{2}$ a espessura do filme. A função cosseno determina o caráter oscilatório, pelo que ao calcular a transformada de Fourier para esta expressão, obtém-se um pico cuja posição corresponde à espessura do filme (Figura 2.6). 

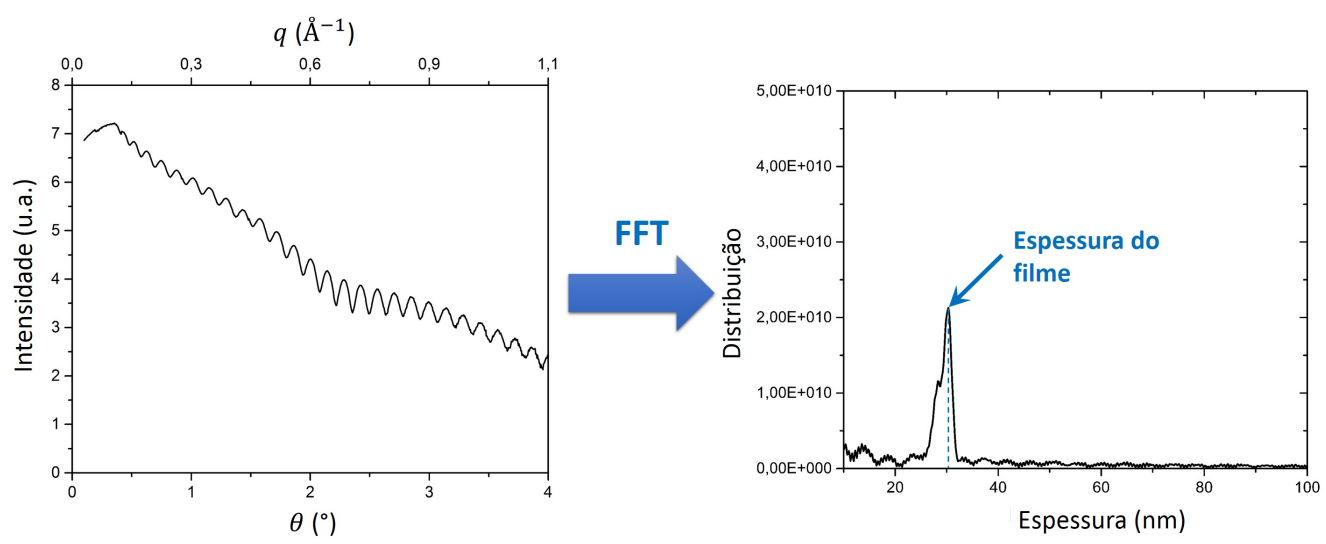

Figura 2.6 - FFT da curva de refletividade para obter a espessura do filme. Quanto menor a espessura, mais alto é o pico do gráfico de FFT, pela dependência recíproca com o vetor $\vec{q}$.

Pelo anterior, a espessura do filme depende da diferença entre os vetores de onda dentro do cristal no espaço recíproco, de modo que para espessuras menores tem-se picos mais altos nos diagramas de FFT.

\subsection{Difração de raios X (DRX)}

Propriedades como a estrutura cristalina, fases cristalográficas, direções preferenciais, entre outras, podem ser determinadas por medidas de difração de raios X (DRX), onde é usado um feixe monocromático de raios X, como no caso das medidas de RRX, sendo que os princípios físicos para ambas técnicas são essencialmente os mesmos, já que na DRX o feixe também incide sobre a amostra com um certo ângulo e é espalhado tanto pelas interfaces, como pelos planos cristalográficos do filme.

Para evitar obter um sinal muito intenso do substrato, as medidas de DRX são feitas utilizando a geometria de ângulo rasante $[50,56]$, onde o ângulo de incidência $\alpha$ é pequeno e fixo, sendo normalmente um pouco maior que o ângulo crítico $\theta_{c}$. Mas, em contraste com as medidas de RRX, o detector gira horizontal e paralelamente à superfície da amostra, num ângulo $2 \varphi$ com respeito à direção do feixe incidente, enquanto que o filme permanece em repouso (Figura 2.7).

Assim, o feixe de raios $\mathrm{X}$ incidente é difratado pelos planos perpendiculares à superfície da amostra, separados entre eles por uma distância $d_{h k l} \operatorname{com}(h k l)$ como os índices de Miller. No caso de cristais cúbicos, esta distância é dada por [51]:

$$
d_{h k l}=\frac{a}{\sqrt{h^{2}+k^{2}+l^{2}}}
$$




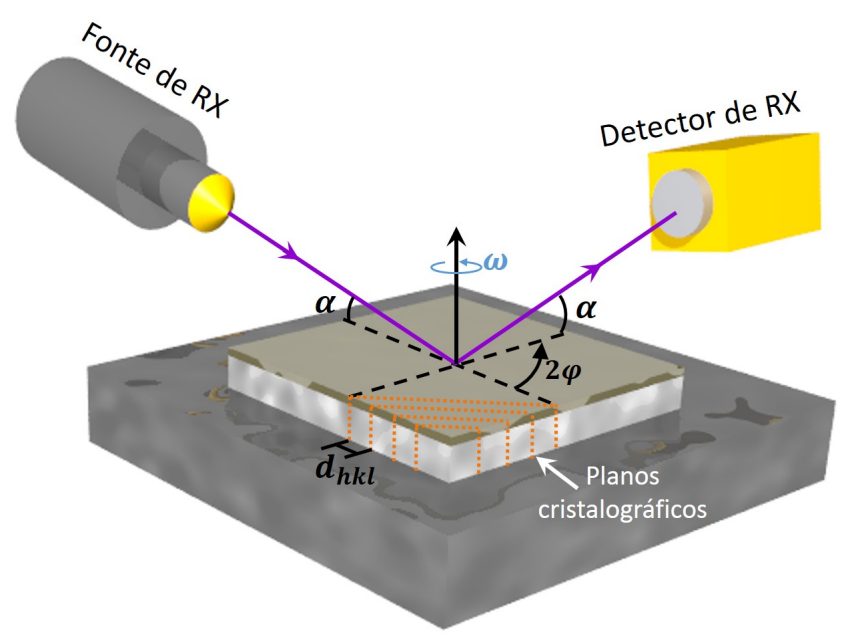

Figura 2.7 - Esquema da geometria num experimento de DRX em ângulo rasante. A amostra gira horizontalmente para que o feixe de raios X seja difratado pelos planos cristalográficos perpendiculares à superfície.

com $a$ como o parâmetro de rede do cristal. Mas na técnica de DRX, as medidas são feitas tanto na região de baixos ângulos $\left(\varphi<8^{\circ}\right)$, como na região de altos ângulos $\left(\varphi>8^{\circ}\right)$, onde a difração devida aos planos cristalográficos paralelos à superfície do filme, é mais relevante [57]. Neste último caso, o vetor da rede recíproca $\vec{q}$ é perpendicular à superfície do filme, e sua intensidade (determinada usando a eq. 2.8) é inversamente proporcional à distância cristalográfica interplanar $|\vec{q}|=2 \pi / d_{h k l}$ [58].

Como a amplitude do espalhamento de raios X para uma célula unitária de um cristal, vem dada por [58]:

$$
A_{i}=\int n_{e}\left(\vec{r}-\vec{r}_{i}\right) e^{-i \vec{k} \cdot\left(\vec{r}-\vec{r}_{i}\right)} d V
$$

onde $\vec{r}-\vec{r}_{i}$ é o vetor de posição dos elétrons com respeito aos núcleos atômicos da célula, $n_{e}(r)$ é a densidade de elétrons e $V$ o volume da célula, então é possível definir o fator de estrutura $S_{k}$ como a somatória das amplitudes de espalhamento de cada átomo dentro da célula como [58]:

$$
S_{k}=\sum_{i=1}^{z} A_{i} e^{-i \vec{k} \cdot \vec{r}_{i}}
$$

com $z$ como o número de átomos por célula unitária. Neste sentido, a interferência construtiva dos feixes espalhados pelos planos cristalográficos, acontece quando $\vec{k} \cdot \vec{r}_{i}$ é múltiplo de $2 \pi$ [51].

Portanto, sob estas condições, os planos cristalográficos geram picos de difração, 
segundo a lei de Bragg nas posições dadas por:

$$
\sin \varphi=\frac{m \lambda}{2 d_{h k l}}
$$

Tais picos, podem ser detectados para gerar os difratogramas correspondentes e com ajuda de software especializado, refiná-los para obter as informações sobre a estrutura cristalina do filme estudado.

\subsection{Ressonância ferromagnética (FMR)}

Para a análise do comportamento ferromagnético em filmes é usualmente utilizada a técnica de espectroscopia por Ressonância Ferromagnética (Ferromagnetic ResonanceFMR), uma técnica que como a RRX e a DRX não é destrutiva, permitindo caracterizar magneticamente as amostras a partir da análise dos espectros de absorção de microondas em presença de campos magnéticos externos.

Experimentos de FMR são análogos aos experimentos de ressonância paramagnética eletrônica (Electron Paramagnetic Resonance - EPR) [1], já que a amostra é colocada numa cavidade de ressonância, onde é excitada com um campo magnético DC constante e homogêneo, assim como com radiação electromagnética geralmente na região da radiofrequência (rf), do tipo de micro-ondas e cuja intensidade é incrementada com ajuda da cavidade (Figura 2.8, a.).

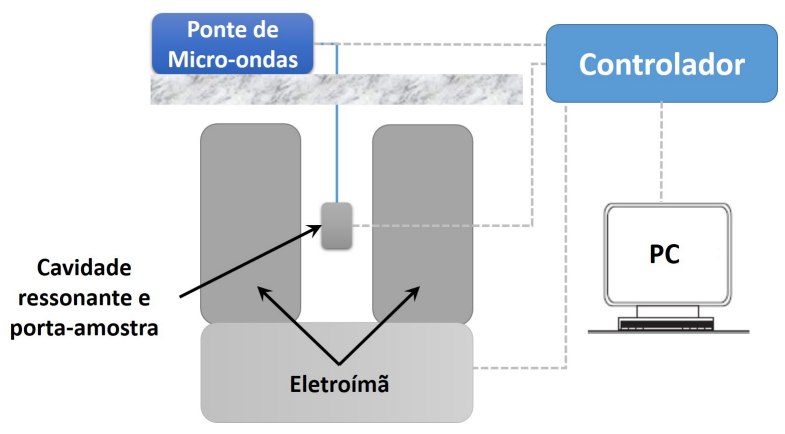

a.

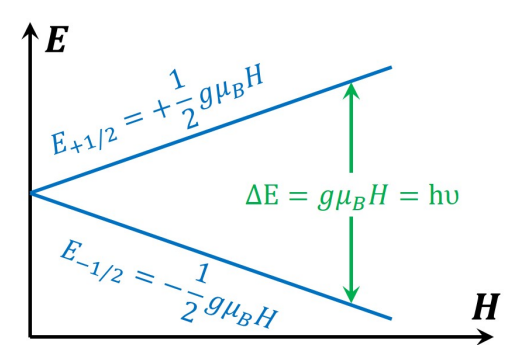

b.

Figura 2.8 - a. Diagrama da montagem experimental numa medida de FMR, b. Ao aplicar um campo magnético externo, a diferença de energia entre os estados de spin aumenta.

Neste tipo de medidas, o campo DC e de rf interagem com os momentos magnéticos de spin dos elétrons desemparelhados. Assim, o campo DC induz um torque sobre os momentos magnéticos da amostra, que faz com que entrem em precessão em torno da direção do campo aplicado. Ao mesmo tempo a energia eletromagnética de rf é 
absorvida pela amostra, provocando transições discretas dos estados de menor energia dos elétrons para os de maior energia, segundo a lei de Planck $\Delta E=h v, \operatorname{com} h$ como a constante de Planck e $v$ a frequência da radiação rf incidente [59, 60].

Comparando a energia do feixe original com o feixe resultante no ponte de microondas é possível obter o espectro de absorção da amostra, o qual é detectável graças ao aumento na diferença de energia entre os estados de spin $1 / 2 \mathrm{e}-1 / 2$, produto do desdoblamento Zeeman gerado pelo campo DC (Figura 2.8, b.).

Como a energia de um elétron em presença de um campo magnético aplicado é dada por [60]:

$$
E= \pm \frac{1}{2} g \mu_{B} H
$$

sendo $\pm 1 / 2$ os valores de spin para o elétron, $g \approx 2$ o fator Landé para o elétron livre, $\mu_{B}$ o magneton de Bohr e $H$ o campo aplicado, então o máximo de absorção ocorre quando a diferença de energia entre os dois estados de spin $\left(\Delta E=E_{+1 / 2}-E_{-1 / 2}\right)$ seja equivalente à energia dos fótons incidentes [59, 60]:

$$
\Delta E=g \mu_{B} H=h v
$$

Em outras palavras, a energia de rf é fortemente absorbida quando a frequência de precessão dos momentos magnéticos na amostra é equivalente à frequência de rf incidente [1]. Pelo anterior o campo magnético DC varia num determinado intervalo de valores, onde espera-se que a diferença de energia $\Delta E$ seja equivalente à energia de micro-ondas $h v$, permitindo apreciar melhor a intensidade de absorção $\alpha$ do material (Figura 2.9, a.).

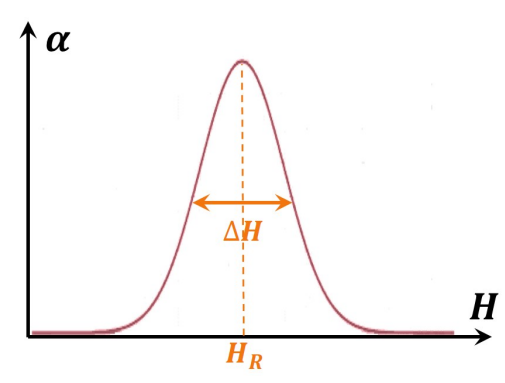

a.

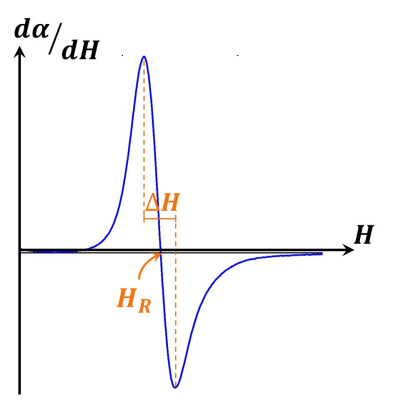

b.

Figura 2.9 - Exemplos de curvas de FMR: a. Espectro de absorção de micro-ondas pela amostra, b. Espectro de absorção na forma da primeira derivada com respeito ao campo aplicado. Os parâmetros $H_{R}$ e $\Delta H$ correspondem ao campo de absorção ressonante e à largura de banda respectivamente.

Com ajuda dos sistemas eletrônicos, a absorção de micro-ondas por parte da amos- 
tra é registrada em função do campo magnético aplicado, obtendo-se assim o espectro de ressonância do material (Figura 2.9, b.). O espectro é obtido pela primeira derivada da absorção com respeito ao campo aplicado, onde a largura de banda $\Delta H$ é dada pela distancia pico a pico e o máximo de absorção pela interceptação da linha do espectro e a linha de base, definindo assim o valor do campo de ressonância $H_{R}$.

Em medidas de FMR, a derivada da absorção com respeito ao campo aplicado é maior que em medidas de EPR [60], já que a interação entre elétrons nos materiais ferromagnéticos é mais intensa que nos materiais paramagnéticos. Isto faz com que a descrição da dinâmica de magnetização do material ferromagnético neste tipo de experimentos, seja mais complexa que nas medidas de EPR, por causa da presença do campo intrínseco da amostra, que obriga a considerar um campo magnético efetivo $H_{e f}$ em vez de um campo externo $H_{0}$ como acontece na EPR, onde o campo intrínseco é desconsiderado [59].

Portanto, a dinâmica da magnetização espontânea $\vec{M}$, dos filmes ferromagnéticos ao interagir com o campo externo gerado pelo eletroímã e pela radiação de micro-ondas, deve ser descrita por meio da equação de Landau-Lifshitz-Gilbert, que no sistema CGS tem a forma $[60,61]$ :

$$
\frac{d \vec{M}}{d t}=-\gamma \vec{M} \times \vec{H}_{e f}+\frac{\alpha}{M_{s}}\left(\vec{M} \times \frac{d \vec{M}}{d t}\right)
$$

onde $\gamma$ é o fator giromagnético, que no caso do elétron livre é $\gamma=1.7588 \times 10^{7} \mathrm{~Hz} \mathrm{Oe}^{-1}$. O campo magnético efetivo, $\vec{H}_{e f}$, é gerado pelo campo aplicado DC, o campo rf das micro-ondas ( $\operatorname{com} v=\omega / 2 \pi)$ e o campo intrínseco do material. O parâmetro $\alpha$ é a constante de amortecimento de Gilbert e $M_{s}$ é a magnetização de saturação do filme. $\mathrm{O}$ primeiro termo do lado direito, representa a interação da amostra com o campo externo, enquanto que o segundo termo descreve o processo de amortecimento viscoso, que evita a precessão perpétua dos momentos magnéticos em torno da direção do campo externo, devido ao torque produzido [59,61].

A partir da expressão (2.17), diferentes métodos de solução da equação diferencial têm sido propostos para obter a frequência de ressonância $\omega[59,61]$. Um método simples que desconsidera aspectos dinâmicos da FMR e discutido em diferentes trabalhos [61-63], permite obter a seguinte relação de dispersão:

$$
\omega=\frac{\gamma}{M \sin \theta}\left(F_{\theta \theta} F_{\varphi \varphi}-F_{\theta \varphi}^{2}\right)^{1 / 2}
$$

sendo $F_{\theta \theta}$ e $F_{\varphi \varphi}$ as derivadas duplas da parte anisotrópica da densidade de energia magnética livre $F$, em termos das coordenadas esféricas $\theta$ e $\varphi$ que representam os 
ângulos de magnetização. A densidade de energia $F$ define os eixos de magnetização fáceis [61].

Para o caso particular das medidas de FMR, onde o experimento é realizado na configuração do campo aplicado paralelo à superfície do filme, a relação de dispersão se reduz a $[6,38,59]$ :

$$
\left(\frac{\omega}{\gamma}\right)_{\|}^{2}=H_{R}^{\|}\left(H_{R}^{\|}+4 \pi M_{e f}\right)
$$

onde $H_{R}^{\|}$é o campo DC de ressonância paralelo à superfície da amostra e $M_{e f}$ é a magnetização efetiva do material. Em experimentos de FMR convencionais, onde a intensidade do campo DC varia para obter os espectros de absorção (Figura 2.9, b.), a constante de anisotropia efetiva $K_{e f}$, pode ser calculada como [38]:

$$
K_{e f}=-2 \pi M_{e f} M_{s}
$$

uma vez conhecida a frequência $\omega$ do ponte de micro-ondas, o valor do campo de ressonância $H_{R}$ e a magnetização de saturação $M_{S}$. Por isto, a técnica de FMR permite obter parâmetros relevantes na caracterização magnética de filmes, contribuindo com outro tipo de medidas magnéticas que iremos apresentar a seguir.

\subsection{Magnetometria por SQUID}

O magnetômetro SQUID (Superconducting Quantum Interference Device) funciona graças a um sensor de fluxo magnético (sensor de SQUID) que opera como um transdutor, transformando fluxos magnéticos em tensões, por meio do fenômeno de indução. O SQUID convencional possui uma bobina primaria (bobina de excitação) que gera um campo magnético alternado no seu interior. Um motor de passo conectado a uma aste, movimenta a amostra de interesse paralelamente ao eixo vertical da bobina (Figura 2.10), induzindo assim um sinal de corrente devido à magnetização da amostra que provoca uma variação do fluxo magnético [64,65].

Essa variação no fluxo é captada por uma bobina secundaria (bobina de captação) que se encontra conectada a um anel supercondutor, ao longo do qual circula uma corrente elétrica (Figura 2.10). As variações de fluxo magnético na bobina geram correntes que interrompem a circulação da corrente no anel supercondutor. Logo, uma corrente de polarização restabelece a corrente no anel obtendo-se um sinal de radiofrequência de saída do sensor, que é captado por mais outra bobina.

Esta transmite o sinal até um amplificador de frequência para transformá-la numa 


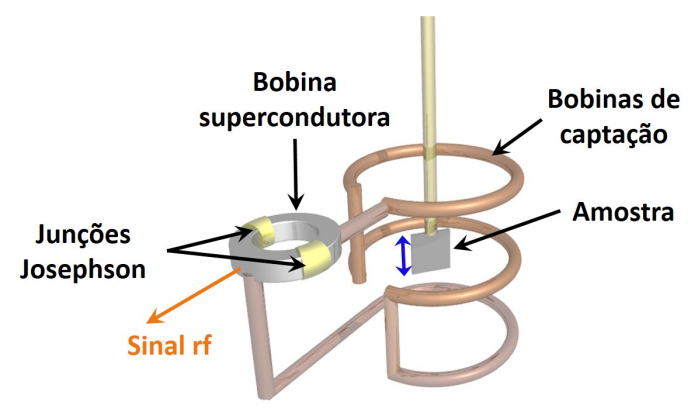

Figura 2.10 - Princípio de funcionamento de um magnetômetro de SQUID.

voltagem analógica, ajustada de maneira estritamente proporcional à corrente circulante na bobina de entrada do SQUID. Portanto a magnetização de uma dada amostra pode ser medida através de um movimento repetitivo ao longo de certa distância e posteriormente lendo a voltagem de saída do sensor SQUID [64]. Se a voltagem do SQUID apresenta um número suficiente de dados pontuais, então a voltagem pode ser representada graficamente como sendo uma função da posição da amostra. O fluxo magnético que detectado pelo SQUID é devido a um momento magnético permanente e à magnetização induzida na amostra [64].

Dependendo do tipo de SQUID, o anel pode ter uma ou duas junções supercondutoras chamadas de junções Josephson, que permitem detectar campos magnéticos muito pequenos. O primeiro caso corresponde ao SQUID RF e o segundo caso ao SQUID DC. As junções servem como um padrão primário de calibração numa dada voltagem, cujo origem está na quantização do fluxo magnético no interior do anel supercondutor. Este quantum de fluxo recebe o nome de fluxon e seu valor é de $2.07 \times 10^{-7} \mathrm{G} \mathrm{cm}^{-2}$, pelo qual é possível medir campos da ordem de $10^{-15} \mathrm{~T}$, sobre valores absolutos de campos magnéticos de $7 \mathrm{~T}$ [64].

Dessa maneira, o funcionamento dos anéis do SQUID está baseado em aspectos importantes de alguns materiais quando resfriados a uma dada temperatura crítica, entre eles: a supercondutividade (ausência de resistência elétrica), o efeito Meissner (ausência total do fluxo do campo magnético no interior de um material supercondutor), o efeito Josephson (surgimento de uma corrente elétrica por efeito túnel entre dois supercondutores separados) e a quantização do fluxo magnético através de uma espira supercondutora (conservação do fluxo magnético numa malha fechada de material supercondutor) [64, 65].

Todos esses fenômenos em conjunto com os dispositivos eletrônicos, permitem obter informação precisa sobre grandezas importantes na caracterização de materiais magnéticos, como a magnetização de saturação, de remanência, campo coercitivo, 
susceptibilidade magnética, entre outras. Isto é possível a partir de curvas de histerese ou de magnetização em função da temperatura obtidas por este método.

\subsection{Microscopia de Força Atômica (AFM)}

A técnica de Microscopia de Força Atômica (Atomic Force Microscopy-AFM) oferece uma grande vantagem na análise de micro e nanoestruturas, já que com ela é possível gerar mapas com boa resolução da topografia da superfície nas amostras, em relação com suas propriedades físicas.

O primeiro microscópio de força atômica foi desenvolvido em 1986 por Gerd Binning, Calvin Quate e Christoph Gerber [66]. Ele emprega uma ponta micrométrica, localizada na extremidade de uma alavanca metálica, que possui a outra extremidade fixa. A alavanca também é micrométrica e flexível com constante de mola $K$ (Figura 2.11, a.).

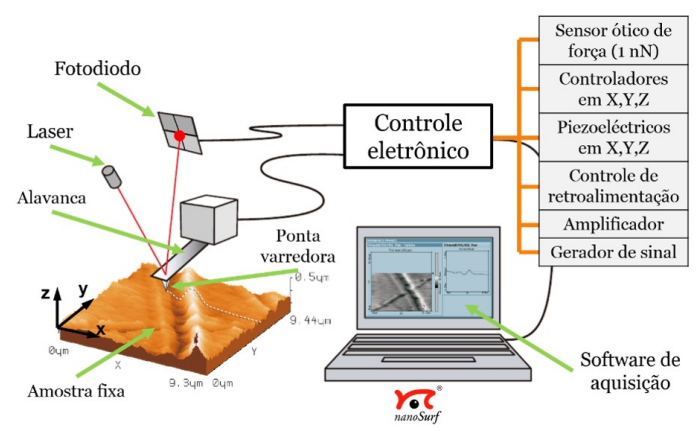

a.

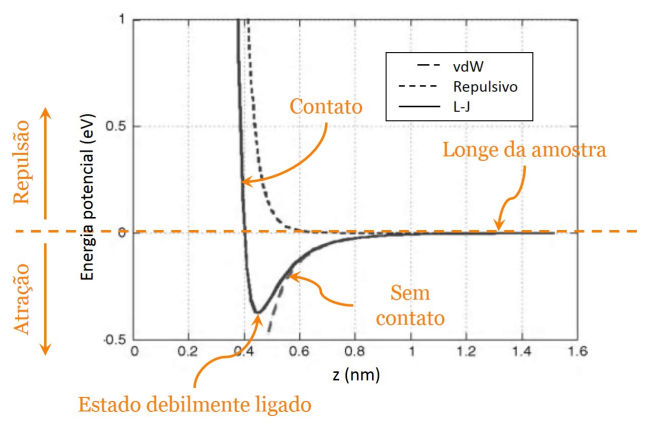

b.

Figura 2.11 - a. Esquema simplificado da operação interna do AFM. A varredura é feita no plano $x y$ e a ponta oscila na direção $z$ [67], b. Potenciais responsáveis da interação ponta-amostra. Dependendo da distância ponta-amostra, o regime pode ser repulsivo ou atrativo (potencial Lennard-Jones) [68].

Como consequência, ao se movimentar a alavanca varrendo a superfície com ajuda do sistema de controle eletrônico, seu extremo livre começa a oscilar verticalmente com uma frequência típica de ressonância, que muda perto da superfície devido à sua rugosidade e às interações da ponta com os materiais que compõem a amostra [68, 69] .

As mudanças de amplitude ou fase na oscilação podem ser detectadas usando um laser e um fotodiodo receptor, de modo que quando o laser é refletido pela parte superior da alavanca, atinge o fotodiodo que lê os movimentos do laser devidos à oscilação. Essa informação é coletada, amplificada e processada pelo software de aquisição de dados (Figura 2.11, a.) para obter um mapa da altura da superfície da 
amostra com muita precisão.

Por seu tamanho, a ponta pode interagir sem contato com a amostra no modo atrativo, através das forças de van der Waals, para fazer uma varredura na superfície da amostra sem tocá-la. Isto acontece graças às interações atômicas entre os dipolos da ponta e da amostra, que dependem da geometria da ponta (pontas finas geram melhor resolução que as pontas grossas) e do potencial de interação. Tais interações surgem quando a ponta se encontra muito próximo à amostra $(0.5 \mathrm{~nm} \leqslant z \leqslant 1 \mathrm{~nm})$.

Tal potencial pode ser modelado usando o potencial Lenard-Jones (Figura 2.11, b.) [69]:

$$
E_{r}=-\frac{A}{r^{6}}+\frac{B}{r^{12}}
$$

onde $A$ e $B$ são constantes de interação e $r$ é a distância entre dipolos, por isso a técnica pode ser usada sobre meios condutores e não condutores [69]. Quando a altura da ponta com respeito à superfície é menor que $0.4 \mathrm{~nm}$, a varredura é feita no modo repulsivo e pode se dizer que a ponta entra em contato com a amostra. Para alturas maiores a $1 \mathrm{~nm}$, já não existe interação dipolar e não é possível obter a topografia da superfície.

Por outro lado, com ajuda do software de controle, a qualidade das imagens é melhorada ajustando diferentes parâmetros que regulam a eletrônica do sistema e reduzem o ruído ao mínimo. Um desses parâmetros é o Setpoint que representa a porcentagem da razão entre a amplitude de oscilação da ponta durante a varredura $(A)$ e a amplitude de oscilação livre $\left(A_{0}\right)$ quando se encontra longe da amostra (eq. 2.22), sendo as amplitudes medidas em $\mathrm{mV}$ ou $\mathrm{nm}$ segundo o sistema usado [68]:

$$
\text { Setpoint }=\frac{A}{A_{0}} \times 100 \%
$$

Isto quer dizer que se o Setpoint é $100 \%$, então $A=A_{0}$, logo a ponta vai vibrar livremente sem interagir com a amostra e não vai ser possível obter imagem da sua superfície. Mas se o Setpoint é menor que $100 \%$, então $A<A_{0}$ devido à interação com a amostra, e consequentemente, a ponta vai ficar mais perto da sua superfície. Quanto menor é o Setpoint mais perto da amostra vai ficar a ponta e a resolução pode ser melhor, mas se o Setpoint é muito baixo $(<30 \%)$, a ponta pode tocar a superfície e deteriorar-se ou estragar a amostra, exceto no modo de litografia onde o objetivo é efetivamente marcar a superfície.

A qualidade da imagem também pode melhorar com o ajuste dos ganhos Proporcional, Integral e Diferencial (PID) no software do microscópio. Os ganhos PID procuram corrigir as variações de amplitude ou frequência produzidas na varredura pelas rugosidades da amostra, as quais fazem com que a interação ponta-amostra se desvie 
do valor estabelecido pelo usuário. Além disso, os ganhos PID corrigem o tempo de detecção-análise-resposta do sistema de retroalimentação do circuito do microscópio, aumentando a precisão da medida [68].

Finalmente, os dados obtidos por AFM podem ser tratados com softwares especializados como o software aberto Gwyddion [70]. O software permite conseguir melhores análises e visualizações das características das superfícies estudadas, reduzindo os erros e artefatos presentes no momento de fazer a varredura. Dependendo do tipo de imagem, do ruído e dos artefatos que ela tenha, o Gwyddion possui opções que procuram solucionar as necessidades da comunidade mundial de usuários das técnicas de SPM [70], facilitando tratamentos mais quantitativos e estatísticos por meio do uso de filtros laplacianos, gaussianos ou com transformadas de Fourier.

\subsection{Microscopia de Força Magnética (MFM)}

A técnica AFM permitiu a criação de outras técnicas similares como a Microscopia de Força Magnética (Magnetic Force Microscopy-MFM), que trabalha com os mesmos princípios do AFM mas usando uma ponta recoberta de finas camadas de materiais magnetizados, para fazer a varredura. Assim, a ponta pode interagir com os campos magnéticos perpendiculares à superfície da amostra (direção $z$ ) gerados pelos dipolos presentes nela. A MFM é um método muito poderoso na observação de configurações magnéticas onde tem origem fenômenos percebidos em escala macro como o efeito Invar, já que consegue medir distribuições do campo magnético diretamente na superfície [69,71].

Uma das vantagens desta técnica, é poder utilizar o modo de contato intermitente (tapping mode) com duas varreduras por linha: na primeira se obtém o mapa da topografia da amostra, em seguida a ponta retorna à posição inicial da linha, sobe uma distância $z$ sobre a superfície (lift) e repete a linha anterior medindo as mudanças na fase da oscilação da alavanca, provocadas pela interação com o campo magnético intrínseco da amostra [71].

O modo de contato intermitente, oferece uma boa resolução, muito próxima à resolução no modo contato, sem danificar a amostra, minimizando a interferência gerada pelos artefatos na superfície, já que a energia de oscilação da ponta é maior que nos outros modos de varredura.

Neste modo a ponta toca a superfície levemente, se afasta e volta a tocá-la, repetindo o processo na linha de varredura inteira, de modo que a força de interação pontaamostra é ora repulsiva (durante o contato), ora atrativa (no afastamento) [68,69, 71]. 
No momento em que a ponta toca a superfície, sua frequência de oscilação varia com respeito à frequência de oscilação livre. Este fato provoca diferenças na fase de oscilação em relação com o sinal de referência, o qual é medido sem a presença da amostra. Essas mudanças podem ser detectadas para obter um mapa de contraste que indica as regiões de atração ou repulsão magnética [68, 69].

As mudanças na fase $(\Delta \phi)$ são proporcionais ao gradiente da força magnética $(\vec{F})$ perpendicular ao plano da amostra [71-73]:

$$
\Delta \phi \propto \nabla \vec{F} \cdot \hat{e}_{z}
$$

onde dita força vem definida pelo gradiente da energia de Zeeman $E_{z}$, que representa a interação entre a magnetização da ponta $\vec{M}_{p}$, e o campo intrínseco da amostra $\vec{H}_{i}$ $[73,74]$ :

$$
\vec{F}=-\nabla E_{z}=\int_{V_{p}} \nabla\left(\vec{M}_{p} \cdot \vec{H}_{i}\right) d V
$$

sendo a integração feita no volume da ponta $V_{p}$. Assumindo um comportamento dipolar para a ponta, com momento magnético $\vec{m}=\int_{V_{p}} \vec{M}_{p} d V$, a força pode ser expressa como [74]:

$$
\vec{F}=\nabla\left(\vec{m} \cdot \vec{H}_{i}\right)
$$

mas como nas medidas de MFM a ponta é magnetizada na direção $z$, detectando assim as variações verticais do campo intrínseco da amostra, então tem-se que $m_{x}=m_{y}=0$, $\vec{H}_{i}=\vec{H}_{z}$ e $\partial H_{z} / \partial x, \partial H_{z} / \partial y \ll \partial H_{z} / \partial z[72,74]$, portanto:

$$
\vec{F} \approx m_{z} \frac{\partial H_{z}}{\partial z}
$$

por conseguinte, as mudanças na fase da oscilação da ponta são proporcionais à segunda derivada em $z$ da componente vertical do campo intrínseco da amostra:

$$
\Delta \phi \propto \nabla \vec{F} \cdot \hat{e}_{z} \approx m_{z} \frac{\partial^{2} H_{z}}{\partial z^{2}}
$$

Essa mudança é detectável já que a influência do campo magnético intrínseco da amostra, modifica a constante de mola original da alavanca $K$, tal que [72]:

$$
K_{0}=K-\nabla F
$$

Assim, se o gradiente de força magnética se orienta entrando na ponta, então a constante de mola da alavanca aumenta (posição 1, figura 2.12), mas se o gradiente se alinha 
saindo da ponta a constante diminui (posição 2, figura 2.12).

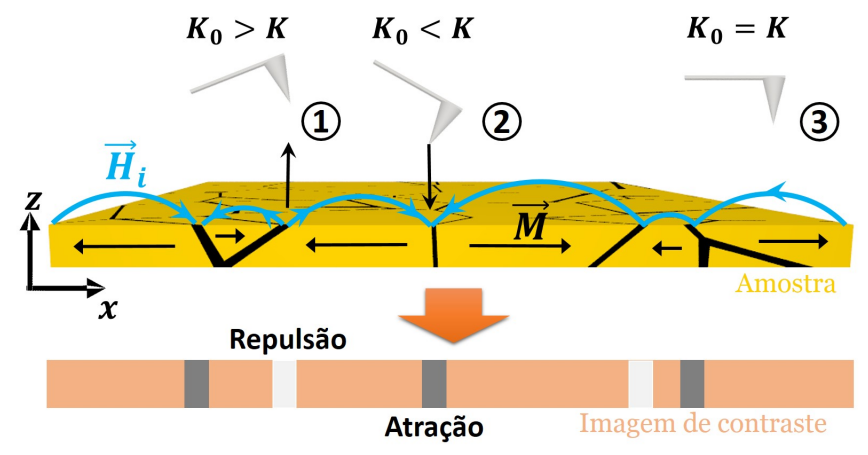

Figura 2.12 - Formação da imagem de MFM, por causa da interação da ponta magnetizada com o campo intrínseco da amostra, $\vec{H}_{i}$.

Neste sentido, as zonas sobre a superfície da amostra onde as variações em $z$ do campo intrínseco são maiores, produzem regiões de atração $\left(K_{0}<K\right)$ ou repulsão $\left(K_{0}>K\right)$, as quais são representadas pelo software como faixas de contraste na medida de variação de fase. Não obstante, se o campo intrínseco não apresenta variações em $z$, a ponta não sofre mudanças na sua fase e a configuração magnética da amostra não é detectada (posição 3, Figura 2.12).

Pelo anterior, o contraste nas imagens de MFM é originado pelas variações do campo intrínseco nas paredes de domínio e nos seus limites [71,75, 76]. Além disso, é importante ter em conta que dito campo na aproximação unidimensional para filmes finos, pode ser representado como [77]:

$$
H_{z}=\frac{1}{2} M_{s} \cos (k x)\left(1-e^{-k t}\right) e^{-k z}
$$

sendo $M_{s}$ a magnetização de saturação, $k=2 \pi / \lambda$ o número de onda, $\lambda$ o comprimento de onda correspondente às oscilações da ponta, $x$ a direção de varredura, $z$ a distância ponta-amostra ou lift e $t$ a espessura do filme. Aqui é possível ver que este campo tem uma queda exponencial com o aumento da distância $z$, pelo que as medidas de MFM devem ser feitas com a ponta o mais próximo possível da amostra [77] para evitar forças de interação dipolar. Pelo anterior, é recomendável utilizar lifts dentre 20 e $100 \mathrm{~nm}$ segundo à rugosidade da superfície da amostra, de modo que sejam reduzidos os efeitos das forças de curto alcance [69].

Mas também devem ser levadas em conta as perdas que sofre o campo intrínseco por causa da espessura do filme, $\left(1-e^{-k t}\right)$, já que quanto maior é a espessura, mais intenso será o campo e melhor será a resolução atingida nas imagens de MFM. Isto 
porque a superposição dos campos gerados pelos momentos magnéticos na superfície e próximos ao substrato, é menor para os filmes grossos em comparação com os finos [77].

Portanto, fazendo varreduras de MFM na mesma região o software pode obter medidas topográficas e imagens de contraste com as variações da fase produzidas pelas interações entre a ponta e as regiões magnéticas e não magnéticas da amostra, para desse modo obter um mapa confiável de seus domínios magnéticos.

A técnica MFM pode mostrar características fundamentais do magnetismo de filmes finos em nanoescala, por meio da medição dos momentos magnéticos locais e dos campos magnéticos intrínsecos. Isto se deve às divergências da magnetização nas paredes dos domínios magnéticos nas amostras [78], fornecendo assim uma melhor imagem da estrutura magnética com boa resolução.

\subsection{Simulações micromagnéticas: O software MuMax3}

Os dados obtidos por meio das técnicas experimentais apresentadas anteriormente, também podem ser usados para alimentar simulações computadorizadas da estrutura micromagnética dos filmes. Isto pode ser feito com ajuda do software de simulação acelerada MUMAX3, desenvolvido pelo grupo DyNaMat (Dynamics of functional Nano Materials) da Universidade Gent na Bélgica [79].

Este software é de domínio público e dispõe de ferramentas para a análise e solução de problemas da dinâmica de magnetização dependente do espaço e do tempo em nano e micromagnetismo. Além disso oferece gráficos e visualizações das configurações magnéticas de interesse. Com estas ferramentas é simplificado consideravelmente o estudo das estruturas magnéticas em filmes, permitindo obter novos resultados simplesmente com a variação de alguns parâmetros.

O software oferece muitas vantagens porque seu código aberto escrito em linguagem de programação Go e CUDA [79], permite facilmente especificar o tipo de problema magnético, o tamanho e geometria da região onde se quer trabalhar, as condições iniciais e de contorno, adicionar contribuições energéticas, etc.

Para iniciar uma simulação, o usuário deve introduzir no software os parâmetros próprios do material tais como a magnetização de saturação $M_{s}$, as direções anisotrópicas, as constantes de anisotropia cubicas ou uniaxiais, a constante de troca $A$, a geometria da amostra e o tipo de magnetização inicial, entre outras coisas. O usuário também pode definir condições experimentais, para simular o comportamento da amostra em presença de campos magnéticos externos, os quais são aplicados uniformemente durante os cálculos. 
Com essa informação, o software calcula a energia total do sistema $E$, que é definida como a soma de todas as contribuições energéticas apresentadas na secção 1.3, incluído o termo de energia térmica. Cada termo energético é discretizado pelo método de diferenças finitas, pois a amostra considerada é dividida numa matriz de $N$ células tridimensionais e ortorrômbicas, onde o cálculo da magnetização reduzida e do campo efetivo é feito no centro de cada célula [79].

Além disso, a energia de troca é determinada em cada célula $i$, tendo em conta o caso padrão da interação entre seis momentos vizinhos em 3D [80, 81]:

$$
E_{i}=\sum_{j \in N_{i}} A \frac{\vec{m}_{i} \cdot\left(\vec{m}_{i}-\vec{m}_{j}\right)}{\Delta_{i j}^{2}}
$$

sendo $N_{i}$, o conjunto das 6 células vizinhas à célula $i, A$ a constante de troca uniforme em todo o espaço, $\vec{m}_{i}$ e $\vec{m}_{j}$ os momentos magnéticos das célula $i$ e $j$ respectivamente, e $\Delta_{i j}$ o tamanho do passo de discretização entre as células $i$ e $j$.

Assim, a energia total $E$, permite obter o campo efetivo do sistema $H_{e f}$, em termos da variação de energia com respeito à magnetização do material $M$ :

$$
H_{e f}=-\frac{1}{\mu_{0}} \frac{\partial E}{\partial M}
$$

onde $\mu_{0}$ é a permeabilidade magnética. Com isto, $H_{e f}$ é calculado em cada célula, segundo a direção da magnetização, que inicialmente pode ser considerada aleatória.

Logo, a dinâmica de magnetização no interior do filme é estabelecida solucionando numericamente a equação diferencial:

$$
\frac{d \vec{m}}{d t}=\vec{\tau}
$$

onde $\vec{m}$ é a magnetização reduzida e $\vec{\tau}$ é o torque resultante definido por três contribuições: o torque Landau-Lifshitz-Gilbert e os torques de transferência de spin Zhang-Li e Slonczewski [79]. O torque de Landau-Lifshitz-Gilbert vem dado pela expressão (2.17) em 3D. Os torques de transferência de spin Zhang-Li e Slonczewski são usados quando existem correntes fluindo pelo material, mas aqui esses casos não serão considerados.

O software MUMAX3 realiza a solução da equação diferencial, utilizando diferentes ordens de convergência do método de Runge-Kutta, com ajuda das funções run (time) ou relax (), que permitem minimizar o estado do sistema para um dado tempo. Assim o software monitora os valores do torque resultante tratando a simulação como um todo, para chegar em estados de equilíbrio energético automaticamente e desse modo, 
finalizar a simulação.

Neste sentido, é obtida a magnetização média em cada célula, para em seguida gerar um mapa vetorial da magnetização dentro da matriz, que pode ser visualizado com as ferramentas gráficas que o software oferece. Com isso, pode ser observada a configuração dos domínios magnéticos no filme em termos da magnetização, pelo que os resultados podem também ser representados como imagens de MFM, uma vez que o software simula a força entre a ponta e a superfície do filme por meio da relação [79]:

$$
\frac{\partial F_{z}}{\partial z}=\sum_{i=x, y, z} M_{i}(x, y) \frac{\partial^{2} H_{p, i}(x, y)}{\partial z^{2}}
$$

onde $H_{p}$, é o campo magnético da ponta, estimado no plano da amostra, como já havíamos mostrado na secção 2.7, equação (2.27). Ademais, o usuário pode definir o lift da ponta para reproduzir melhor o contraste de fase nas suas imagens de MFM.

MUMAX3 também oferece muita mais informação sobre o resultado da simulação, como tabelas de dados que contêm os valores das contribuições energéticas, da energia total, das componentes da magnetização no filme, do ângulo máximo entre spins vizinhos, entre outros parâmetros. Se o usuário considerou campos magnéticos externos, então pode obter os gráficos simulados de histerese com ajuda do gnuplot, que pode ser vinculado ao software.

Contudo também, MuMAX3 tem sido usado na criação de simulações para o estudo de: processos de magnetização de nanoestruturas em diferentes compostos e ligas, evolução dos estados de spin e da anisotropia magnética nesses compostos e ligas, problemas de ressonância ferromagnética, estudo de paredes de domínio, etc. [79].

Assim, este tipo de software especializado constitui-se num suporte indispensável no estudo das características magnéticas de distintos tipos de materiais e fenômenos magnéticos no nível nanométrico. Esta ferramenta além das técnicas experimentais, apoiam e complementam as pesquisas em áreas pujantes da Física, como o Micromagnetismo. 


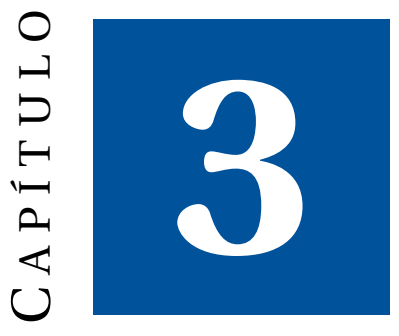

\section{Resultados e discussão}

Três filmes policristalinos de $\mathrm{Fe}_{1-x} \mathrm{Ni}_{x}$, foram depositados sobre substratos de $\mathrm{Si}$ via sputtering DC, com uma pressão base de $5 \times 10^{-7}$ mbar. A pressão do Ar foi de $1.8 \times 10^{-1}$ mbar e o alvo usado era feito de pastilhas em pó de FeNi de alta pureza, comprimidos com composição nominal. Além disso, foram recobertos com uma camada passivadora de paládio $(\mathrm{Pd})$, para evitar sua oxidação.

Os filmes foram nomeados inicialmente como FeNi-1, FeNi-2 e FeNi-3, já que era sabido que tinham diferentes espessuras. As concentrações relativas de Fe e de Ni foram determinadas por meio de medidas de espectroscopia de raios X por energia dispersiva (Energy-dispersive Spectrocopy-EDS), usando um espectrômetro Shimadzu EDX-720HS, com tubo de Rh para análise de elementos químicos entre sódio e urânio (Na-U). O equipamento encontra-se a disposição na Central Analítica do Instituto de Química da UnB. Os resultados (Tabela 3.1) indicam que os filmes possuem a concentração Invar, perto dos valores nominais.

Os filmes também foram caracterizados estrutural e magneticamente com ajuda das técnicas mostradas no capitulo anterior. Os resultados das medições com suas

Tabela 3.1 - Concentrações relativas de Fe e Ni para os filmes estudados, estimadas por EDS. Erro percentual: $0.2 \%$

\begin{tabular}{|ccc|}
\multicolumn{3}{c}{ Concentração Relativa } \\
\hline FeNi-1 & FeNi-2 & FeNi-3 \\
\hline 65.4 & 63.8 & 63.8 \\
34.6 & 36.2 & 36.2 \\
\hline
\end{tabular}


respectivas análises são apresentados a seguir.

\subsection{Medidas de RRX e DRX}

Medidas de RRX e DRX em ângulo rasante, foram feitas no Departamento de Física, do Centro de Ciências Exatas e Tecnológicas da Universidade Federal de Viçosa, em Viçosa-MG, usando um difratômetro Bruker D8 Discover com goniômetro $2 \theta$ e tubo de $\mathrm{Cu} \mathrm{K} \alpha$ - Energia de $8047 \mathrm{eV}$ e $\lambda=1.5418 \AA$ (Figura 3.1).

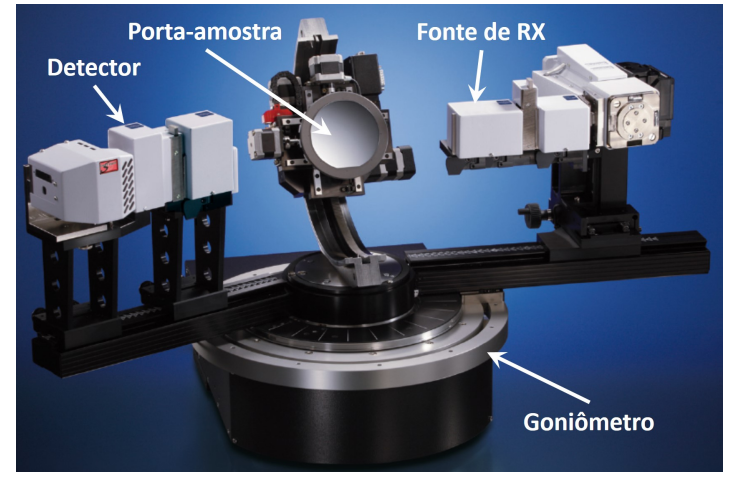

a.

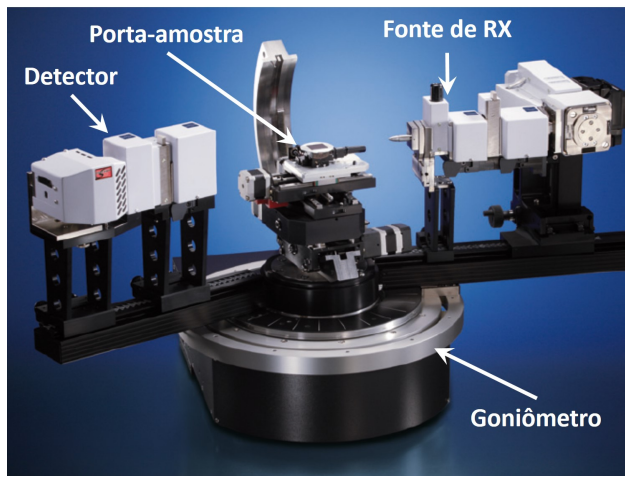

b.

Figura 3.1 - Montagem no difratômetro Bruker D8 Discover para a. medidas de RRX e b. medidas de DRX em ângulo rasante [82].

Curvas de refletividade (Figura 3.2) mostram ângulos críticos de $\theta_{c}=0.35^{\circ} \pm 0.05^{\circ}$ para todas as amostras, muito próximo ao valor teórico de $0.32^{\circ}$ obtido para estas ligas [83]. A semelhança entre os ângulos críticos das amostras indica a pouca dispersão para os três filmes, isto porque suas condições de deposição foram muito similares. Abaixo deste ângulo, espera-se o fenômeno de reflexão total, onde a intensidade do feixe de raios $\mathrm{X}$ refletido é constante.

Usando a expressão (2.3), foi estimada aproximadamente a densidade de elétrons para os filmes:

$$
n_{e}=\frac{\theta_{c}^{2} \pi}{r_{e} \lambda^{2}} \approx 1.75 \AA^{-3}
$$

Para o caso do filme FeNi-1, faixas de Kiessig muito bem definidas puderam ser vistas (gráficos internos, figura 3.2, a.), indicando o filme de menor espessura. O filme FeNi-3 não apresentou claramente estas faixas, já que este filme possui uma espessura maior. A espessura também influi no alcance de detecção, pois para os filmes FeNi-1 e FeNi-2, $2 \theta \approx 8^{\circ}$, porém para o filme FeNi-3 $2 \theta \approx 2^{\circ}$. Acima destes valores começam a aparecer os picos de difração. 


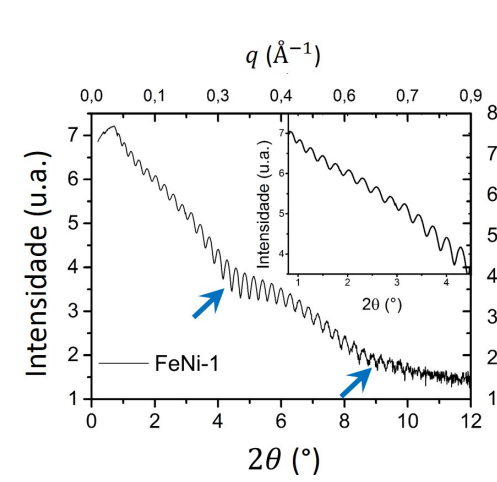

a.

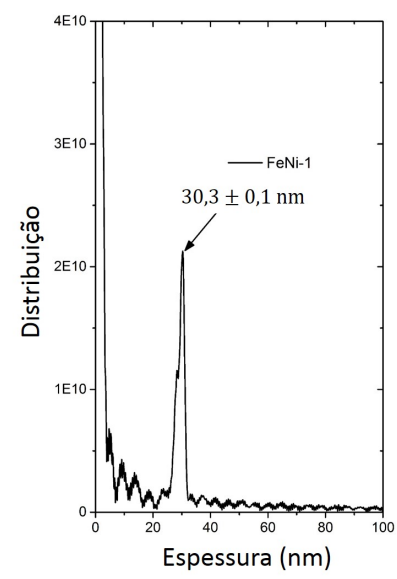

d.

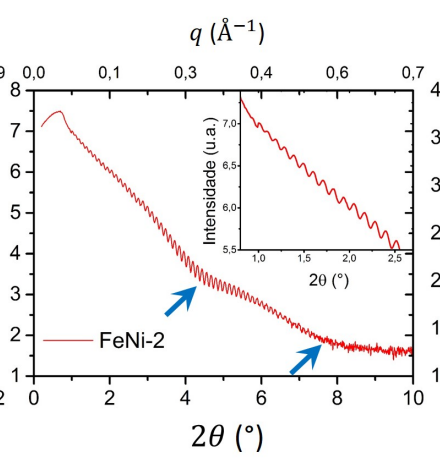

b.

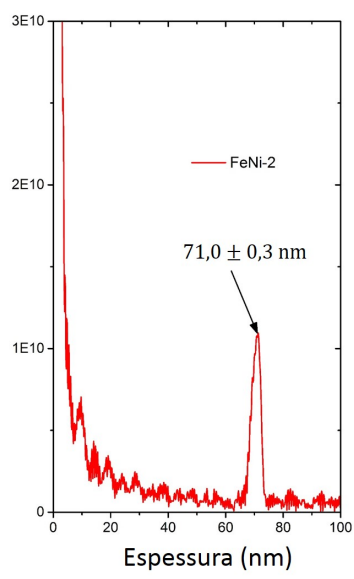

e.

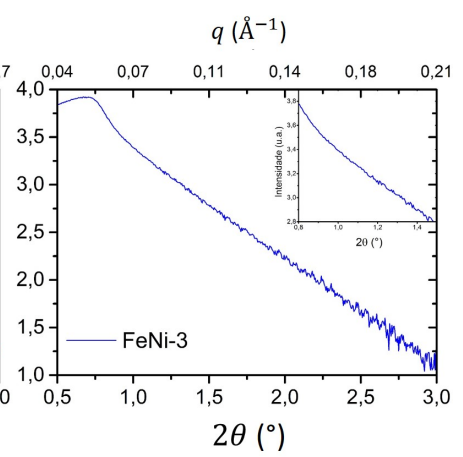

c.

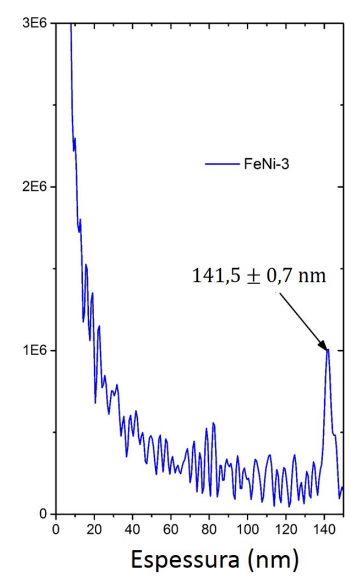

f.

Figura 3.2 - (Acima) Medidas de RRX para os filmes: a. FeNi-1, b. FeNi-2 e c. FeNi-3. Os gráficos internos mostram melhor as primeiras faixas de Kiessig para cada filme. As setas apontam aos mínimos de interferência causados pelo revestimento de Pd. (Abaixo) FFT das medidas de RRX para os filmes: d. FeNi-1, e. FeNi-2 e f. FeNi-3. Os picos de maior intensidade indicam a espessura do filme.

Nas curvas de refletividade também é possível observar oscilações com distâncias angulares muito maiores, da ordem de $2 \Delta \theta \approx 3.6^{\circ}$, principalmente nos filmes FeNi- $1 \mathrm{e}$ FeNi-2 (setas, figura 3.2). Essas oscilações são devidas às faixas de Kiessig, originadas pela presença da camada passivadora de Pd. Usando a expressão (2.6), foi estimada a espessura dessa camada como segue:

$$
t=\frac{\lambda}{2\left(\sin \theta_{2}-\sin \theta_{1}\right)}=22.95 \pm 0.06 \AA
$$

sendo $\theta_{1}=0.35 \pm 0.01$ e $\theta_{2}=4.55 \pm 0.01$; o erro foi obtido usando a expressão (2.7). Este valor está de acordo com a espessura esperada de uma camada passivadora, da ordem de $20 \AA$.

Para estimar a espessura da camada de FeNi, foi usado o método da transformada 
rápida de Fourier (FFT) com ajuda do software do equipamento para melhorar a precisão no cálculo. Os valores obtidos foram de $30.3 \pm 0.1 \mathrm{~nm}, 71.0 \pm 0.3 \mathrm{~nm}$ e $141.5 \pm 0.7 \mathrm{~nm}$ para os filmes FeNi-1, FeNi-2 e FeNi-3 respectivamente (Figura 3.2).

Por fim, os difratogramas gerados com medidas em ângulo rasante $\left(\alpha=0.5^{\circ}\right)$, no intervalo $5^{\circ} \leq 2 \varphi \leq 90^{\circ}$ (Figura 3.3), apresentaram em todos os casos o pico característico da liga FeNi na fase fcc (111), centrado na posição de $44^{\circ}$, como é confirmado por diferentes trabalhos $[5,8,84,85]$.

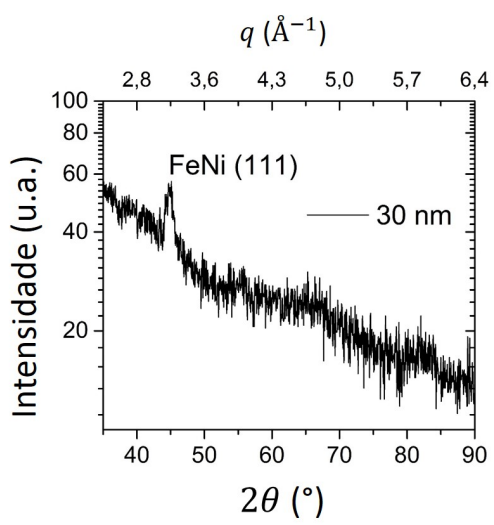

a.

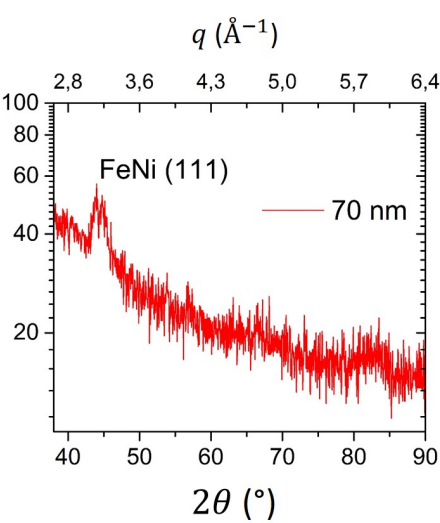

b.

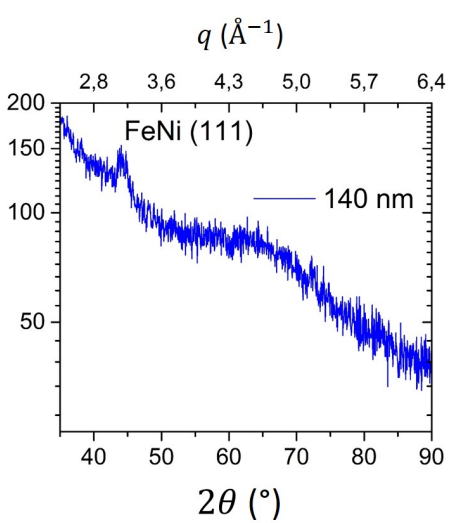

c.

Figura 3.3 - Difratogramas para os filmes Invar de FeNi36. Em todos os casos é distinguido o pico (111) da fase fcc da liga FeNi.

O pico (111) é apreciável nos difratogramas porque possui uma intensidade alta, mas o ruído nas medidas não permite apreciar outro tipo de fases cristalográficas com picos de difração menos intensos, que podem estar presentes em ângulos maiores a $2 \varphi=44^{\circ}$.

\subsection{Medidas de FMR}

Medidas de Ressonância Ferromagnética foram realizadas com ajuda do Grupo de Nanoestruturas Semicondutoras e Magnéticas (GNSM), do Núcleo de Física Aplicada (NFA) no Instituto de Física da Universidade de Brasília (UnB), em Brasília-DF, usando um espectrômetro Bruker EPR (Electron Paramagnetic Resonance) com o software Xenon e uma cavidade ressonante retangular ER 4109EF.

Foi empregada radiação de micro-ondas de frequência constante $(v=9.8 \mathrm{GHz})$ com uma potência de $0.5 \mathrm{~mW}$ e uma frequência de modulação de $100 \mathrm{kHz}$. O campo magnético DC foi aplicado em temperatura ambiente e paralelamente ao plano dos filmes, mudando sua intensidade no intervalo $0 \leq H \leq 12 \mathrm{kOe}$, com um passo $\delta H=1$ Oe. 


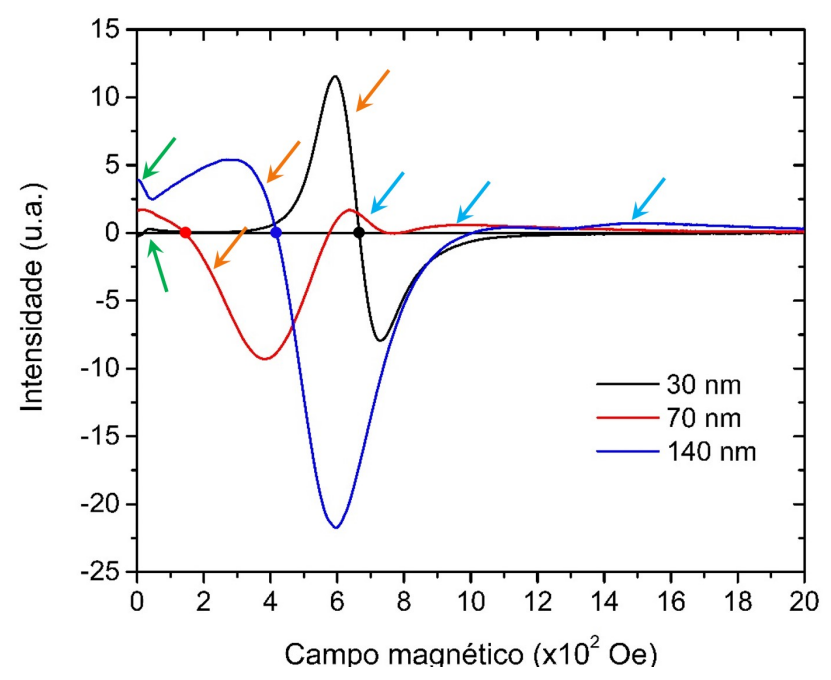

Figura 3.4 - Espectros de ressonância no plano para cada filme Invar. Os pontos mostram os campos de ressonância, setas laranjas indicam os modos principais de ressonância, setas verdes indicam os modos LFMA e setas azuis indicam os modos causados provavelmente por uma segunda fase magnética.

Desta forma, foram obtidos os espectros de ressonância para cada filme (Figura 3.4), onde os campo de ressonância correspondem aos valores de campo magnético indicados com pontos no gráfico. Nos espectros são observados três tipos de modos de ressonância: 1) os modos sinalados com setas laranjas (figura 3.4) correspondem aos modos principais de ressonância ou modos uniformes, os quais apresentam as maiores intensidades [86]. 2) Os modos indicados por setas verdes na região de baixos campos aplicados; provavelmente têm a ver com a absorção de micro-ondas não ressonante desencadeada pela dinâmica das paredes de domínios magnéticos e a consequente variação da impedância na amostra, tais modos são conhecidos como modos de absorção de micro-ondas em baixo campo (Low Field Microwave Absorption - LFMA) [87, 88]. 3) Os modos de ressonância situados à direita do modo uniforme (setas azuis) possivelmente tratam de uma outra fase magnética na amostra, com magnetização efetiva menor produto do processo de produção [6,38]. Assim, os filmes de FeNi36 podem apresentar modos de ressonância em campos magnéticos menores a 1200 Oe.

Os espectros também parecem indicar eixos fáceis de magnetização no plano das amostras, já que elas atingem a ressonância em campos baixos $(<1 \mathrm{kOe})$ paralelos à superfície dos filmes (Tabela 3.2). Não obstante, existe uma anomalia no filme de $70 \mathrm{~nm}$ de espessura, onde o campo de ressonância parece muito mais baixo que para os outros filmes, com os modos de ressonância de uma segunda fase magnética mais proeminentes.

Além do mais, pode-se ver que o campo de ressonância diminui para espessuras 
Tabela 3.2 - Campos de ressonância $H_{R}$, largura de banda $\Delta H$, tempo de relaxação $\tau$ e magnetização efetiva obtidos para cada filme Invar em medidas de FMR, segundo suas espessuras.

\begin{tabular}{ccccc} 
Espessura (nm) & $H_{R}(\mathbf{O e})$ & $\Delta H(\mathbf{O e})$ & $\tau(\mathbf{n s})$ & $M_{\text {ef }}\left(\mathrm{emu} / \mathrm{cm}^{3}\right)$ \\
30 & 665 & 134 & 0.85 & 1413.8 \\
70 & 142 & 369 & 0.31 & 6857.5 \\
140 & 418 & 328 & 0.35 & 2300.2 \\
\hline
\end{tabular}

maiores, enquanto que a largura da banda aumenta, o que sugere uma redução na energia de troca para os filmes mais espessos, isto porque é necessário aplicar um campo magnético maior para o filme mais fino $(30 \mathrm{~nm})$, de modo que consiga-se superar a energia de troca e assim desacoplar os estados de spin para favorecer a ressonância.

Por outro lado, a largura pico a pico do espectro é semelhante para os filmes de 70 e $140 \mathrm{~nm}$, mas também é relativamente alta. Este fato, somado ao surgimento dos modos de ressonância volumétricos (bulk) e superficiais nestes filmes, indicam presença de inomogeneidades magnéticas e estruturais [59, 89, 90] tanto internas como superficiais, produto da policristalinidade das amostras, em contraste com o filme de $30 \mathrm{~nm}$, cuja largura de banda menor permite deduzir que o tamanho dos seus cristalitos são menores, em comparação aos outros filmes.

Tendo em conta que a largura de banda $\Delta H$ encontra-se conectada com o tempo de relaxação pela forma [59]:

$$
\tau=\frac{2}{\gamma \Delta H}
$$

sendo $\gamma$ o fator giromagnético, encontrou-se que $\tau$ é maior para o filme mais fino, mas em todos os casos são da ordem de $10^{-10}$ segundos (Tabela 3.2), valor esperado para a maioria dos materiais ferromagnéticos.

Também foi calculada a magnetização efetiva para cada amostra usando a equação (2.19). Dita magnetização aumenta com a espessura dos filmes, sendo máxima para o filme de $70 \mathrm{~nm}$ por causa da anomalia no seu campo de ressonância (Tabela 3.2). O valor da magnetização efetiva para o filme de $30 \mathrm{~nm}\left(1413 \mathrm{emu} / \mathrm{cm}^{3} \approx 1.4 \times 10^{6} \mathrm{~A} / \mathrm{m}\right)$, corresponde-se com o valor experimental esperado, obtido em outros trabalhos para filmes deste tipo de ligas, onde as estruturas fcc e bcc surgem no mesmo tempo [91]. Mas a magnetização encontrada para os outros filmes resultou muito maior que do que dito valor esperado.

Para obter mais informações sobre a constante de troca $A$, sobre os tipos de inomogeneidades e sobre o comportamento e estrutura magnética dos filmes, seria necessário fazer medidas de ressonância a fim de obter modos de ressonância de onda de spin (spin wave ressonance-SWR), onde campos magnéticos da ordem dos 20 kOe para estes 
filmes, são aplicados perpendicularmente à superfície das amostras. Infelizmente não foi possível fazer estas medidas devido a limitações técnicas, já que o equipamento atinge somente campos de até $14 \mathrm{kOe}$, portanto medidas de magnetometria com SQUID foram feitas visando complementar estas análises.

\subsection{Medidas de magnetometria por SQUID}

Medidas de magnetometria por SQUID em temperatura ambiente, foram feitas no Laboratório de Caracterização Magnética do Núcleo de Física Aplicada no Instituto de Física da UnB, com um magnetômetro MPMS 3 (Magnetic Property Measurement System) da empresa Quantum Design Inc. (Figura 3.5, a.).

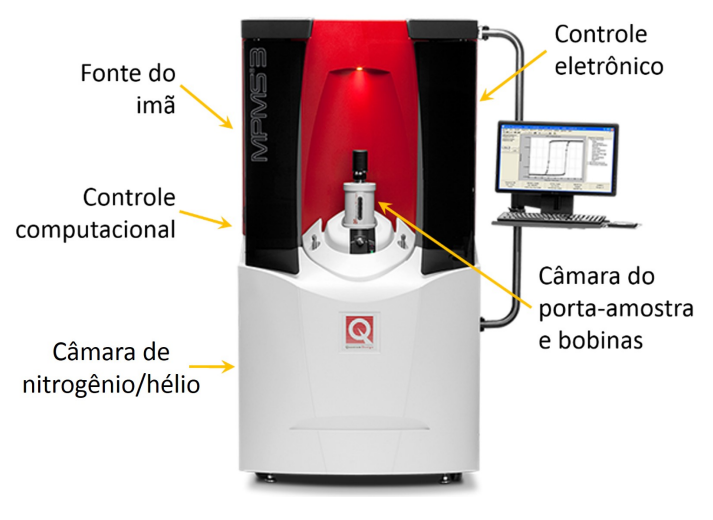

a.

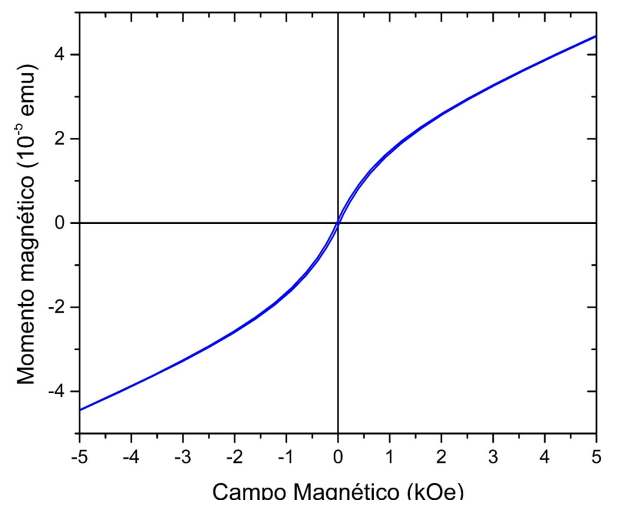

b.

Figura 3.5 - a. Magnetômetro SQUID Quantum Design MPMS 3 [92] e b. sinal paramagnético do porta-amostra de latão, subtraído dos sinais das amostras.

O dispositivo oferece a sensibilidade de um SQUID com a versatilidade de outros tipos de magnetômetros como o VSM (Vibrating Sample Magnetometer), já que no MPSM 3 a amostra oscila dentro do campo magnético como se estivesse num VSM, permitindo obter medidas mais rápidas que no SQUID convencional, mas com a mesma sensibilidade, a qual pode ser de até $10^{-8} \mathrm{emu}$ [92].

Já que o magnetômetro realiza medidas de momento magnético $(\mu)$ do material em unidades emu ( $1 \mathrm{emu}=10^{-3} \mathrm{Am}^{2}$ ), foi calculada a magnetização volumétrica, $M_{V}$, dividindo os valores de momento magnético entre o volume $V$ das amostras:

$$
M_{V}=\frac{\mu}{V}
$$

onde $V$ foi obtido medindo as bordas laterais dos filmes usados nas medidas e multiplicando estes valores pelas espessuras encontradas com medidas de EDS. Isto é 
possível graças a que ao clivar os filmes, eles se fraturam pelos planos cristalográficos, deixando bordas retas e uniformes. O erro percentual associado ao cálculo do volume das amostras foi estimado em $4 \%$ aproximadamente.

As medidas de $\mu$ foram feitas com a amostra num ambiente de baixa pressão, produzido dentro da câmara do porta-amostra onde também encontra-se o sistema de bobinas (Figura 3.5, a.). Não obstante, foi realizada uma medida do porta-amostra (branco), isto porque ele apresentou um sinal paramagnético (Figura 3.5, b.) devido ao latão, que depois foi subtraído das medidas dos filmes.

Assim, com ajuda do software de controle foi programado o protocolo de medida, onde a amostra é desmagnetizada com um campo magnético alternado, que diminui suavemente sua intensidade desde 20 kOe até zero em temperatura constante. Para obter o laço de histerese foi aplicado paralelamente à superfície dos filmes, um campo magnético de 500 Oe para atingir a magnetização de saturação, então a intensidade do campo aplicado foi reduzida até -500 Oe para produzir o primeiro trecho do laço. Em seguida foi aumentada a intensidade do campo aplicado até fechar o laço de histerese. O mesmo processo foi seguido com campo aplicado de $70 \mathrm{kOe}$ na direção perpendicular à superfície dos filmes.

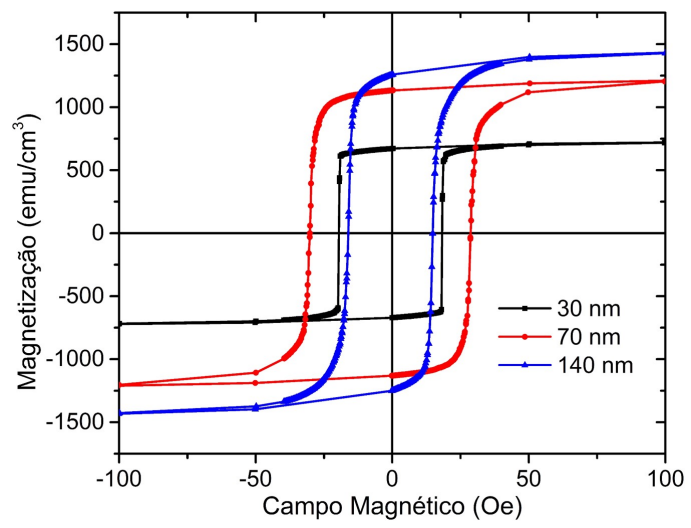

a.

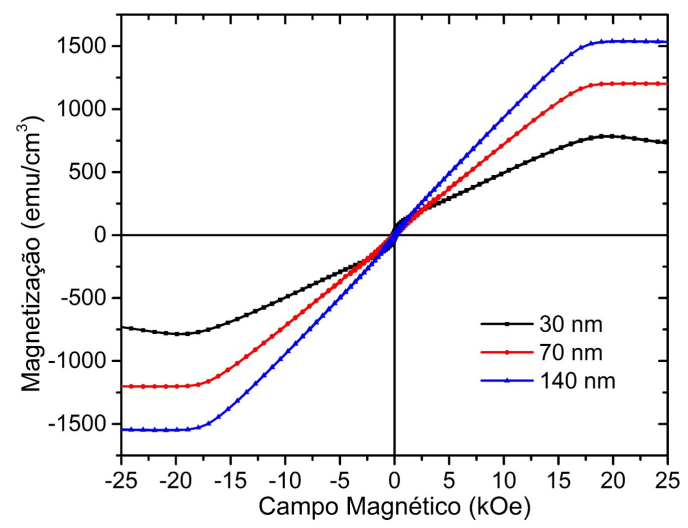

b.

Figura 3.6 - Curvas de magnetização para campos aplicados paralelos (a.) e perpendiculares (b.) à superfície dos filmes em temperatura ambiente.

As curvas de magnetização com campos paralelos e perpendiculares às superfícies dos filmes (Figura 3.6) concordaram com as medidas de FMR, pois as amostras conseguem magnetizar facilmente no plano, com campos de saturação relativamente baixos ( 400 Oe). Mas quando o campo é aplicado perpendicularmente, a magnetização tem um comportamento quase linear e a saturação é alcançada em campos muito intensos da ordem dos $19 \mathrm{kOe}$. 
O coeficiente de orientação, $c_{o}$, definido pela relação (1.16), como o índice da distribuição das direções locais de magnetização em torno da direção média [35], atingiu valores altos em torno de 0.90 , ou seja, a magnetização remanente das amostras equivalia ao $90 \%$ da magnetização de saturação. Isto indica que as amostras depois de ser saturadas pelo campo aplicado no plano, possuem uma memória magnética na ausência do campo, pois a maioria dos momentos magnéticos se alinham paralelos ou quase paralelos ao eixo de fácil magnetização.

Esse resultado indica que as magnetizações locais nos domínios magnéticos, ficam alinhadas no plano da amostra perto dos eixos fáceis de magnetização que podem estar na direção (111). Portanto, os eixos de difícil magnetização devem ser perpendiculares à superfície das amostras. Valores para o $c_{o}$ e para outras grandezas associadas às curvas de magnetização no plano (Figura 3.6, a.), podem ser observados na Tabela 3.3.

Tabela 3.3 - Grandezas associadas às curvas de magnetização no plano para os três filmes estudados, segundo sua espessura.

\begin{tabular}{cccccc}
\hline Espessura $(\mathbf{n m})$ & $M_{S}\left(\mathbf{e m u} / \mathbf{c m}^{3}\right)$ & $M_{r}\left(\mathbf{e m u} / \mathbf{c m}^{3}\right)$ & $c_{o}=M_{r} / M_{S}$ & $H_{c i}(\mathbf{O e})$ & $C Q$ \\
70 & 730 & 671 & 0.92 & 20 & 0.94 \\
70 & 1257 & 1132 & 0.90 & 30 & 0.91 \\
140 & 1475 & 1257 & 0.85 & 16 & 0.89 \\
\hline
\end{tabular}

As magnetizações de saturação e remanência para os filmes mais espessos, concordam com os valores reportados na literatura [8, 10, 84], mas os dados mostram também que estas grandezas são diretamente proporcionais à espessura dos filmes, pois aumentam com o incremento na espessura, com uma taxa aproximada de $6.77 \mathrm{e}$ $5.32 \mathrm{emu} \mathrm{cm}^{-3} \mathrm{~nm}^{-1}$ respectivamente, o que faz com que o $c_{o}$ diminua ao acrescentar a espessura. $\mathrm{O}$ acréscimo nestas magnetizações, implica por sua vez um incremento na anisotropia efetiva do material, segundo a expressão (1.15).

Curvas de histerese no plano, exibem também campos coercitivos intrínsecos baixos e magnetizações de remanência altas para os três filmes, atestando o comportamento ferromagnético mole das amostras no plano. Este aspecto pode ser confirmado pelo cálculo do coeficiente de quadratura, CQ, definido pela razão [39]:

$$
C Q=\frac{S}{M_{r} H_{c i}}
$$

onde $S$ é a área sob a curva de magnetização no segundo quadrante e $H_{c i}$ o campo coercitivo intrínseco. Portanto o CQ é adimensional e varia entre 0 e 1 . Quanto mais próximo de 1 esteja o $C Q$, e se o $H_{c i}$ é baixo como nosso caso, então o material é 
ferromagnético mole e mais quadrada será a curva de histerese.

No entanto, o campo coercitivo intrínseco apresenta uma anomalia para o filme de $70 \mathrm{~nm}$, já que é esperada uma redução do $H_{c i}$ com o aumento na espessura [84], não obstante neste caso, dita amostra possui o maior campo coercitivo de todas as amostras. Geralmente, o incremento no $H_{c i}$ está relacionado com o aumento no número de domínios e de paredes de domínios no interior do filme. Mas tendo em vista as medidas de FMR, onde foram encontrados modos indicativos de outra fase magnética, tal vez proveniente da rugosidade da amostra, é possível que o aumento no campo coercitivo deste filme também esteja relacionado com o incremento na anisotropia de superfície, gerado na hora da deposição, mas os dados disponíveis não permitem confirmar isto.

Por outro lado, curvas de magnetização para campos perpendiculares às superfícies dos filmes (Figura 3.6, b.), manifestaram a presença de uma direção de difícil magnetização fora do plano das amostras e portanto uma alta componente da anisotropia magneto-cristalina nessa direção. Nestes casos, o campo de saturação, também chamado de campo de anisotropia $H_{k}$ [35,36], foi quase o mesmo para todos os filmes (Tabela 3.4), sendo três ordens de grandeza maior que o campo de saturação no plano.

Tabela 3.4 - Grandezas associadas às curvas de magnetização fora do plano para os três filmes estudados, segundo sua espessura.

\begin{tabular}{cccccc}
$\begin{array}{c}\text { Espessura } \\
(\mathbf{n m})\end{array}$ & $\begin{array}{c}M_{s} \\
\left(\mathbf{e m u} / \mathbf{c m}^{3}\right)\end{array}$ & $\begin{array}{c}H_{k} \\
(\mathbf{k O e})\end{array}$ & $\begin{array}{c}K_{e f} \\
\left(\mathbf{e r g} / \mathbf{c m}^{3}\right)\end{array}$ & $\begin{array}{c}K_{u 1} \\
\left(\mathbf{e r g} / \mathbf{c m}^{3}\right)\end{array}$ & $\begin{array}{c}L_{e x} \\
(\mathbf{n m})\end{array}$ \\
30 & 786 & 19 & $6.67 \times 10^{6}$ & $6.94 \times 10^{6}$ & 5.4 \\
70 & 1199 & 19 & $1.05 \times 10^{7}$ & $1.13 \times 10^{7}$ & 3.2 \\
140 & 1537 & 19 & $1.29 \times 10^{7}$ & $1.40 \times 10^{7}$ & 2.7 \\
\hline
\end{tabular}

Usando as equações (1.11), (1.15), a magnetização de saturação e o campo de anisotropia dos filmes, foram calculadas as constantes de anisotropia efetiva, $K_{e f}$ e uniaxial, $K_{u 1}$, assumindo uma anisotropia magneto-cristalina uniaxial induzida pela orientação preferencial (111) da estrutura e pela anisotropia de forma dos filmes, produto da suas espessuras (Tabela 3.4). As ordens de grandeza dos valores obtidos para estas constantes, correspondem-se com os dados reportados na literatura [89].

Pode-se ver que as constantes de anisotropia crescem com o aumento na espessura dos filmes. Tendo em conta que a energia de anisotropia é a energia necessária para superar o acoplamento spin-orbita nos átomos da rede cristalina das amostras, então o aumento nos valores da constante de anisotropia indica que dito acoplamento é mais forte em filmes mais espessos.

Finalmente, foi calculado o comprimento de troca, $L_{e x}$, para cada filme, por meio 
da expressão (no sistema CGS) [93, 94]:

$$
L_{e x}=\sqrt{\frac{A}{2 \pi M_{s}^{2}}}
$$

sendo $A \sim 10^{-6} \mathrm{erg} / \mathrm{cm}$ a constante de troca reportada na literatura [91, 93] e $M_{s}$ a magnetização de saturação. O comprimento de troca é um parâmetro que determina um limite abaixo do qual as interações de troca no material são mais intensas que as interações magnetostáticas [94], e em simulações tridimensionais de microestruturas magnéticas, define o tamanho favorável das células usadas para a discretização dos problemas. Esse comprimento diminui com o aumento na espessura dos filmes, ficando em torno dos $3 \mathrm{~nm}$ na média.

\subsection{Medidas de AFM/MFM}

Com base na informação coletada sobre o comportamento magnético dos filmes de FeNi36, foram feitas imagens de Microscopia de Força Atómica e Magnética (AFM/MFM) de alta resolução, sobre a superfície dos filmes. Tais imagens foram obtidas no Laboratório de Superfícies e Interfaces (LabSInt) do Instituto de Física da UnB (Brasília - DF) e no Laboratório de Ciência de Superfícies (LCS), localizado no Laboratório Nacional de Nanotecnologia (LNNano) do Centro Nacional de Pesquisa em Energia e Materiais (CNPEM) em Campinas - SP.

O equipamento usado foi um microscópio Nanosurf Flex-Axiom AFM com um controlador Nanosurf C3000 (Figura 3.7, a.) que permite uma resolução de 24 bits, facilitando com isso a precisão e aquisição dos dados [67].

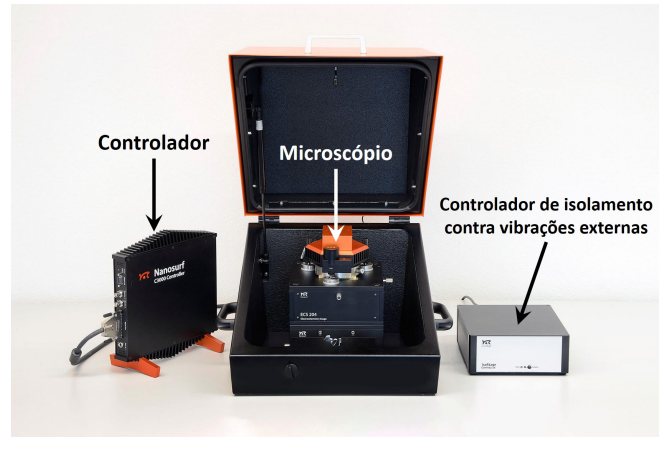

a.

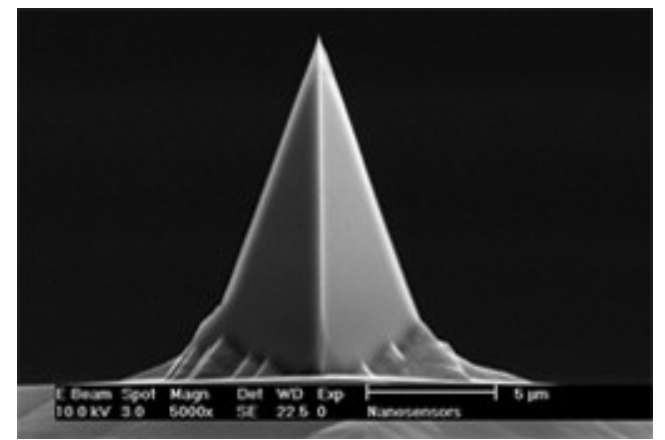

b.

Figura 3.7 - a. Microscópio Nanosurf Flex-Axiom AFM e b. ponta Nanosensors PPP-MFMR de silício revestida de cobalto usada para geração das imagens de MFM em modo de Não Contato. Altura $=225 \mu \mathrm{m}$, largura $=28 \mu \mathrm{m}$, espessura $=3 \mu \mathrm{m}$ [95] . 
Uma vez que as medidas de AFM são muito sensíveis aos movimentos da alavanca é preciso ter um sistema de isolamento contra possíveis vibrações, as quais podem afetar consideravelmente a medida, por isso o microscópio possui um controlador Nanosurf Isostage que protege o equipamento do ruido gerado por vibrações externas. Além disso o microscópio encontra-se sobre uma base de $230 \mathrm{~kg}$ feita de granito e metal com suportes de borracha para aumentar o isolamento contra vibrações no prédio.

Para evitar forças desnecessárias devidas a cargas elétricas superficiais que afetem a força de interação ponta-superfície, o porta-amostra foi aterrado em todas as medidas. Contudo, o microscópio é isolado por uma caixa em acrílico conectada a um controlador de umidade e temperatura, para manter o sistema a temperatura ambiente e com uma umidade relativa de $5 \%$ aproximadamente, já que se a umidade do ambiente fosse alta, uma camada de água poderia formar-se na superfície produzindo forças de tensão que pudessem interferir na medida ou oxidar a ponta do microscópio, alterando sua geometria e a resolução da imagem.

Foi empregada uma ponta Nanosensors PPP-MFMR (Point Probe Plus Magnetic Force Microscopy - Reflex Coating) [95] de silício revestida com uma fina camada de cobalto que atua como material magnético e facilita a interação com os dipolos magnéticos da amostra (Figura 3.7, b.).

Antes de começar a medida, a ponta foi colocada com seu eixo vertical paralelo ao campo magnético de um imã permanente forte durante 5 segundos, para que seus domínios magnéticos fossem novamente alinhados e assim conseguir uma melhor interação com a amostra.

Tabela 3.5 - Parâmetros ajustados no software controlador do microscópio para as medidas de AFM/MFM.

\begin{tabular}{cc} 
Parâmetro & Valor \\
Setpoint & $65 \%$ \\
Ganho P & 2000 \\
Ganho I & 2000 \\
Ganho D & 0 \\
Lift & $50 \mathrm{~nm}$ \\
\hline
\end{tabular}

As amostras foram estudas na ausência de campo magnético externo, sem ser submetidas a processos de magnetização previamente. O microscópio foi ajustado no modo de Contraste de Fase com dupla varredura (Dual scan), para obter os dados da topografia na primeira varredura e os dados magnéticos na segunda. O tempo de varredura por linha foi de 1 segundo com aquisição de 512 pontos por linha para obter uma boa resolução. Outros parâmetros importantes são apresentados na tabela 3.5. 
Por fim, as imagens obtidas foram tratados com o software Gwyddion [70], um software modular de licença livre que oferece importantes ferramentas para a filtragem, correção, ajuste, manipulação e análise das imagens obtidas por meio de qualquer das técnicas SPM ou de outras técnicas que produzam imagens e dados em 2D.

Imagens de $10 \times 10 \mu \mathrm{m}^{2}$ (Figura 3.8), mostram uma topografia muito plana com presença de alguns grãos (picos brancos), os quais possuem alturas maiores para os filmes de 70 e $140 \mathrm{~nm}$ de espessura.

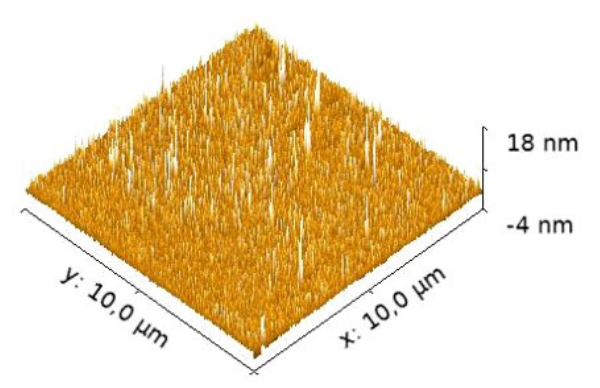

a.

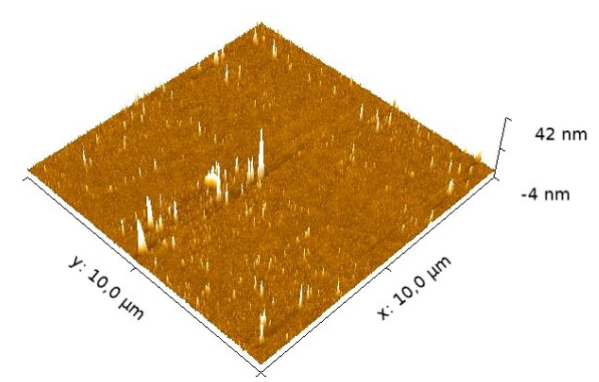

b.

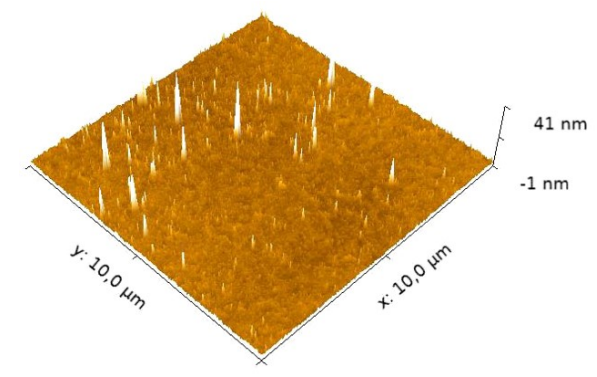

c.

Figura 3.8 - Imagens 3D da topografia dos filmes de FeNi36 de a. $30 \mathrm{~nm}$, b. $70 \mathrm{~nm}$ e c. $140 \mathrm{~nm}$ de espessura.

A boa coalescência do material foi verificada pelas imagens de topografia que mostram superfícies planas, as quais eram esperadas devido a este tipo de liga metálica, pois ela cristaliza formando filmes policristalinos, com um empacotamento relativamente compacto de tipo cubico, distribuindo-se uniformemente sobre a superfície do filme com baixos níveis de aglomeração.

Utilizando várias imagens de topografia para cada filme e o software Gwyddion, foram obtidos alguns parâmetros estatísticos que evidenciam a pouca rugosidade das superfícies (Tabela 3.6), mostrando que elas são atomicamente planas. A rugosidade média $R_{a}$, é o parâmetro que permite estimar os desvios da superfície real em relação com a superfície ideal, que seria um plano de rugosidade nula localizado à altura média $\bar{z}$. 
Tabela 3.6 - Parâmetros de rugosidade calculados para uma área de $100 \mu \mathrm{m}^{2}$, de acordo com a espessura dos filmes.

\begin{tabular}{cccc}
\hline \multirow{2}{*}{ Parâmetro } & \multicolumn{3}{c}{ Espessura (nm) } \\
& $\mathbf{3 0}$ & $\mathbf{7 0}$ & $\mathbf{1 4 0}$ \\
\hline Altura média $\bar{z}(\mathrm{~nm})$ & 1 & 1 & 2 \\
Altura máxima $(\mathrm{nm})$ & 18 & 42 & 41 \\
Rugosidade média $R_{a}(\mathrm{~nm})$ & 0.49 & 0.53 & 0.69 \\
RMS da rugosidade $R_{r m s}(\mathrm{~nm})$ & 0.84 & 1 & 1.27 \\
\hline
\end{tabular}

A $R_{a}$ é definida como a média da variação da altura calculada com respeito à altura média $\bar{z}[70]$ :

$$
R_{a}=\frac{1}{N} \sum_{i=1}^{N}\left|z_{i}-\bar{z}\right|
$$

sendo $z_{i}$ a altura do ponto $i$ na imagem e $N$ o número de pontos que compõem a imagem, o qual foi de 512 pontos para todos os casos. Por outro lado, a $R_{r m s}$ é definida como a raiz quadrada do valor médio dos quadrados das diferenças de alturas com respeito a $\bar{z}$ :

$$
R_{r m s}=\sqrt{\frac{1}{N} \sum_{i=1}^{N}\left\langle z_{i}-\bar{z}\right\rangle^{2}}
$$

A $R_{r m s}$ tem a vantagem de acentuar a detecção de picos e vales em superfícies muito lisas, elevando o erro ao quadrado. Assim, observa-se que as rugosidades médias dos filmes $R_{a}$, são da ordem de $0.5 \mathrm{~nm}$, enquanto que a raiz quadrada média da rugosidade $R_{r m s}$ é de $1 \mathrm{~nm}$ em média, indicando a boa qualidade da deposição do material e o baixo nível de impurezas na superfície.

Além disso, quanto menor a espessura dos filmes mais lisa tende a ser a superfície, como indicam os parâmetros $R_{a}$ e $R_{r m s}$, os quais são menores para o filme de $30 \mathrm{~nm}$. Mesmo assim, as alturas médias são iguais para os filmes de 30 e $70 \mathrm{~nm}$, sendo que para o filme de $140 \mathrm{~nm}$ a altura média se duplica (Tabela 3.6).

\subsubsection{Imagens de AFM/MFM para o filme de $140 \mathrm{~nm}$ de espes- sura}

Nas medidas de MFM era esperado um sinal magnético forte devido aos resultados obtidos com as medidas de FMR e magnetometria. Mesmo sem a presença de um campo magnético externo, as imagens resultantes mostraram um sinal próprio da configuração magnética dos filmes, ao longo de todas as amostras.

Assim, imagens de MFM foram analisadas em relação com as imagens de topografia. 


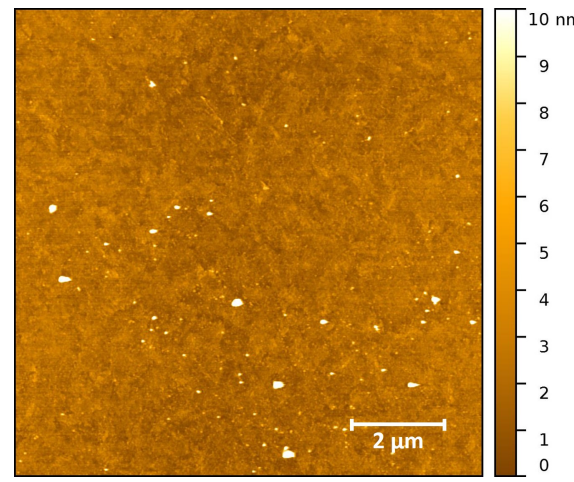

a.

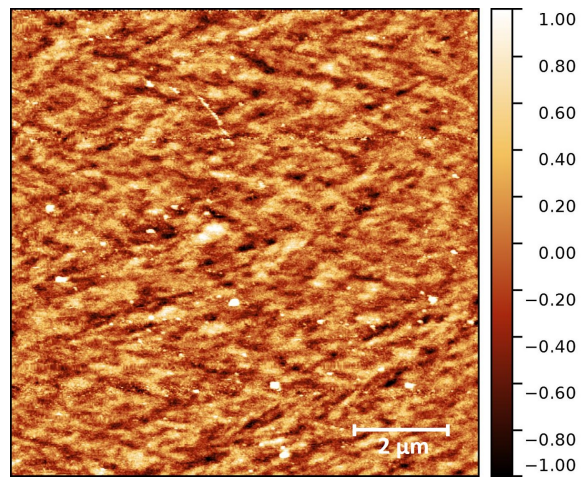

b.

Figura 3.9 - a. Imagem da topografia e b. imagem de MFM para o filme de FeNi36 de $140 \mathrm{~nm}$ de espessura. Tamanho das imagens: $10 \times 10 \mu \mathrm{m}^{2}$.

Inicialmente para o filme de $140 \mathrm{~nm}$ de espessura, a imagem de topografia (Figura 3.9, a.) apresentou uma superfície pouco rugosa como já foi dito, enquanto que a imagem de MFM (Figura 3.9, b.) mostra uma morfologia distinta à imagem de topografia, pelo que é possível dizer que as variações de fase manifestadas nestas imagens, são devidas às forças de interação magnéticas ponta-amostra e não pela rugosidade da superfície, com exceção de alguns grãos muito altos que originam alguns pontos brilhantes na imagem de MFM.

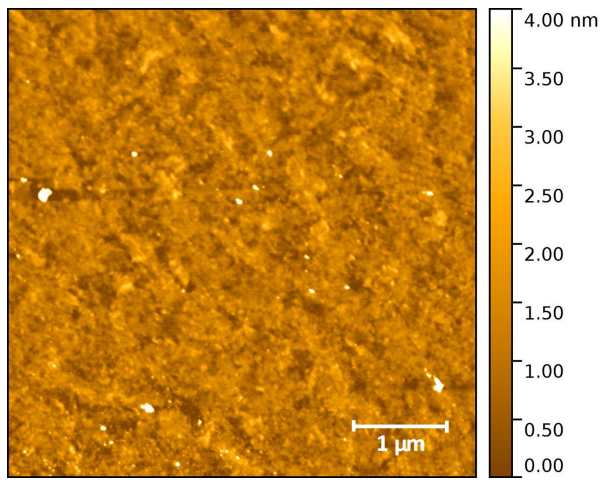

a.

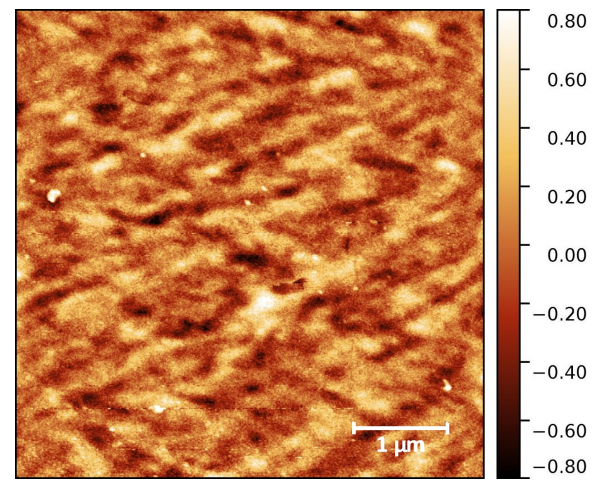

b.

Figura 3.10 - Imagens reduzidas: a. da topografia e b. de MFM para o filme de FeNi36 de $140 \mathrm{~nm}$ de espessura. Tamanho das imagens: $5 \times 5 \mu \mathrm{m}^{2}$.

No entanto, pelo tamanho da imagem, a estrutura magnética para esta amostra não é facilmente apreciável, pelo que foi feita uma medida do mesmo filme numa região de menor tamanho (Figura 3.10). Nesta nova imagem, podem-se ver melhor as zonas de contraste de fase (faixas claras e escuras) onde as variações em $z$ do campo magnético intrínseco do material são maiores, formando caminhos em ziguezague sobre quase 
toda a zona analisada.

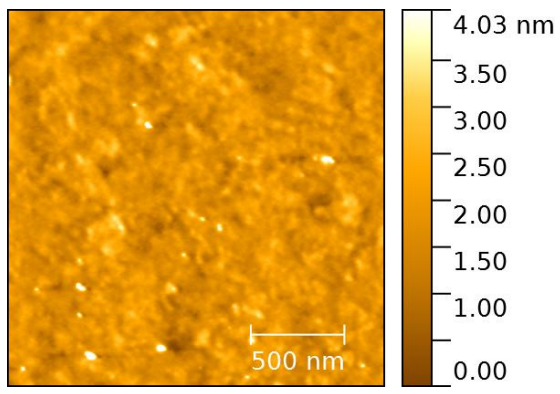

a.

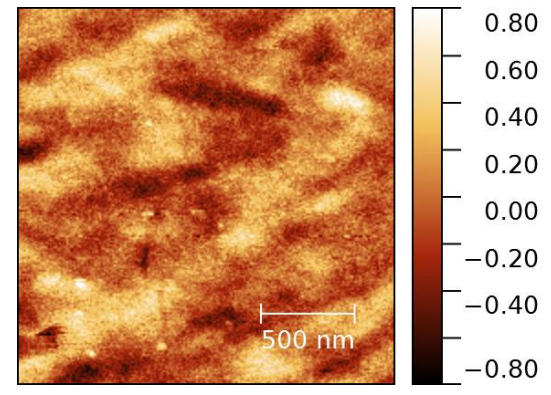

b.

Figura 3.11 - Zoom das imagens de topografia (a.) e MFM (b.) para o filme de FeNi36 de $140 \mathrm{~nm}$ de espessura. Tamanho das imagens: $2 \times 2 \mu \mathrm{m}^{2}$.

Por essa razão, tais faixas representam paredes de domínios magnéticos, em quanto que as áreas sem contraste na imagem (zonas laranjas), representam domínios magnéticos onde o campo intrínseco do material se alinha paralelo à superfície. Neste último caso, não existem variações em $z$ apreciáveis, já que os momentos magnéticos presentes nestes domínios também se alinham com o plano do filme.

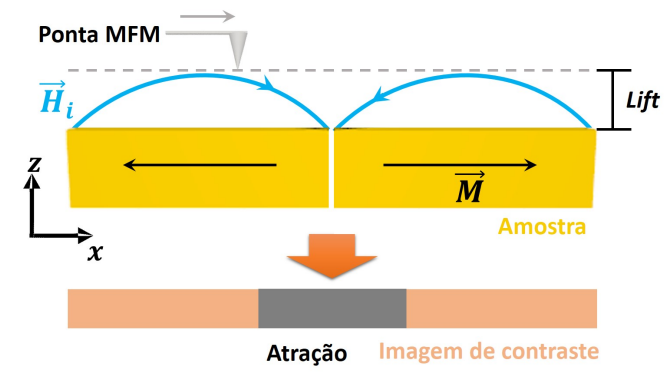

a.

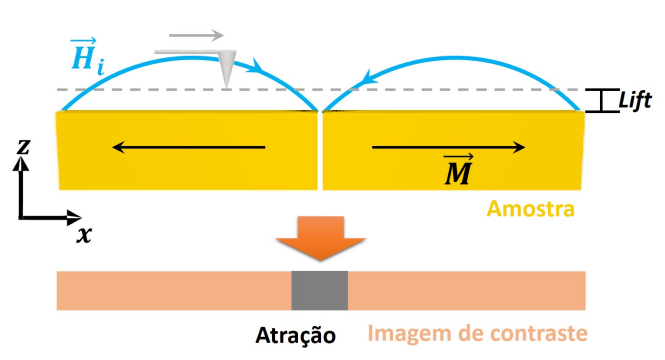

b.

Figura 3.12 - Influência do lift nas imagens de MFM: a. um lift alto gera contrastes amplos pela grande divergência das linhas do campo intrínseco $\vec{H}_{i}$, b. um lift menor faz os efeitos da divergência menores e melhora a resolução.

Uma ampliação para $2 \times 2 \mu \mathrm{m}^{2}$ (Figura 3.11) foi feita nas imagens anteriores com ajuda do software Gwyddion, para visualizar melhor essas zonas de contraste com sua respectiva topografia.

Na ampliação, as regiões magnéticas e o padrão de ziguezague puderam ser visualizados mais claramente. Cada trecho do ziguezague obtido tem um comprimento de $700 \mathrm{~nm}$ e uma largura dentre 100 e $200 \mathrm{~nm}$ na média, mas deve se considerar que a largura destas faixas pode ser influenciada pelo lift da ponta. Quanto maior é a altura da ponta com respeito à superfície, mais amplas serão as faixas de contraste, já que 
as linhas do campo magnético intrínseco apresentam mais divergência e vice-versa (Figura 3.12).

Por outro lado, os trechos em ziguezague não são uniformes e seus comprimentos variam notavelmente. Em algumas partes do filme, as zonas de atração/repulsão aparecem como ilhas no meio de zonas de zero contraste, fato que pode ser ocasionado pela policristalinidade do material.

\subsubsection{Imagens de AFM/MFM para o filme de $70 \mathrm{~nm}$ de espessura}

A imagem de topografia do filme de FeNi36 com $70 \mathrm{~nm}$ de espessura (Figura 3.13, a.), também apresenta uma morfologia distinta, em termos de contraste de fase, aonde é evidenciado um padrão magnético de ziguezague mais claro do que no caso anterior (observar figuras 3.9, b. e 3.13, b.).

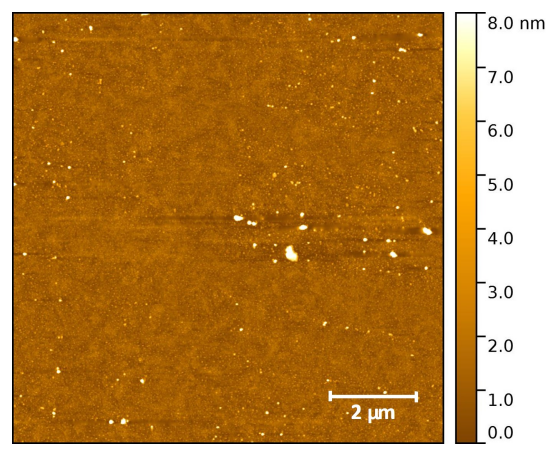

a.

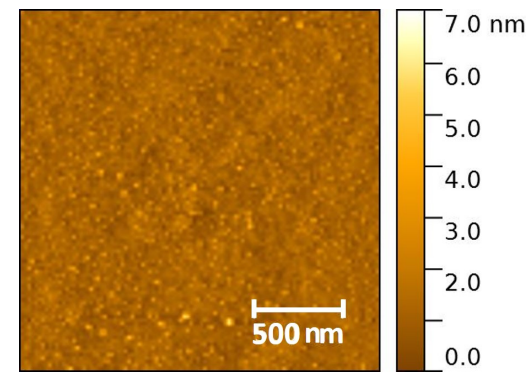

c.

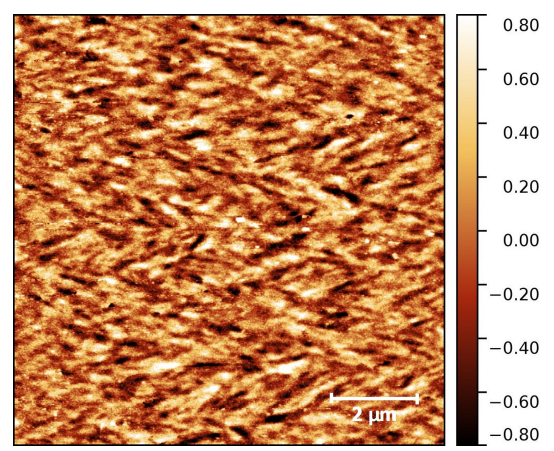

b.

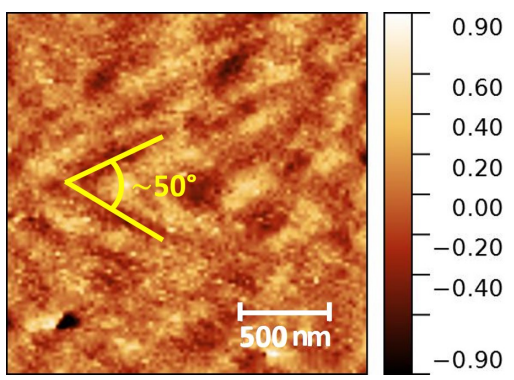

d.

Figura 3.13 - a. e c. mostram imagens de topografia, enquanto que b. e d. apresentam imagens de MFM para o filme de FeNi36 de $70 \mathrm{~nm}$ de espessura. Tamanho das imagens: $10 \times 10 \mu \mathrm{m}^{2}$ (superiores) e $2 \times 2 \mu \mathrm{m}^{2}$ (inferiores).

O filme de $70 \mathrm{~nm}$ apresentou trechos em ziguezague aparentemente mais finos que o filme de $140 \mathrm{~nm}$, já que a largura média de tais trechos era menor a $100 \mathrm{~nm}$, pelo que podem estar representando paredes de domínio onde o campo intrínseco da amostra apresenta uma alta divergência perpendicular à superfície. 
Uma ampliação de $2 \times 2 \mu \mathrm{m}^{2}$ (Figura 3.13, d.) revelou as faixas de maior contraste, formando ângulos de $\sim 50^{\circ}$, com algumas ilhas de contraste em meio das zonas sem sinal magnético como no caso anterior. Verifica-se que tais trechos não são contínuos, resultando em caminhos em ziguezague que indicam uma estrutura magnética não uniforme.

O aumento no contraste de fase nestas imagens, em comparação com os outros filmes, pode ser relacionado com as anomalias apresentadas nas medidas de FMR e magnetometria para este filme, onde foram observados modos de ressonância superficiais mais intensos e um campo coercitivo maior, em relação com os filmes de 30 e $140 \mathrm{~nm}$ de espessura. Portanto é provável que a anisotropia superficial neste filme seja mais intensa e o número de domínios e paredes de domínio seja maior em relação com os outros filmes, causando estes efeitos.

\subsubsection{Imagens de AFM/MFM para o filme de $30 \mathrm{~nm}$ de espessura}

Finalmente o filme de FeNi36 de $30 \mathrm{~nm}$ que possui a superfície mais plana dos filmes estudados (Figura 3.14, a.) exibiu um sinal magnético mais fraco e irregular em relação com as demais amostras (Figura 3.14, b.), posto que é possível ver linhas de contraste de diferentes comprimentos, os quais vão desde os $300 \mathrm{~nm}$ até os $4 \mu \mathrm{m}$, como no caso das faixas longas mostradas na parte superior esquerda da imagem de MFM (Figura 3.14, b.). Ademais as larguras das faixas de repulsão/atração ficam em torno dos $190 \mathrm{~nm}$.

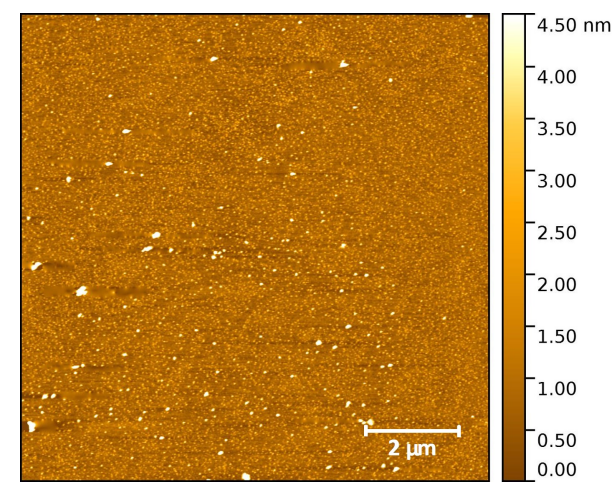

a.

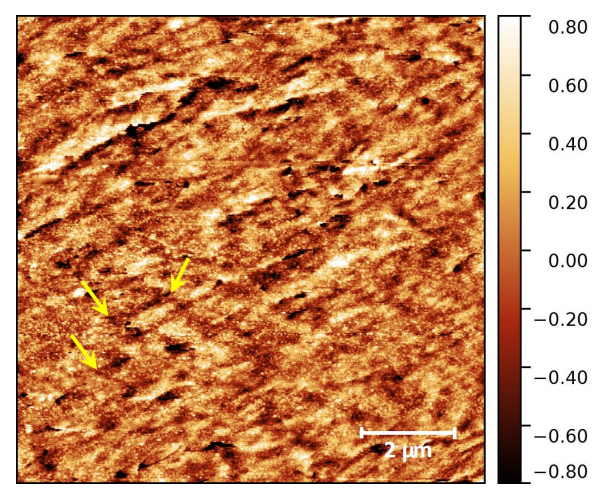

b.

Figura 3.14 - a. Imagem de topografia e b. imagem de MFM para o filme de FeNi36 de $30 \mathrm{~nm}$ de espessura. Tamanho das imagens: $10 \times 10 \mu \mathrm{m}^{2}$.

O padrão de ziguezague nesta amostra não ficou tão evidenciado, sendo visível somente em algumas partes da superfície como indicado pelas setas na imagem de MFM (Figura 3.14, b.). Os ângulos formados entre os trechos em ziguezague continuam 
sendo de $50^{\circ} \mathrm{em}$ média.

O fato que leva o padrão em ziguezague a ficar mais descontínuo, pode ser devido a ser mais fino, dificultando o surgimento de um alto número de momentos magnéticos perpendiculares à superfície, dentro das paredes de domínio, os quais induziriam divergências mais intensas do campo intrínseco da amostra en $z$. O anterior implicaria um estado de maior energia difícil de manter pelo sistema, pelo que a maioria das paredes de domínio neste filme devem ser tipo Néel (paralelas à superfície).

A dificuldade na detecção das faixas de contraste nesta amostra é explicada também pela equação (2.29), onde foi mostrado que quanto menor é a espessura do filme, menor é a intensidade do campo dispersivo detectado pela ponta do MFM, na superfície da amostra. Por isso é provável que aqui a maioria de momentos magnéticos fiquem paralelos ao plano do filme, sem interagir com a ponta do microscópio, apresentando contraste reduzido.

As faixas de maior comprimento e largura, podem ser devidas também à presença de cristalitos que na hora da deposição, ficaram com seus eixos fáceis fora da superfície do filme, orientados e separados aleatoriamente por causa da policristalinidade do filme.

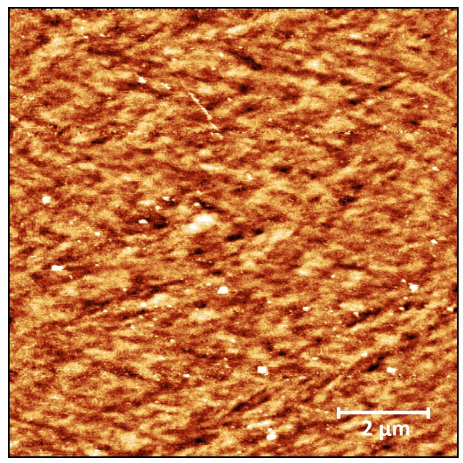

a.

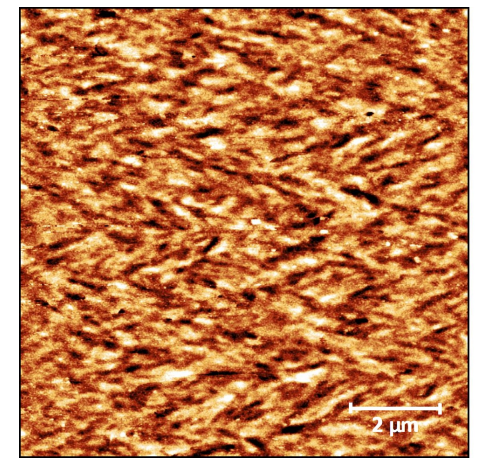

b.

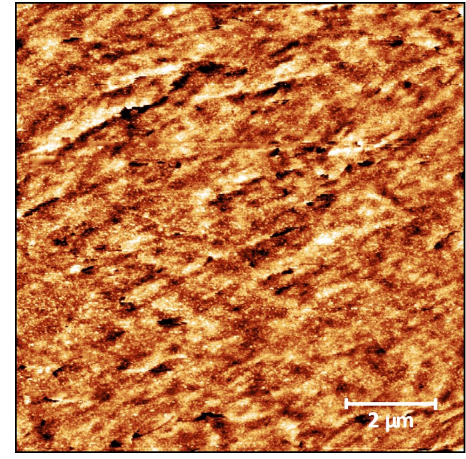

c.

Figura 3.15 - Comparativo entre as imagens de MFM dos filmes de FeNi36 de: a. 140 nm, b. 70 $\mathrm{nm}$ e c. $30 \mathrm{~nm}$ de espessura.

A figura 3.15 apresenta novamente as imagens de MFM dos três filmes a título de comparação. É notável o maior contraste gerado pelos trechos em ziguezague na amostra de $70 \mathrm{~nm}$ de espessura, como já foi comentado.

A irregularidade nos trechos apresentados nas amostras, origina-se da policristalinidade do material que obriga aos grãos dos filmes a formar microestruturas magnéticas não homogêneas, governadas pela interação dipolar entre eles. No entanto, esta aleatoriedade deve competir com a anisotropia magneto-cristalina local e de forma, que 
no último caso apresenta dependência com a espessura dos filmes, fazendo com que os momentos magnéticos se alinhem seguindo o perfil da direção de magnetização, formando domínios magnéticos entre os trechos de ziguezague, com magnetizações antiparalelas em cada lado dos trechos, sobre o plano dos filmes (Figura 3.16).

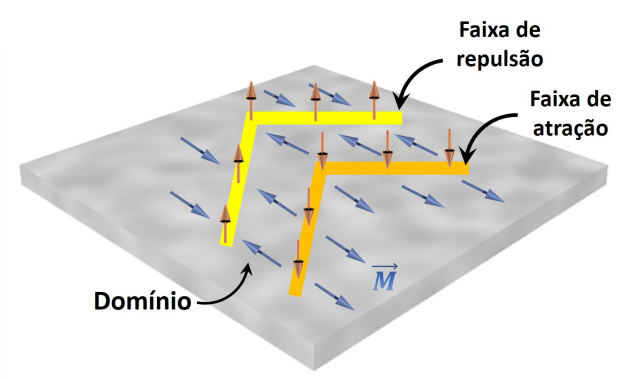

Figura 3.16 - Representação dos domínios nas imagens de MFM. Entre as faixas de contraste são formados os domínios magnéticos com direções antiparalelas.

Consequentemente, as faixas de contraste nas imagens de MFM, que representam regiões onde as variações em $z$ do campo intrínseco são maiores, surgem como paredes de domínio com uma magnetização resultante [32, 96]: faixas claras representam momentos magnéticos que produzem repulsão, enquanto que faixas escuras representam momentos magnéticos que produzem atração.

Os momentos magnéticos nestas faixas se alinham desse modo perpendicular ou obliquamente à superfície das amostras, e permitem a mudança da direção da magnetização entre vizinhos (Figura 3.16).

Esta ideia é confirmada pelo fato do que em filmes ferromagnéticos, se a espessura $t$, é maior do que a relação $20 \cdot L_{e x}$, então a estrutura das paredes de domínio tende a alinhar os momentos magnéticos perpendicularmente à superfície do filme [32, 96], o que acontece em todos os filmes.

O formato em ziguezague destas paredes, é explicado por alguns autores como uma consequência do campo intrínseco que se estende acima e embaixo do filme, evitando as regiões de campo concentrado que fazem impossível a formação deste tipo de paredes [32]. Para complementar estas observações foram realizadas simulações das imagens de MFM com o software MUMAX3. Os resultados são apresentados na seção seguinte. 


\subsection{Simulações das microestruturas magnéticas}

Imagens de MFM somente permitem apreciar as configurações magnéticas na superfície dos filmes, contendo implicitamente informação sobre a estrutura dos domínios e das paredes de domínio no volume das amostras. Para obter uma representação aproximada da configuração magnética interna dos filmes Invar estudados, foram construídas simulações computadorizadas em 3D usando o software MUMAX3 [79], onde foi estabelecida para todas as amostras uma região espacial de $2 \mu \mathrm{m} \times 2 \mu \mathrm{m} \times t$, sendo $t$ a espessura dos filmes em nanômetros.

Dito espaço foi dividido em $500 \times 500 \times n$ células, onde cada célula tinha um tamanho de $4 \times 4 \times 4 \mathrm{~nm}^{3}$, de modo que $n=t / 4$. Assim, os comprimentos das células foram da ordem dos comprimentos de troca apresentados na tabela 3.4. Nas simulações foram desconsiderados os efeitos térmicos ( $T=0 \mathrm{~K}$ ) em ausência de campos magnéticos externos e foram escolhidas magnetizações iniciais aleatórias, para evitar induzir certos tipos de configurações no começo dos cálculos. O tempo de simulação foi de $10^{-9} \mathrm{~s}$, tendo em conta que os tempos de relaxação nestas ligas são menores que este valor, como indicado na tabela 3.2 e os mapas vetoriais foram tratados com o software OOMMF (Object Oriented MicroMagnetic Framework) [37,80].

Os parâmetros usados pelo software tais como constante de troca, $A$, constante de anisotropia uniaxial, $K_{u 1}$, e magnetização de saturação, $M_{s}$ (Tabela 3.7), em unidades do SI, foram obtidos por meio das medidas de DRX, FMR e magnetometria apresentadas no capítulo anterior. A constante de troca reportada na literatura para ligas Invar é da ordem de $10^{-11} \mathrm{~J} / \mathrm{m}[89,91]$, mas para obter configurações magnéticas aproximadas a aquelas mostradas pelas imagens de MFM, este valor foi mudado segundo a espessura dos filmes.

Tabela 3.7 - Parâmetros das amostras Invar usados para a elaboração das simulações.

\begin{tabular}{cccc} 
Espessura $(\mathrm{nm})$ & $A\left(\times 10^{-11} \mathrm{~J} / \mathrm{m}\right)$ & $K_{u 1}\left(\mathrm{~J} / \mathrm{m}^{3}\right)$ & $M_{S}(\mathrm{~A} / \mathrm{m})$ \\
30 & 0.6 & $6.9 \times 10^{5}$ & $7 \times 10^{5}$ \\
70 & 1 & $1.1 \times 10^{6}$ & $1.2 \times 10^{6}$ \\
140 & 0.95 & $1.4 \times 10^{6}$ & $1.4 \times 10^{6}$ \\
\hline
\end{tabular}

A constante de amortecimento de Gilbert, $\alpha$, necessária para resolver a equação de Landau-Lifshitz-Gilbert, foi tomada como 0.5 com o fim de facilitar a rápida convergência das soluções. Além disso, e tendo em conta os difratogramas de DRX, foi assumida uma anisotropia uniaxial na direção (111) para todos os filmes, já que nestas condições as imagens simuladas tendem a ser mais semelhantes com as imagens medidas. Ou- 
tro tipo de configurações com anisotropias uniaxiais e cubicas no plano e totalmente perpendiculares, foram testadas sem sucesso.

Com base nesses parâmetros de entrada, imagens de MFM foram simuladas com um lift de $50 \mathrm{~mm}$, como foi feito nas medidas de microscopia. As simulações foram comparadas com imagens experimentais do mesmo tamanho $\left(2 \times 2 \mu \mathrm{m}^{2}\right)$, numa escala cinza para facilitar a comparação (Figura 3.17).

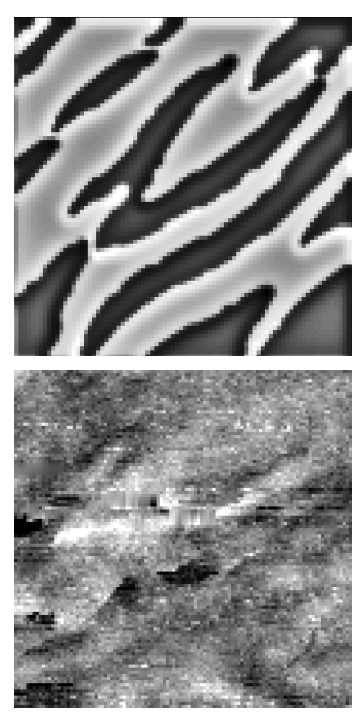

a.

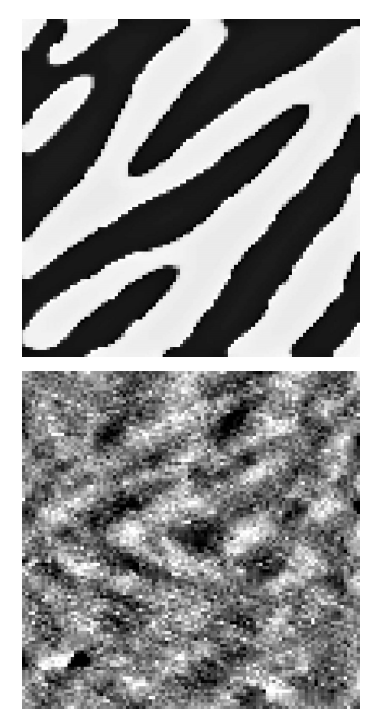

b.
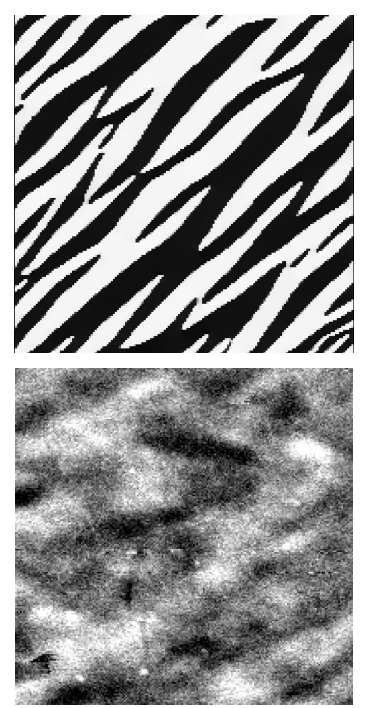

c.

Figura 3.17 - Comparativo entre as imagens de MFM simuladas (superiores) e medidas (inferiores) para os filmes FeNi36 de a. 30nm, b. $70 \mathrm{~nm}$ e c. $140 \mathrm{~nm}$ de espessura.

O filme de $30 \mathrm{~nm}$ de espessura, possui regiões onde não é apreciável a configuração em ziguezague apresentada nos outros filmes, pois aqui são observados domínios magnéticos mais alargados e irregulares, como mostrado na imagem simulada. Mesmo assim a simulação deste comportamento, como dos outros filmes, é complexa pela policristalinidade das amostras e as possíveis inomogeneidades presentes nelas.

As simulações das amostras de 70 e $140 \mathrm{~nm}$ de espessura, tendem a mostrar configurações com picos no plano semelhantes aos presentes nas estruturas em ziguezague observadas por MFM, incluindo algumas ilhas menores, mas ainda existem diferenças notórias entre as simulações e as medidas, já que os ângulos de abertura destas estruturas são menores e seus domínios muito mais alargados que nas imagens de MFM.

Para observar melhor as direções das magnetizações locais nos domínios magnéticos nestas simulações, imagens da magnetização reduzida foram geradas com o MuMAX3. Os comportamentos são similares em todas as amostras pelo que aqui será 
tomado como exemplo o filme de $70 \mathrm{~nm}$ de espessura. Inicialmente foi analisado o comportamento dos momentos magnéticos na superfície dos filmes (Figura 3.18, a.), onde são apreciados domínios magnéticos com magnetizações netas paralelas à superfície $\mathrm{e}$ divididos por paredes de domínio muito estreitas.

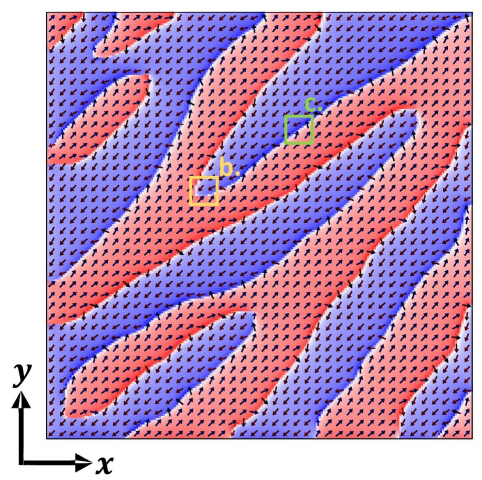

a.

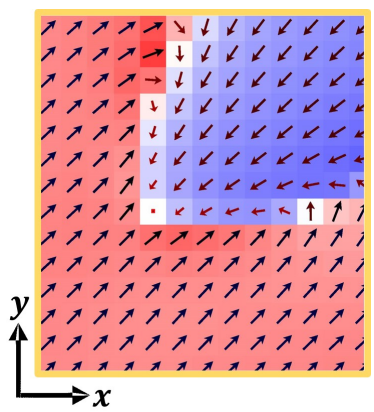

b.

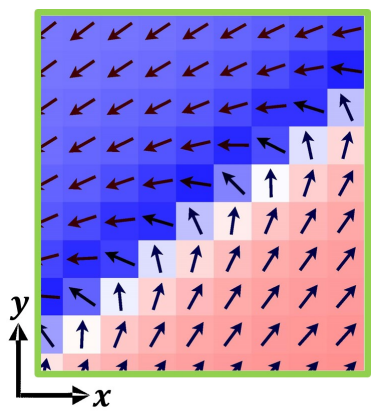

c.

Figura 3.18 - Simulação dos domínios magnéticos na superfície do filme Invar de $70 \mathrm{~nm}$ de espessura (a.), mostrando uma ampliação sobre uma parede tipo Bloch (b.) e outro sobre uma parede tipo Néel (c.). As cores são usadas para distinguir os domínios com magnetizações opostas.

Aqui podem acontecer duas situações: se os domínios magnéticos encontram-se frente a frente (Figura 3.18, b.), as paredes de domínio entre eles tendem a ser de tipo Bloch como era esperado, pois nesta situação os momentos devem virar saindo do plano para facilitar a mudança da direção de magnetização entre domínios; mas se os domínios estão um do lado do outro (Figura 3.18, c.), então são formadas paredes tipo Néel, onde os momentos giram no plano do filme.

Quanto mais amplo é o ângulo de abertura dos trechos em ziguezague, mais extensas são as paredes de domínio tipo Bloch, e maior seria o sinal magnético na direção $z$ percebido pela microscopia de MFM. Não obstante, no interior do filme a situação é um pouco distinta, já que simulações numa profundidade de $35 \mathrm{~nm}$ dentro do filme, mostram paredes de domínio com uma forte componente de magnetização no eixo $z$, como mostrado pelas bordas dos domínios magnéticos com cores mais intensos (Figura 3.19 , a.).

O caso anterior acontece já que os momentos magnéticos no interior dos filmes, se alinham na direção (111) (Figura 3.19, b.). Isto, junto com a anisotropia de forma, obrigam os momentos magnéticos a se alinhar paralelos à superfície dos filmes quando se encontram perto dela, mas internamente devem virar até ficar perpendiculares, manifestando assim uma estrutura de parede tipo Bloch. Como consequência, os filmes 


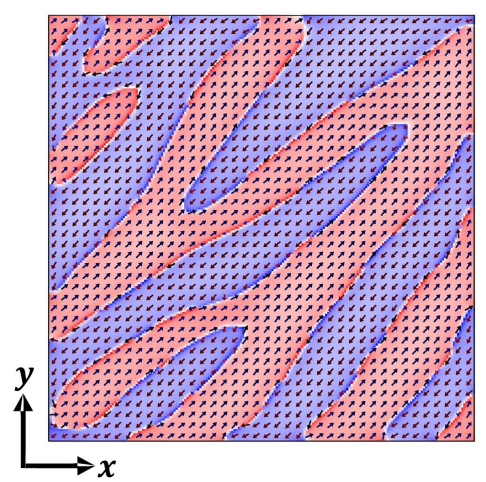

a.

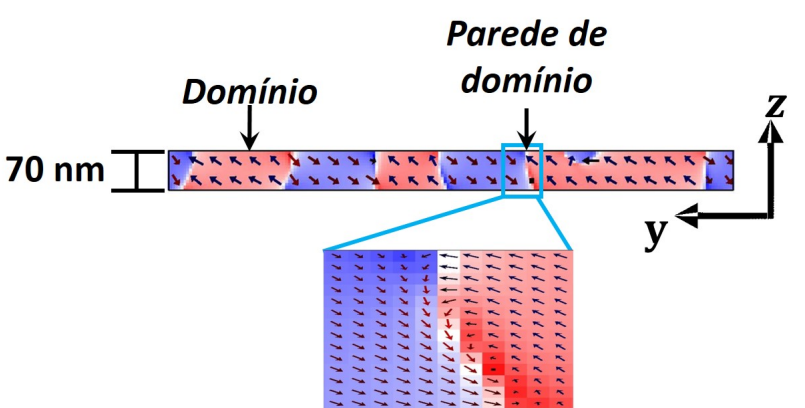

b.

Figura 3.19 - a. Simulação dos domínios magnéticos no interior do filme Invar de 70 nm, numa profundidade de $35 \mathrm{~nm}$, b. vista lateral dos domínios e das paredes de domínio.

possuem uma componente de magnetização alta no plano, mas também apresentam uma componente vertical. Note-se que as paredes de domínio tipo Bloch dentro dos filmes, são oblíquas, por causa da inclinação na magnetização local dos domínios, além disso, a estrutura das paredes nestas condições é semelhante à estrutura de um vórtice orientado verticalmente.

Neste sentido, em ausência de campos externos, filmes Invar mais grossos tendem a formar paredes Néel nas suas superfícies com paredes Bloch no interior do seu volume, enquanto que filmes mais finos tendem a formar paredes Néel unicamente, como esperado. No entanto, devido às inomogeneidades na superfície dos filmes ou defeitos na sua estrutura interna originados na hora da deposição, ditas configurações podem ser muito mais complexas, dando passo a padrões mais irregulares como mostrado nas imagens de MFM obtidas neste trabalho. 


\section{Conclusões}

Três filmes policristalinos de FeNi depositados sobre substratos de Si via sputtering DC, inicialmente com concentrações desconhecidas, foram caracterizados e suas microestruturas magnéticas analisadas, por meio de diferentes técnicas experimentais não destrutivas e de simulações computadorizadas. As medidas por EDS com raios $X$, mostraram que os filmes tinham a concentração $\mathrm{Fe}_{0.64} \mathrm{Ni}_{0.36}$, ou seja, apresentam a concentração Invar. O fenômeno Invar é de grande interesse cientifico e tecnológico, pois nele o coeficiente de dilatação da liga diminui consideravelmente, fato que tem a ver com as propriedades e configuração magnética do material. Não obstante essa relação ainda não é muito clara, apesar dos avanços teóricos e experimentais neste campo.

$\mathrm{O}$ anterior motivou ainda mais o estudo destes filmes, cujas espessuras foram determinadas em 30, 70 e $140 \mathrm{~nm}$ aproximadamente, por meio de medidas de refletometria com raios $\mathrm{X}$, enquanto que medidas de DRX apresentaram picos intensos na direção (111), revelando a fase fcc das amostras. Essa informação foi fundamental para a análise micromagnética dos filmes e para o desenvolvimento das simulações, realizadas em função das espessuras.

Por outro lado, medidas de FMR permitiram mostrar que os filmes Invar possuíam inomogeneidades magnéticas e estruturais por causa da sua policristalinidade, as quais são mais importantes em filmes de maior espessura, onde modos de ressonância LFMA e DARMA são mais acentuados. O filme de $30 \mathrm{~nm}$ revelou um espectro com o modo de ressonância principal mais definido, pelo que sua homogeneidade estrutural e magnética é maior com respeito aos outros filmes. As inomogeneidades supracitadas, são mais prováveis com o aumento na espessura e tendem a incrementar a magnetização efetiva, a energia de troca e portanto a constante de troca dos filmes, mas não foi possível determinar este ultimo parâmetro por causa das limitações no espectrômetro de EPR.

No entanto, a amostra de $70 \mathrm{~nm}$ de espessura apresentou uma anomalia no seu espectro de FMR, pois seu campo de ressonância foi muito mais baixo em relação aos demais filmes. Essa amostra também apresentou anomalia no seu campo coercitivo 
intrínseco como indicado pelas medidas de magnetometria, pois este parâmetro resultou ser duas vezes maior que nos outros casos. É provável que estas anomalias sejam devidas ao aumento no número de domínios e paredes de domínio, os quais eventualmente induzem um aumento na anisotropia superficial do filme.

A estrutura magnética dos filmes também foi analisada graças às medidas de magnetometria por SQUID, as quais expuseram um comportamento ferromagnético mole com histerese no plano das amostras, onde as magnetizações de saturação e de remanência eram crescentes, em relação com a espessura dos filmes. Este fato, além do comportamento linear da magnetização fora do plano, são provas de uma forte componente da magnetização paralela ao plano das amostras. A diminuição no coeficiente de orientação $\left(c_{o}=M_{r} / M_{s}\right)$ ao incrementar a espessura, sugere também um pequeno aumento na componente da magnetização dos filmes fora do plano, aspecto que tem a ver com o aumento nas constantes de anisotropia efetiva e uniaxial, o aumento na intensidade de acoplamento spin-orbita, assim como o acrescentamento no número de paredes tipo Bloch.

Os valores positivos da constante de anisotropia efetiva, junto com os resultados anteriores, fizeram considerar uma anisotropia uniaxial responsável do surgimento dos eixos fáceis no plano dos filmes, favorecida pela anisotropia de forma na direção perpendicular, produto da espessura das amostras e que evita a criação de eixos de magnetização fáceis perpendiculares à superfície das amostras. Essa informação permitiu dar mais sentido às imagens obtidas com as técnicas de AFM e MFM, as quais manifestaram características fundamentais da morfologia e do magnetismo dos filmes em nanoescala, por meio da medição direta da rugosidade da superfície e das variações em $z$ do campo intrínseco das amostras, devidas às divergências da magnetização nas paredes dos domínios magnéticos.

Tais imagens revelaram topografias pouco rugosas, principalmente para o filme mais fino, assim como estruturas magnéticas em ziguezague formadas pelas paredes de domínio das amostras, muito mais perceptíveis nos filmes de 70 e $140 \mathrm{~nm}$. A espessura destes filmes favoreceu a formação deste tipo de estruturas, as quais são mais irregulares no filme de $30 \mathrm{~nm}$, onde é energeticamente mais difícil mantê-las.

As anomalias apresentadas nas medidas magnéticas para a amostra de $70 \mathrm{~nm}$, presumivelmente geraram o aumento no contraste de fase nas imagens de MFM para este filme, tendo em conta que as varreduras foram feitas baixo as mesmas condições em todos os casos. Assim, resultou mais fácil observar neste filme a configuração magnética em ziguezague, em meio das irregularidades magnéticas provocadas pela policristalinidade das amostras. Com isso, considerou-se uma estrutura de domínio 
como indicada na figura 3.16, tentando ser coerentes com as medidas de magnetometria e de MFM, usadas como base para a criação das simulações micromagnéticas com o software MUMAX3.

Os resultados das simulações confirmaram a ideia proposta para a estrutura dos domínios magnéticos, indicando eixos fáceis de magnetização paralelos ao plano dos filmes. Portanto, a anisotropia magneto-cristalina junto com a anisotropia de forma, induzida pela espessura, têm uma grande influência na configuração magnética dos filmes, principalmente os de maior espessura. Isto sugere que nestes casos a energia de anisotropia é mais intensa que a energia de troca, o que obriga aos momentos magnéticos, no interior dos domínios, a se alinhar perto dos eixos de fácil magnetização no plano.

Deste modo e baseados nos resultados das simulações, a configuração magnética dos filmes Invar, tende a formar domínios magnéticos com uma alta componente de magnetização no plano, limitados por paredes de domínio que podem ser tipo Bloch ou Néel na superfície, segundo a interação entre domínios, mas no interior dos filmes, comportam-se como paredes tipo Bloch, sendo que esta característica depende fortemente da espessura.

Neste sentido, as técnicas de AFM/MFM apesar de ser muito versáteis, pela rapidez e facilidade na preparação e medição das amostras, assim como pela importante informação proporcionada, devem ser complementadas com outro tipo de técnicas experimentais, de modo que seja refinada a informação sobre as propriedades físicas dos sistemas em estudo, como foi apresentado neste trabalho. As simulações computacionais constituem-se também como ferramentas poderosas para simplificar a análise da configuração micromagnética de filmes ferromagnéticos, ao tempo que melhoram e favorecem a compreensão do funcionamento dos métodos experimentais.

Espera-se que as análises aqui expostas sobre as estruturas magnéticas em filmes Invar, sejam de ajuda para futuras pesquisas sobre estes aspectos. Neste sentido seria interessante estudar melhor a dependência da configuração magnética com a espessura dos filmes empregando uma maior variedade de amostras. Pode-se também fazer uma análise mais detalhada das características e constituição das paredes de domínio, ou da dinâmica de magnetização em nanoestruturas finas, onde os fenômenos podem ser melhor entendidos que no caso de filmes extensos. A relação entre o tamanho dos cristalitos, o campo coercitivo intrínseco e as constantes de anisotropia, também pode ser estudada melhor para aclarar o modo em que interagem a energia de anisotropia magnética e a energia de troca em filmes ferromagnéticos moles e policristalinos. 


\section{Referências Bibliográficas}

[1] C. Kittel, Introduction to solid state physics. John Wiley Inc., 1986.

[2] C. Guillaume, "Investigations on Nickel and its alloys," Comptes Rendus de l'Académie des Sciences, vol. 125, 1897.

[3] Aperam, "Aperam alloys and specialties innovatis." http://www . aperam.com/en/ alloys-imphy/invar/, 2012. [Online; Acessado 15 de setembro de 2015].

[4] K. Fukamichi, Invar Alloys. Springer Materials.

[5] S. Thomas, S. Al-Hathi, D. Sakthikumar, I. Al-Omari, R. Ramanujan, Y. Yoshida, and M. Anantharaman, "Microstructure and random magnetic anisotropy in $\mathrm{Fe}-\mathrm{Ni}$ based nanocrystalline thin films," Journal of Physics D: Applied Physics, vol. 41, pp. 1-8, 2008.

[6] I. Vazhenina, R. Iskhakov, L. Chekanova, S. Stolyar, and V. Yakovchuk, "Ferromagnetic and spin-wave resonance in $\mathrm{Fe}_{x} \mathrm{Ni}_{1-x}(0<\mathrm{x}<1)$ films," Solid State Phenomena, vol. 233-234, pp. 682-685, 2015.

[7] J. Lin, Y. Wu, C. Yang, and W. Wang, "Measurement of thermal expansion coefficient of INVAR foil using atomic force microscopy,” Measurement, vol. 47, pp. 373-378, 2014.

[8] B. Glaubitz, S. Buschhorn, F. Brüssing, R. Abrudan, and H. Zabel, "Development of magnetic moments in $\mathrm{Fe}_{1-x} \mathrm{Ni}_{x}$ alloys," Journal of Physics: Condensed Matter, vol. 23, 2011.

[9] I. Abrikosov, A. Kissavos, F. Liot, B. Alling, S. Simak, O. Peil, and A. Ruban, "Competition between magnetic structures in the Fe rich fcc FeNi alloys," Physical Review $B$, vol. 76, no. 1, p. 014434, 2007. 
[10] W. Tang, C. Gerhards, J. Heise, and H. Zabel, "Structure and magnetic properties of Fe1-x Ni x / Cu Invar superlattices,” Journal of Applied Physics, vol. 80, no. 2327, 1996.

[11] D. Rancourt, P. Hargraves, G. Lamarche, and R. Dunlap, "Microstructure and low temperature magnetism of FeNi invar alloys," Journal of Magnetism and Magnetic Materials, vol. 87, no. 1-2, pp. 71-82, 1990.

[12] G. Dumpich, U. Kastner, J.and Kirschbaum, H. Muhlbauer, J. Liang, T. Lubeck, and E. Wassermann, "Invar behavior of fcc Fe-Ni thin films," Physical Review B, vol. 46, no. $14,1992$.

[13] Y. Ustinovshikov and I. Shabanova, "A study of microstructures responsible for the emergence of the Invar and permalloy effects in Fe-Ni alloys," Journal of Alloys and Compounds, vol. 578, pp. 292-296, 2013.

[14] S. Vitta, A. Khuntia, G. Ravikumar, and D. Bahadur, "Electrical and magnetic properties of nanocrystalline Fe 100-x Ni x alloys," Journal of Magnetism and Magnetic Materials, vol. 320, no. 3, pp. 182-189, 2008.

[15] J. Robertson, G. Ice, C. Sparks, X. Jiang, P. Zschack, F. Bley, S. Lefebvre, and M. Bessiere, "Local atomic arrangements in Fe 63.2 Ni 36.8 Invar from diffuse X-ray scattering measurements," Physical Review Letters, vol. 82, no. 14, p. 2911, 1999.

[16] J. Lynn, N. Rosov, M. Acet, and H. Bach, "Polarization analysis of the magnetic excitations in Fe65Ni35 Invar," Journal of Applied Physics, vol. 75, no. 10, pp. 60696071, 1994.

[17] E. Maliszewski and S. Bednarski, "Lattice dynamics of Fe0.65Ni0.35 classical Invar," physica status solidi (b), vol. 211, no. 2, pp. 621-629, 1999.

[18] N. Moghimi, F. R. Rahsepar, S. Srivastava, N. Heinig, and K. T. Leung, "Shapedependent magnetism of bimetallic FeNi nanosystems," Journal of Materials Chemistry C, vol. 2, no. 31, pp. 6370-6375, 2014.

[19] L. Eckertova, Physics of thin films. Springer Science \& Business Media, 2012.

[20] A. P. Guimarães, Principles of nanomagnetism. Springer Science \& Business Media, 2009.

[21] K. L. Chopra, Thin film phenomena. McGraw-Hill, 1969. 
[22] D. Cao, Z. Wang, E. Feng, J. Wei, J. Wang, and Q. Liu, "Magnetic properties and microstructure investigation of electrodeposited FeNi/ITO films with different thickness," Journal of Alloys and Compounds, vol. 581, pp. 66-70, 2013.

[23] D. Navas, C. Redondo, G. A. B. Confalonieri, F. Batallan, A. Devishvili, O. IglesiasFreire, A. Asenjo, C. A. Ross, and B. P. Toperverg, "Domain-wall structure in thin films with perpendicular anisotropy: Magnetic force microscopy and polarized neutron reflectometry study," Physical Review B, vol. 90, no. 5, p. 054425, 2014.

[24] M. Francombe and J. Vossen, Physics of Thin Films. Academic Press, Inc., 1987.

[25] D. Jiles, Introduction to magnetism and magnetic materials. CRC press, 2015.

[26] C. Zener, "Interaction between the $d$ shells in the transition metals," Physical Review, vol. 81, no. 3, p. 440, 1951.

[27] S. Blundell, "Magnetism in condensed matter," 2003.

[28] B. Cullity and C. Graham, Introduction to magnetic materials. John Wiley \& Sons, 2011.

[29] R. M. Bozorth, "Ferromagnetism," Ferromagnetism, by Richard M. Bozorth, pp. 992. ISBN 0-7803-1032-2. Wiley-VCH, August 1993., vol. 1, 1993.

[30] A. Blixt, Growth and Magnetic Properties of Fe- and FeNi-based Thin Films and Multilayers. Tese de doutorado, Uppsala University, 2004.

[31] A. Aharoni, Introduction to the Theory of Ferromagnetism, vol. 109. Clarendon Press, 2000.

[32] A. Hubert and R. Schäfer, Magnetic domains: the analysis of magnetic microstructures. Springer Science \& Business Media, 2008.

[33] M. Barthelmes, Magnetic-force microscopy and micromagnetic simulations on domains of structured ferromagnets. Tese de doutorado, Universität Hamburg, 2003.

[34] E. de Lacheisserie, D. Gignoux, and M. Schlenker, Magnetism: Fundamentals. Springer Science+ Business Media, 2005.

[35] S. Chikazumi and C. Graham, Physics of Ferromagnetism 2e. No. 94, Oxford University Press on Demand, 2009. 
[36] J. Bland and B. Heinrich, Ultrathin Magnetic Structures I: An Introduction to the Electronic, Magnetic and Structural Properties. Ultrathin Magnetic Structures, Springer Berlin Heidelberg, 2006.

[37] M. Donahue and D. Porter, "The object oriented micromagnetic framework (OOMMF) project at ITL/NIST.” http://math.nist.gov/oommf, 1998.

[38] M. Morales, H. Lassri, A. Biondo, A. Rossi, and E. Baggio-Saitovitch, "Magnetic properties of Ni 81 Fe 19/W 90 Ti 10 multilayers," Journal of Magnetism and Magnetic Materials, vol. 256, no. 1, pp. 93-99, 2003.

[39] E. De Lacheisserie, D. Gignoux, and M. Schlenker, Magnetism: II-Materials and Applications. Springer Science \& Business Media, 2012.

[40] Y. Nakamura, “The Invar Problem,” IEEE Transactions on Magnetics, vol. 12, no. 4, 1976.

[41] E. Wassermann, Invar: Moment-Volume instabilities in transition metals and alloys. Elsevier Science Publishers B.V., 1990.

[42] V. Crisan, P. Entel, H. Ebert, H. Akai, D. D. Johnson, and J. Staunton, "Magnetochemical origin for Invar anomalies in iron-nickel alloys," Physical Review B, vol. 66, no. 1, p. 014416, 2002.

[43] H. Fujimori, Physics and Applications of Invar Alloys. Maruzen Co., 1978.

[44] R. Scorzelli, "A study of phase stability in invar Fe-Ni alloys obtained by nonconventional methods," Hyperfine Interactions, vol. 110, no. 1-2, pp. 143-150, 1997.

[45] N. Ashcroft and N. Mermin, Solid State Physics. Harcourt College Publishers, 1976.

[46] A. Katsuki and K. Terao, eds., Spontaneous Volume Magnetostriction of Invar Alloys, 1972.

[47] R. Weiss, "The origin of the Invar effect," Proceedings of the Physical Society, vol. 82, no. 2, p. 281, 1963.

[48] M. Schilfgaarde, I. Abrikosov, and B. Johansson, "Origin of the Invar effect in ironnickel alloys," Nature, vol. 400, no. 6739, pp. 46-49, 1999.

[49] I. Abrikosov, O. Eriksson, P. Soderlind, H. L. Skriver, and B. Johansson, “Theoretical aspects of the $\mathrm{Fe}_{c} \mathrm{Ni}_{1-c}$ Invar alloy," Physical Review B, vol. 51, no. 2, p. 1058, 1995. 
[50] U. Pietsch, V. Holy, and T. Baumbach, High-Resolution X-Ray Scattering: From Thin Films to Lateral Nanostructures. Advanced Texts in Physics, Springer New York, 2013.

[51] J. Als-Nielsen and D. McMorrow, Elements of Modern X-ray Physics. Wiley, 2011.

[52] E. Chason and T. Mayer, "Thin film and surface characterization by specular X-ray reflectivity," Critical Reviews in Solid State and Material Sciences, vol. 22, no. 1, pp. 1-67, 1997.

[53] H. Kiessig, "Interferenz von Röntgenstrahlen an dünnen Schichten," Annalen der Physik, vol. 402, no. 7, pp. 769-788, 1931.

[54] L. G. Parratt, "Surface studies of solids by total reflection of X-rays," Physical Review, vol. 95, no. 2, p. 359, 1954.

[55] K. Sakurai, M. Mizusawa, and M. Ishii, "Significance of frequency analysis in Xray reflectivity: Towards analysis which does not depend too much on models," Transactions of the Materials Research Society of Japan, vol. 33, no. 3, pp. 523-528, 2008.

[56] T. C. Huang and P. K. Predecki, eds., Grazing-incidence X-ray technique for surface, interface and thin-film analysis, International Centre for Diffraction Data, ICDD, 1997.

[57] I. K. Schuller, "New class of layered materials," Physical Review Letters, vol. 44, no. 24, p. 1597, 1980.

[58] B. Warren, X-Ray Diffraction. Dover Books on Physics, Dover Publications, 2012.

[59] S. Vonsovskii, Ferromagnetic Resonance: The Phenomenon of Resonant Absorption of a High-Frequency Magnetic Field in Ferromagnetic Substances. Elsevier Science, 1966.

[60] O. Yalçın, Ferromagnetic Resonance - Theory and Applications. InTech, 2013.

[61] M. Farle, "Ferromagnetic resonance of ultrathin metallic layers," Reports on Progress in Physics, vol. 61, no. 7, p. 755, 1998.

[62] J. Pelzl and U. Netzelmann, "Locally resolved magnetic resonance in ferromagnetic layers and films," in Photoacoustic, photothermal and photochemical processes at surfaces and in thin films, pp. 313-365, Springer, 1989. 
[63] J. Smit and H. Beljers, "Ferromagnetic resonance absorption in BaFe12O19, a highly anisotropic crystal," Philips Res. Rep, vol. 10, no. 113, p. 31, 1955.

[64] J. Clarke and A. Braginski, The SQUID Handbook: Fundamentals and Technology of SQUIDs and SQUID Systems. Wiley, 2006.

[65] R. Fagaly, "Superconducting quantum interference device instruments and applications," Review of Scientific Instruments, vol. 77, no. 10, p. 101101, 2006.

[66] G. Binnig, C. F. Quate, and C. Gerber, "Atomic force microscope," Physical Review Letters, vol. 56, no. 9, p. 930, 1986.

[67] Nanosurf, "Flex-axiom - afm for materials research." https : //www . nanosurf . com/en/products/flex-axiom-afm-for-materials-research, 2000. [Online; Acessado 15 de maio de 2016].

[68] G. Haugstad, Atomic force microscopy: understanding basic modes and advanced applications. John Wiley \& Sons, 2012.

[69] P. Eaton and P. West, Atomic Force Microscopy. Oxford University Press, 2010.

[70] D. Nečas and P. Klapetek, "Gwyddion: an open-source software for SPM data analysis," Open Physics, vol. 10, no. 1, pp. 181-188, 2012.

[71] L. Coelho, Espalhamento ressonante de raios $X$ no estudo de nanoestruturas. Tese de doutorado, Universidade Federal de Minas Gerais, 2008.

[72] F. Ferri, M. Pereira-da Silva, and E. Marega, Magnetic Force Microscopy: Basic Principles and Applications, ch. 3. InTech, 2012.

[73] U. Hartmann, "Magnetic force microscopy," Annual review of materials science, vol. 29, no. 1, pp. 53-87, 1999.

[74] D. Rugar, H. Mamin, P. Guethner, S. Lambert, J. Stern, I. McFadyen, and T. Yogi, "Magnetic force microscopy: General principles and application to longitudinal recording media," Journal of Applied Physics, vol. 68, no. 3, pp. 1169-1183, 1990.

[75] W. Rave, L. Belliard, M. Labrune, A. Thiaville, and J. Miltat, "A magnetic force microscopy analysis of soft thin film elements," IEEE Transactions on Magnetics, vol. 30, no. 6, pp. 4473-4478, 1994. 
[76] R. Engel-Herbert, J. Mohanty, A. Ney, T. Hesjedal, L. Däweritz, and K. Ploog, “Understanding the submicron domain structure of MnAs thin films on GaAs (001): Magnetic force microscopy measurements and simulations," Applied physics letters, vol. 84, no. 7, pp. 1132-1134, 2004.

[77] S. Porthun, L. Abelmann, and C. Lodder, "Magnetic force microscopy of thin film media for high density magnetic recording," Journal of Magnetism and Magnetic Materials, vol. 182, no. 1, pp. 238-273, 1998.

[78] R. B. Proksch, S. Foss, and E. D. Dahlberg, "High resolution magnetic force microscopy of domain wall fine structures," IEEE Transactions on Magnetics, vol. 30, no. 6, pp. 4467-4472, 1994.

[79] A. Vansteenkiste, J. Leliaert, M. Dvornik, M. Helsen, F. Garcia-Sanchez, and B. Van Waeyenberge, “The design and verification of mumax3," Aip Advances, vol. 4, no. 10, p. 107133, 2014.

[80] M. Donahue and R. McMichael, “Exchange energy representations in computational micromagnetics," Physica B: Condensed Matter, vol. 233, no. 4, pp. 272-278, 1997.

[81] M. Donahue, "A variational approach to exchange energy calculations in micromagnetics," Journal of Applied Physics, vol. 83, no. 11, pp. 6491-6493, 1998.

[82] Bruker, "Advanced x-ray diffraction system for materials research applications." https: //www . bruker . com/, 2010. [Online; Acessado 11 de outubro de 2016].

[83] CRXO, “The center for x-ray optics - x-ray database." http://cxro.1bl.gov//, 2010. [Online; Acessado 8 de janeiro de 2017].

[84] J. G. Kim, K. H. Han, S. H. Song, and A. Reilly, "Magnetic properties of sputtered soft magnetic Fe-Ni films with an uniaxial anisotropy," Thin Solid Films, vol. 440, no. 1, pp. 54-59, 2003.

[85] T. Tashiro, M. Mizuguchi, T. Kojima, T. Koganezawa, M. Kotsugi, T. Ohtsuki, and K. Takanashi, "Structural and magnetic properties of FeNi thin films fabricated on amorphous substrates," Journal of Applied Physics, vol. 117, no. 17, p. 17E309, 2015.

[86] L. Maksymowicz and D. Sendorek, "Surface modes in magnetic thin amorphous films of GdCoMo alloys," Journal of magnetism and magnetic materials, vol. 37, no. 2, pp. 177-188, 1983. 
[87] J. Kim, J. Kim, and K. H. Kim, "Low-field microwave absorption behaviors on single layer magnetic film and exchange coupled multilayer magnetic film," Current Applied Physics, vol. 14, no. 4, pp. 548-551, 2014.

[88] J. Lee, J. Kim, and K. H. Kim, "Effect of the magnetization process on low-field microwave absorption by FeBN magnetic thin film,” physica status solidi (a), vol. 211, no. 8, pp. 1900-1902, 2014.

[89] M. Pires, M. Araujo Filho, J. Tedesco, J. Ardisson, and W. Macedo, “Out-of-plane magnetic anisotropy in columnar grown Fe-Ni films," Journal of Physics and Chemistry of Solids, vol. 75, no. 10, pp. 1124-1131, 2014.

[90] R. McMichael, D. Twisselmann, and A. Kunz, "Localized ferromagnetic resonance in inhomogeneous thin films," Physical review letters, vol. 90, no. 22, p. 227601, 2003.

[91] R. Kordecki, T. Kochmann, H. Volz, J. Pelzl, E. Becker, G. Dumpich, and Z. Frait, "Spin wave resonance in thin films and in bulk samples of FeNi invar alloys," Physica B: Condensed Matter, vol. 161, no. 1-3, pp. 285-288, 1990.

[92] QuantumDesign, “Magnetic property measurement system.” http://www . qdusa. com/products/mpms3.html, 2014. [Online; Acessado 30 de maio de 2016].

[93] G. Herzer, "Grain size dependence of coercivity and permeability in nanocrystalline ferromagnets," IEEE Transactions on Magnetics, vol. 26, no. 5, pp. 1397-1402, 1990.

[94] G. S. Abo, Y.-K. Hong, J. Park, J. Lee, W. Lee, and B.-C. Choi, “Definition of magnetic exchange length,” IEEE Transactions on Magnetics, vol. 49, no. 8, pp. 4937-4939, 2013.

[95] Nanosensors, "PPP-MFMR.” http://www. nanosensors.com/, 2003. [Online; Acessado 22 de maio de 2016].

[96] A. Hubert, “Charged walls in thin magnetic films," IEEE Transactions on Magnetics, vol. 15, no. 5, pp. 1251-1260, 1979. 